\title{
Mapping of Motor Function with Neuronavigated Transcranial Magnetic Stimulation: A Review on Clinical Application in Brain Tumors and Methods for Ensuring Feasible Accuracy
}

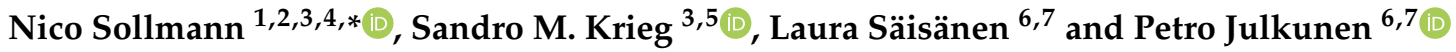 \\ 1 Department of Diagnostic and Interventional Radiology, University Hospital Ulm, Albert-Einstein-Allee 23, \\ 89081 Ulm, Germany \\ 2 Department of Diagnostic and Interventional Neuroradiology, School of Medicine, Klinikum rechts der Isar, \\ Technical University of Munich, Ismaninger Str. 22, 81675 Munich, Germany \\ 3 TUM-Neuroimaging Center, Klinikum rechts der Isar, Technical University of Munich, 81675 Munich, Germany; \\ sandro.krieg@tum.de \\ 4 Department of Radiology and Biomedical Imaging, University of California San Francisco, 185 Berry Street, \\ San Francisco, CA 94143, USA \\ 5 Department of Neurosurgery, School of Medicine, Klinikum rechts der Isar, Technical University of Munich, \\ Ismaninger Str. 22, 81675 Munich, Germany \\ 6 Department of Clinical Neurophysiology, Kuopio University Hospital, 70029 Kuopio, Finland; \\ laura.saisanen@kuh.fi (L.S.); Petro.Julkunen@kuh.fi (P.J.) \\ 7 Department of Applied Physics, University of Eastern Finland, 70211 Kuopio, Finland \\ * Correspondence: nico.sollmann@tum.de
}

check for

updates

Citation: Sollmann, N.; Krieg, S.M.; Säisänen, L.; Julkunen, P. Mapping of Motor Function with Neuronavigated Transcranial Magnetic Stimulation: A Review on Clinical Application in Brain Tumors and Methods for Ensuring Feasible Accuracy. Brain Sci. 2021, 11, 897. https://doi.org/ 10.3390/brainsci11070897

Academic Editor: Lorenzo Rocchi

Received: 4 June 2021

Accepted: 2 July 2021

Published: 7 July 2021

Publisher's Note: MDPI stays neutral with regard to jurisdictional claims in published maps and institutional affiliations.

Copyright: (c) 2021 by the authors. Licensee MDPI, Basel, Switzerland. This article is an open access article distributed under the terms and conditions of the Creative Commons Attribution (CC BY) license (https:// creativecommons.org/licenses/by/ $4.0 /)$.

\begin{abstract}
Navigated transcranial magnetic stimulation (nTMS) has developed into a reliable noninvasive clinical and scientific tool over the past decade. Specifically, it has undergone several validating clinical trials that demonstrated high agreement with intraoperative direct electrical stimulation (DES), which paved the way for increasing application for the purpose of motor mapping in patients harboring motor-eloquent intracranial neoplasms. Based on this clinical use case of the technique, in this article we review the evidence for the feasibility of motor mapping and derived models (risk stratification and prediction, nTMS-based fiber tracking, improvement of clinical outcome, and assessment of functional plasticity), and provide collected sets of evidence for the applicability of quantitative mapping with nTMS. In addition, we provide evidence-based demonstrations on factors that ensure methodological feasibility and accuracy of the motor mapping procedure. We demonstrate that selection of the stimulation intensity (SI) for nTMS and spatial density of stimuli are crucial factors for applying motor mapping accurately, while also demonstrating the effect on the motor maps. We conclude that while the application of nTMS motor mapping has been impressively spread over the past decade, there are still variations in the applied protocols and parameters, which could be optimized for the purpose of reliable quantitative mapping.
\end{abstract}

Keywords: brain stimulation; brain tumor; electric field; eloquent cortex; functional mapping; motor mapping; motor threshold; navigated transcranial magnetic stimulation; neuronavigation; presurgical evaluation

\section{Introduction}

Navigated transcranial magnetic stimulation (nTMS) combines the use of neuronavigation with TMS to target neurostimulation inductively to the brain cortex, utilizing views of the brain anatomy with sub-centimeter precision and enabling tracking of the coil during stimulation (e.g., using an infrared (IR) tracking system combined with the stimulator; Figure 1) [1]. For over a decade, nTMS has been used in diagnostic setups (e.g., to perform non-invasive clinical mapping of motor or other brain functions) or for therapeutic purpose (e.g., to treat major depression or other psychiatric diseases as well as chronic pain). Preceding nTMS as we know it today, early approaches conducted mapping based on anatomical 
landmarks placed over the scalp or used frameless stereotactic systems to localize and track stimulations [2-4]. However, such approaches seemed limited for clinical use where high precision and reliability is warranted in relation to individual brain anatomy that can be both spatially and functionally deranged due to pathology. Technological advancements have enabled the estimation of the spatial extent and geometry of the electric field (EF) induced by stimulation [1,5-7]. Specifically, the development of nTMS using EF-based neuronavigation acknowledges that the EF induced by stimulation strongly depends on several factors such as skull thickness and coil tilting, amongst others. In this context, accurate and efficient modelling of the EF is essential to pinpoint the impact of stimulation and to understand its effects [1,5-7]. Since nTMS using such EF-based neuronavigation is currently considered the most accurate method for targeting stimulation, this article focusses on this technique.

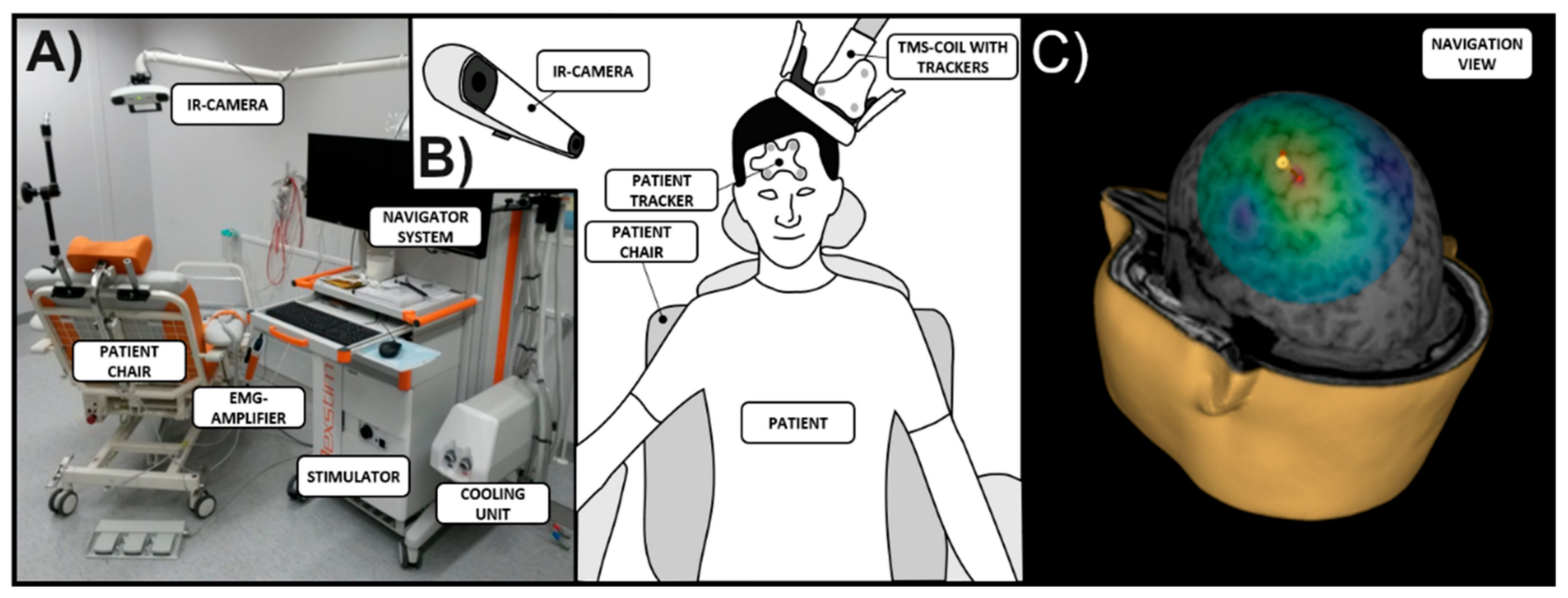

Figure 1. Setup for nTMS mapping. (A) Hardware of the nTMS system, including an infrared camera, EMG amplifier, neuronavigation monitor, and the stimulator with a cooling unit as the central components. (B) Patient positioning during mapping procedures, requiring initial co-registration of the patient's head with cranial MRI (using a head tracker attached to the patient's forehead) to be able to track the stimulating coil (equipped with infrared trackers) in relation to individual brain anatomy. (C) Navigation view during the mapping procedure, showing the stimulating coil (yellow marker) with its orientation (red arrow) and modelled EF distribution.

Overall, interest towards combining neuronavigation with TMS has experienced more and more interest in the research community as indicated by the increasing trend in published studies (Figure 2). From a clinical perspective, nTMS has been gaining importance especially as a tool for preoperative mapping used for planning and intraoperative resection guidance in patients harboring functionally eloquent brain neoplasms [1,8-11]. As of today, mapping of motor function has become the mainstay of nTMS, making so-called nTMS motor mapping in patients with motor-eloquent lesions an ideal use case for the technique. In modern neuro-oncological surgery, achieving an optimal balance between the extent of resection (EOR) of a brain tumor and the individual functional status of the patient is the major principle for surgical resection [12]. Prognostically, a safely performed maximized tumor resection is of utmost importance as incomplete resection is correlated to lower survival rates and quality of life for patients with malignant glioma as the prominent entity of intra-axial brain tumors [13-18]. To maximize the EOR while keeping surgeryrelated decline of function (e.g., paresis in the context of the motor system) to the lowest level achievable, intraoperative direct electrical stimulation (DES) is performed as the goldstandard method for assessing subcortical and cortical functional representations [19-23]. Outside of the operating theater, nTMS motor mapping and later-developed nTMS-based tractography can be performed for this purpose. As the major field of current application, 
the first part of this article focusses on the clinical utility of nTMS-based motor mapping and derived tractography in patients with motor-eloquent brain neoplasms.

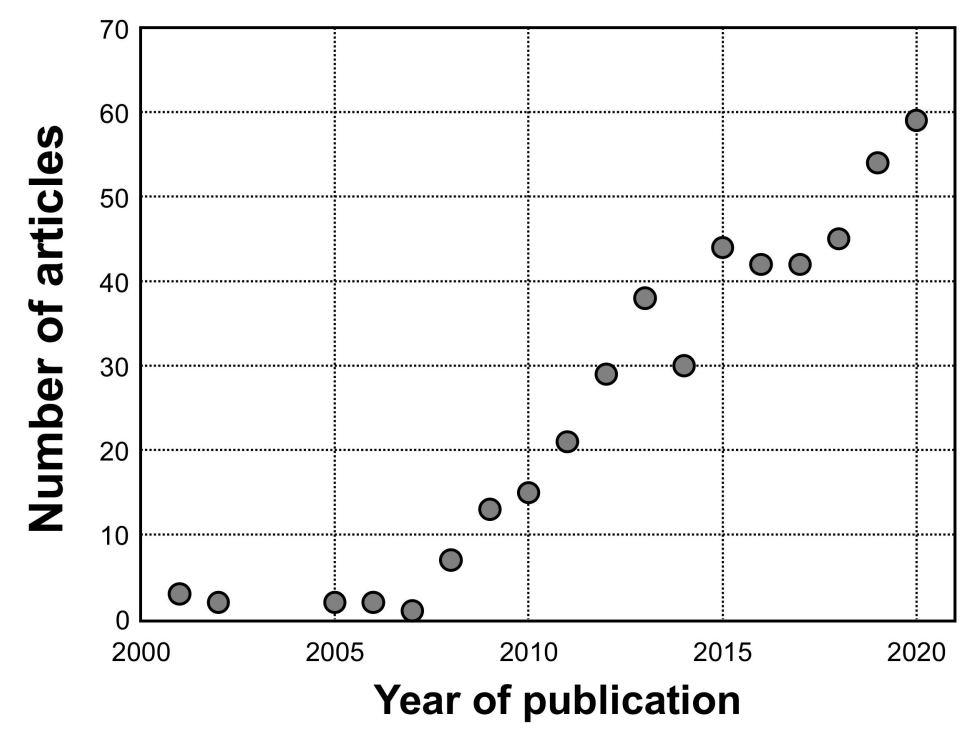

Figure 2. Number of articles on nTMS published annually between 2002 and 2020 as indexed in PubMed (on the 21st of May in 2021). The search query in PubMed was defined as follows: ("navigated transcranial magnetic stimulation" OR "navigated TMS" OR "neuronavigated TMS" OR "neuronavigated transcranial magnetic stimulation").

From a methodological perspective, the nTMS parameters selected for motor mapping, such as the stimulation intensity (SI), number of applied stimuli, and the density of the applied stimulation grid, affect the outcome and accuracy of the motor mapping (Figure 3) [24-27]. Specifically, optimal selection becomes especially important when quantitative parameters are drawn from the motor maps, e.g., to characterize the location of motor function or to define its extent on the cortex. Quantitative mapping refers to those quantitative parameters derived from nTMS motor mapping, based on the recorded responses and location information related to the responses. The quantitative parameters in nTMS motor mapping include the locations of the motor hotspot and center of gravity $(\mathrm{CoG})$, and area and volume of the motor map, which are all based on recorded amplitudes of motor-evoked potentials (MEPs) elicited by stimulation (Figure 3) [24-27]. The motor hotspot location is often considered as the location of the maximum MEP amplitude response $[28,29]$. It not only characterizes the major location of the motor representation, but is also used as the location where the resting motor threshold (rMT) is determined and around which the motor map extends. The CoG is defined as the amplitude-weighted location representing the location in the motor representation area where the center of motor activation lies $[28,30,31]$. The volume of the motor map is usually calculated by summing the MEP amplitudes within a motor map, e.g., within a stimulus grid [30-33]. The area of the motor map on the other hand binarizes the MEP responses to positive and negative responses and represents the area covered by positive responses (i.e., spots where stimulation elicited an MEP with a certain amplitude) [27,34,35]. Importantly, wrong selection or wrong interpretation of these quantitative parameters affects the confidence in the motor map and, in the worst case, could lead to imprecise motor maps that may have harmful consequences to the patient when used for preoperative planning and intraoperative resection guidance in neuro-oncological surgery. The technical solutions and refinements realized in the nTMS systems by the manufacturers are also important for the overall performance of motor mapping, albeit representative comparisons between different manufacturer-specific approaches have not yet been made in the literature. Given the crucial role quantitative parameters play for nTMS motor mapping, the second part of this article demonstrates the significance of certain parameters used in motor mapping to 
apply quantitative measures on the resulting individual motor maps. Finally, we speculate on the future of nTMS motor mapping by the potential in advancing from current trends towards purely quantitative motor mapping, which would have direct clinical impact. Relevant studies were identified by PubMed search (http:/ / www.ncbi.nlm.nih.gov/pubmed; accessed on 21 May 2021).

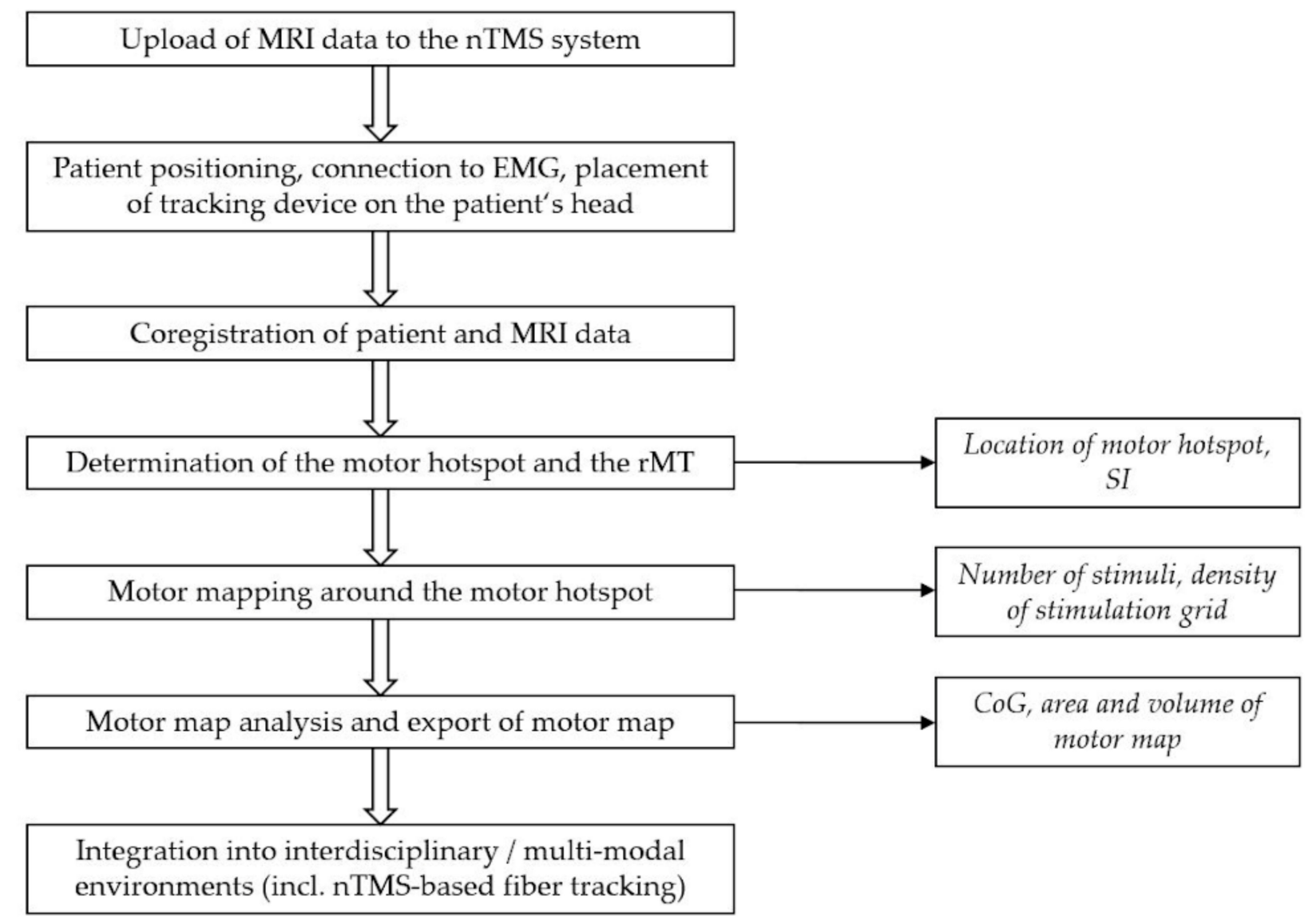

Figure 3. Overview of the main steps during the nTMS mapping procedure, starting with upload of the MRI data to the nTMS system and resulting in the generation of the individual motor map that can be further used for nTMS-based fiber tracking and other interdisciplinary or multi-modal applications. In addition, the main quantitative parameters that can be extracted from the single steps are shown (including the location of the motor hotspot, SI, number of stimuli, density of the stimulation grid, CoG, area, and volume of the motor map).

\section{Clinical Application of nTMS for Mapping Motor Function}

2.1. Feasibility, Reliability, and Comparison with Other Methods

The gold standard for functional brain mapping is defined by DES. Thus, any other technique for mapping purposes needs to be validated against it. First case reports in patients with intracranial metastasis (MET), meningioma (MEN), and low-grade glioma (LGG) have already indicated good agreement between preoperative motor mapping by nTMS and DES [32-34]. Specifically, in an early series of 20 patients with different entities of intracranial neoplasms, the motor hotspot was located on the same gyrus for nTMS and DES mappings in all enrolled cases, with distances of motor hotspots between techniques amounting to values $<1 \mathrm{~cm}$ for specific cortical muscle representations [35]. In this regard, Table 1 provides an overview of studies on reliability of nTMS motor mapping and comparison with other methods, mainly including DES.

The initial impression of high concordance between motor maps provided by preoperatively acquired nTMS motor mapping and those derived from DES was confirmed by subsequent studies that aimed to enroll larger patient cohorts with different entities of 
brain lesions and performed comparisons with a third method. Specifically, comparative analyses were achieved for nTMS and task-based functional magnetic resonance imaging (fMRI) versus DES mappings since task-based fMRI appeared as a widely used alternative to nTMS, with all major studies consistently revealing closer distances for localizations of cortical motor function between preoperative nTMS and DES compared with task-based fMRI activation maps [36-41]. Exemplarily, in a series of 26 patients, distances between motor hotspots of nTMS and DES amounted to $4.4 \pm 3.4 \mathrm{~mm}$ on average [38]. However, when comparing distances between activation in task-based fMRI and nTMS motor hotspots, larger distances of $9.8 \pm 8.5 \mathrm{~mm}$ for upper extremity (uE) and $14.7 \pm 12.4 \mathrm{~mm}$ for lower extremity (IE) muscle representations were observed [38]. More recently, considering motor representations of the $\mathrm{uE}, \mathrm{lE}$, and tongue in 36 patients with intracranial tumors, there were significantly smaller Euclidean distances as well as a better spatial overlap between DES and nTMS compared with task-based fMRI [41]. In this regard, one study suggested that nTMS motor mapping is as accurate in recurrent gliomas as it seems to be prior to the initial surgery, opening up the possibility to reuse nTMS motor mapping in the individual course of disease [39]. Similar to results for nTMS motor mapping versus fMRI, in an investigation comparing the accuracy of nTMS with magnetoencephalography (MEG) and DES mapping, distances between motor hotspots of nTMS and DES mappings were significantly smaller than those between the activation in MEG and nTMS motor hotspots [42].

The implementation of nTMS motor mapping confirmed the expected anatomy in $22 \%$, added awareness of high-risk functional areas in $27 \%$, modified the approach in $16 \%$, changed the planned EOR in $8 \%$, and changed the surgical indication in 3\% of patients among a cohort of 73 patients with different entities of brain neoplasms [43]. Similarly, another study concluded that nTMS motor mapping enabled an exact localization of the motor cortex in $88.2 \%$, provided the neurosurgeon with new unexpected information about functional anatomy in $70.6 \%$, and facilitated a modification of the surgical approach to spare the motor cortex from damage in $29.4 \%$ of patients [44]. Further, the availability of nTMS data improved the neurosurgeons' confidence in identifying the motor strip or central region $[38,40]$. Importantly, valuable motor mapping data from nTMS may be generated irrespective of the distinct experience level of the operator (after a certain interval of training), with average intra-examiner distances between CoGs for an expert investigator amounting to $4.4 \mathrm{~mm}$ and $4.9 \mathrm{~mm}$ for the expert versus novice investigator, with comparable values in the investigated healthy subjects as well as in patients with brain tumors [45].

Regarding potential variability of MEP latencies or the SI applied during nTMS motor mapping as a function of the rMT, it has been revealed in large cohorts of patients with motor-eloquent tumors that sex and antiepileptic drug (AED) intake, amongst other factors, may considerably contribute to MEP latency variability as well as variability of the determined rMT $[46,47]$. Interestingly, also the tumor grading according to the World Health Organization (WHO) scheme may be held accountable for a certain degree of variability introduced to nTMS motor mappings because MEP latencies of $1 E$ muscles increased with the WHO grading, and correlations between the increase in WHO grading and a decreased rMT were observed for IE muscles [48]. From a more methodological perspective, efforts have been made to expand accurate nTMS-based motor mapping beyond the limits of the supposed primary motor cortex, and to increase robustness by introducing altered threshold values for MEP amplitudes [49,50]. Future research will determine the distinct relevance of such influencing factors for motor mapping by nTMS in patients with brain tumors, in whom such potential confounders of motor mapping results are still largely neglected in the clinical routine workflow. 


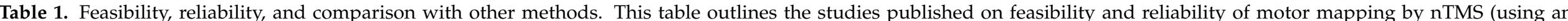

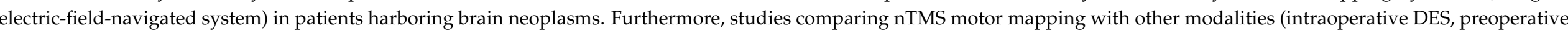
fMRI, and preoperative MEG) are included.

\begin{tabular}{|c|c|c|c|c|c|c|c|}
\hline Author & Year & Cohort & $\begin{array}{c}\text { Tumor } \\
\text { Entities }\end{array}$ & $\begin{array}{l}\text { nTMS } \\
\text { Method }\end{array}$ & $\begin{array}{l}\text { Techniques for } \\
\text { Comparison }\end{array}$ & $\begin{array}{c}\text { Main } \\
\text { Objective }\end{array}$ & $\begin{array}{c}\text { Main } \\
\text { Findings }\end{array}$ \\
\hline $\begin{array}{c}\text { Coburger et al. } \\
\text { [32] }\end{array}$ & 2011 & $\begin{array}{l}\text { 75-year-old } \\
\text { woman }\end{array}$ & MEN & $\begin{array}{l}\text { Preoperative } \\
\text { motor mapping } \\
(60-80 \mathrm{~V} / \mathrm{m})\end{array}$ & Intraoperative DES & $\begin{array}{c}\text { To correlate nTMS } \\
\text { with DES }\end{array}$ & $\begin{array}{l}\text { - The motor strip as determined by DES was located in the } \\
\text { same cortical area where motor responses were elicited } \\
\text { by nTMS. } \\
\text { nTMS motor mapping is a helpful tool for preoperative } \\
\text { planning. }\end{array}$ \\
\hline Picht et al. [33] & 2011 & $\begin{array}{l}\text { 63-year-old } \\
\text { woman }\end{array}$ & MET & $\begin{array}{c}\text { Preoperative and } \\
\text { postoperative }(4 \mathrm{th} \\
\text { postoperative day) } \\
\text { motor mapping } \\
(110 \% \mathrm{rMT})\end{array}$ & Intraoperative DES & $\begin{array}{l}\text { To test nTMS in a } \\
\text { patient with severe } \\
\text { preoperative motor } \\
\text { impairment and to } \\
\text { correlate with DES }\end{array}$ & $\begin{array}{ll}- & \text { nTMS motor mapping demonstrated intact corticospinal } \\
\text { pathways in presence of hemiplegia. } \\
-\quad \text { nTMS motor mapping modified the surgical strategy. } \\
-\quad \text { nTMS and DES mappings agreed well. }\end{array}$ \\
\hline Picht et al. [35] & 2011 & $\begin{array}{l}20 \text { adult } \\
\text { patients }\end{array}$ & $\begin{array}{l}\text { HGG, MET, } \\
\text { MEN, Other }\end{array}$ & $\begin{array}{l}\text { Preoperative } \\
\text { motor mapping } \\
(110 \% \mathrm{rMT})\end{array}$ & Intraoperative DES & $\begin{array}{l}\text { To compare the } \\
\text { accuracy of nTMS } \\
\text { with DES }\end{array}$ & $\begin{array}{l}\text { - Motor hotspots were located on the same gyrus for nTMS } \\
\text { and DES mappings in all cases. } \\
\text { Distances between motor hotspots of nTMS and DES } \\
\text { mappings amounted to } 7.8 \pm 1.2 \mathrm{~mm} \text { for the APB and to } \\
7.1 \pm 0.9 \text { mm for the TA muscles. } \\
\text { - } \quad \text { nTMS and DES mappings agreed well. }\end{array}$ \\
\hline Forster et al. [37] & 2011 & $\begin{array}{l}11 \text { adult } \\
\text { patients }\end{array}$ & $\begin{array}{l}\text { LGG, HGG, } \\
\text { MET, Other }\end{array}$ & $\begin{array}{l}\text { Preoperative } \\
\text { motor mapping } \\
(110 \% \mathrm{rMT})\end{array}$ & $\begin{array}{l}\text { Preoperative fMRI } \\
\text { Intraoperative DES }\end{array}$ & $\begin{array}{l}\text { To compare the } \\
\text { accuracy of nTMS with } \\
\text { fMRI and DES }\end{array}$ & 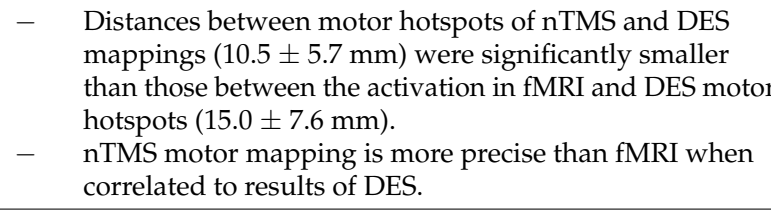 \\
\hline Picht et al. [43] & 2012 & $\begin{array}{l}73 \text { adult } \\
\text { patients }\end{array}$ & $\begin{array}{l}\text { LGG, HGG, } \\
\text { MET, MEN, } \\
\text { Other }\end{array}$ & $\begin{array}{l}\text { Preoperative } \\
\text { motor mapping (110\% } \\
\text { rMT) and nTMS-based } \\
\text { tractography (but } \\
\text { not considered) }\end{array}$ & Intraoperative DES & $\begin{array}{l}\text { To evaluate the } \\
\text { influence, benefit, and } \\
\text { impact of nTMS } \\
\text { on surgery }\end{array}$ & $\begin{array}{l}\text { - nTMS motor mapping confirmed the expected functiona } \\
\text { anatomy in } 22 \% \text {, added awareness of high-risk areas in } \\
27 \% \text {, modified the approach in } 16 \% \text {, changed the planned } \\
\text { EOR in } 8 \% \text {, and changed the surgical indication in } 3 \% \\
\text { of patients. } \\
\text { nTMS motor mapping has positive impact on surgical } \\
\text { planning and on the surgery itself. }\end{array}$ \\
\hline
\end{tabular}


Table 1. Cont.

\begin{tabular}{|c|c|c|c|c|c|c|c|}
\hline Author & Year & Cohort & $\begin{array}{l}\text { Tumor } \\
\text { Entities }\end{array}$ & $\begin{array}{l}\text { nTMS } \\
\text { Method }\end{array}$ & $\begin{array}{l}\text { Techniques for } \\
\text { Comparison }\end{array}$ & $\begin{array}{c}\text { Main } \\
\text { Objective }\end{array}$ & $\begin{array}{l}\text { Main } \\
\text { Findings }\end{array}$ \\
\hline Krieg et al. [38] & 2012 & $\begin{array}{l}26 \text { adult } \\
\text { patients }\end{array}$ & $\begin{array}{l}\text { LGG, HGG, } \\
\text { MET, Other }\end{array}$ & $\begin{array}{l}\text { Preoperative } \\
\text { motor mapping } \\
(110 \% \text { rMT for uE and } \\
130 \% \text { for lE muscles })\end{array}$ & $\begin{array}{l}\text { Preoperative fMRI } \\
\text { Intraoperative DES }\end{array}$ & $\begin{array}{l}\text { To compare the } \\
\text { accuracy of nTMS with } \\
\text { fMRI and DES }\end{array}$ & $\begin{array}{l}\text { - Distances between motor hotspots of nTMS and DES } \\
\text { mappings }(4.4 \pm 3.4 \mathrm{~mm}) \text { were significantly smaller than } \\
\text { those between the activation in fMRI and nTMS motor } \\
\text { hotspots }(9.8 \pm 8.5 \mathrm{~mm} \text { for uE and } 14.7 \pm 12.4 \mathrm{~mm} \text { for } \\
\text { 1E muscles). } \\
\text { - In most cases of tumors in the precentral gyrus the } \\
\text { neurosurgeon admitted easier identification of the central } \\
\text { region in awareness of nTMS motor maps. } \\
\text { nTMS and DES mappings agreed well. }\end{array}$ \\
\hline $\begin{array}{c}\text { Coburger et al. } \\
{[34]}\end{array}$ & 2012 & 3-year-old boy & LGG & $\begin{array}{c}\text { Preoperative } \\
\text { motor mapping } \\
(130 \mathrm{~V} / \mathrm{m} \text { for } \mathrm{uE} \text { and } \\
220 \mathrm{~V} / \mathrm{m} \text { for } 1 \mathrm{E} \text { muscles })\end{array}$ & Intraoperative DES & $\begin{array}{l}\text { To test nTMS in a child } \\
\text { and to correlate } \\
\text { with DES }\end{array}$ & $\begin{array}{l}-\quad \text { DES verified the location of nTMS motor hotspots. } \\
-\quad \text { nTMS is a precise tool for preoperative motor mapping } \\
\text { and is feasible even in young, pediatric patients. }\end{array}$ \\
\hline $\begin{array}{c}\text { Tarapore et al. } \\
\text { [42] }\end{array}$ & 2012 & $\begin{array}{l}24 \text { adult } \\
\text { patients }\end{array}$ & $\begin{array}{l}\text { LGG, HGG, } \\
\text { Other }\end{array}$ & $\begin{array}{l}\text { Preoperative } \\
\text { motor mapping } \\
(110 \% \mathrm{rMT})\end{array}$ & $\begin{array}{l}\text { Preoperative MEG } \\
\text { Intraoperative DES }\end{array}$ & $\begin{array}{l}\text { To compare the } \\
\text { accuracy of nTMS with } \\
\text { MEG and DES }\end{array}$ & 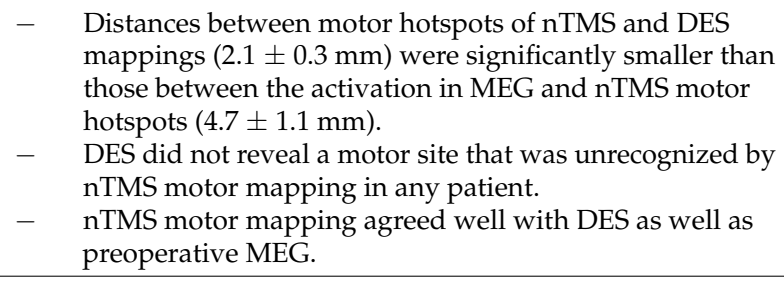 \\
\hline $\begin{array}{c}\text { Coburger et al. } \\
{[36]}\end{array}$ & 2013 & $\begin{array}{l}28 \text { adult } \\
\text { patients and } 2 \\
\text { patients }<18 \\
\text { years }\end{array}$ & $\begin{array}{l}\text { LGG, HGG, } \\
\text { MET, MEN, } \\
\text { Other }\end{array}$ & $\begin{array}{c}\text { Preoperative } \\
\text { motor mapping } \\
(110 \% \mathrm{rMT} \text { in adult } \\
\text { patients and aMT in } \\
\text { patients }<18 \text { years })\end{array}$ & $\begin{array}{l}\text { Preoperative fMRI } \\
\text { Intraoperative DES }\end{array}$ & $\begin{array}{l}\text { To compare the } \\
\text { accuracy of nTMS with } \\
\text { fMRI and DES }\end{array}$ & $\begin{array}{l}\text { - Mean accuracy to localize the motor cortex was higher for } \\
\text { nTMS motor mapping compared with fMRI. } \\
\text { - In the subgroup of intrinsic tumors, nTMS motor } \\
\text { mapping produced significantly higher accuracy for lE } \\
\text { muscle representations than fMRI. }\end{array}$ \\
\hline Krieg et al. [39] & 2013 & $\begin{array}{l}31 \text { adult } \\
\text { patients }\end{array}$ & $\begin{array}{l}\text { LGG, HGG, } \\
\text { MET, MEN, } \\
\text { Other }\end{array}$ & $\begin{array}{l}\text { Preoperative } \\
\text { motor mapping } \\
(110 \% \text { rMT for uE and } \\
130 \% \text { for lE muscles })\end{array}$ & $\begin{array}{l}\text { Preoperative fMRI } \\
\text { Intraoperative DES }\end{array}$ & $\begin{array}{l}\text { To compare the accuracy } \\
\text { of nTMS with fMRI and } \\
\text { DES in recurrent gliomas } \\
\text { vs. initially } \\
\text { operated tumors }\end{array}$ & $\begin{array}{l}\text { - } \quad \text { nTMS motor mapping correlated well with DES in } \\
\text { recurrent gliomas }(6.2 \pm 6.0 \mathrm{~mm}) \text { and newly diagnosed } \\
\text { tumors }(5.7 \pm 4.6 \mathrm{~mm}), \text { yet without a significant difference. } \\
\text { Compared with fMRI, the difference was larger for uE } \\
\text { muscle representations (recurrent: } 8.5 \pm 7.2 \mathrm{~mm} \text {; new: } \\
9.8 \pm 8.6 \mathrm{~mm}) \text { and } 1 \mathrm{E} \text { muscle representations (recurrent: } \\
17.1 \pm 10.6 \mathrm{~mm} \text {; new: } 13.8 \pm 13.0 \mathrm{~mm}), \text { yet without a } \\
\text { significant difference. } \\
\text { nTMS motor mapping was as accurate in recurrent } \\
\text { gliomas as it has been prior to the initial surgery. }\end{array}$ \\
\hline
\end{tabular}


Table 1. Cont.

\begin{tabular}{|c|c|c|c|c|c|c|c|}
\hline Author & Year & Cohort & $\begin{array}{l}\text { Tumor } \\
\text { Entities }\end{array}$ & $\begin{array}{l}\text { nTMS } \\
\text { Method }\end{array}$ & $\begin{array}{l}\text { Techniques for } \\
\text { Comparison }\end{array}$ & $\begin{array}{c}\text { Main } \\
\text { Objective }\end{array}$ & $\begin{array}{l}\text { Main } \\
\text { Findings }\end{array}$ \\
\hline $\begin{array}{c}\text { Mangraviti et al. } \\
\text { [40] }\end{array}$ & 2013 & $\begin{array}{l}8 \text { adul } \\
\text { tpatients }\end{array}$ & $\begin{array}{l}\text { LGG, HGG, } \\
\text { MET, Other }\end{array}$ & $\begin{array}{l}\text { Preoperative } \\
\text { motor mapping } \\
(110 \% \text { rMT for uE and } \\
130 \% \text { for lE muscles })\end{array}$ & $\begin{array}{l}\text { Preoperative fMRI } \\
\text { Intraoperative DES }\end{array}$ & $\begin{array}{l}\text { To compare the } \\
\text { accuracy of nTMS with } \\
\text { fMRI and DES }\end{array}$ & $\begin{array}{l}\text { Distances between motor hotspots of nTMS and DES } \\
\text { mappings }(8.5 \pm 4.6 \mathrm{~mm}) \text { were significantly smaller than } \\
\text { those between the activation in fMRI and DES motor } \\
\text { hotspots }(12.9 \pm 5.7 \mathrm{~mm}) \text {. } \\
\text { - Visualization of nTMS motor hotspots improved the } \\
\text { neurosurgeons' confidence in identifying the motor strip } \\
\text { as well as in planning of surgical strategies. }\end{array}$ \\
\hline $\begin{array}{c}\text { Zdunczyk et al. } \\
{[45]}\end{array}$ & 2013 & $\begin{array}{l}10 \text { adult } \\
\text { patients (and } 10 \\
\text { healthy } \\
\text { volunteers) }\end{array}$ & $\begin{array}{l}\text { LGG, HGG, } \\
\text { MET, MEN, } \\
\text { Other }\end{array}$ & $\begin{array}{c}\text { Preoperative } \\
\text { motor mapping } \\
(110 \% \text { rMT) } \\
\text { (and two motor } \\
\text { mappings per subject in } \\
\text { the healthy volunteers) }\end{array}$ & - & $\begin{array}{l}\text { To assess the intra- and } \\
\text { inter-examiner } \\
\text { reliability of } \\
\text { nTMS mapping }\end{array}$ & $\begin{array}{l}\text { - Distances between CoGs for the expert examiner in } \\
\text { healthy volunteers were } 4.4(1.9-7.7) \mathrm{mm} \text { and } 4.9 \text { (2.4-9.2) } \\
\text { mm for the expert vs. novice examiner. } \\
\text { The reliability of nTMS motor mapping in tumor patients } \\
\text { appeared to be comparable to those in healthy subjects. }\end{array}$ \\
\hline Rizzo et al. [44] & 2014 & $\begin{array}{l}17 \text { adult } \\
\text { patients }\end{array}$ & $\begin{array}{l}\text { LGG, HGG, } \\
\text { MET, MEN, } \\
\text { Other }\end{array}$ & $\begin{array}{c}\text { Preoperative } \\
\text { motor mapping } \\
(110-115 \% \text { rMT for } \mathrm{uE} \\
\text { and } 130 \% \text { for } 1 \mathrm{E} \\
\text { muscles })\end{array}$ & Intraoperative DES & $\begin{array}{l}\text { To evaluate the } \\
\text { influence, benefit, and } \\
\text { impact of nTMS } \\
\text { on surgery }\end{array}$ & $\begin{array}{l}\text { nTMS motor mapping exactly localized the motor cortex } \\
\text { in } 88.2 \% \text {, provided the neurosurgeon with new } \\
\text { unexpected information about functional anatomy of the } \\
\text { motor area in } 70.6 \% \text {, and led to a change of the surgical } \\
\text { strategy in } 29.4 \% \text { of patients. } \\
\text { nTMS motor mapping has objective and subjective } \\
\text { benefits on surgical planning and on the surgery itself. }\end{array}$ \\
\hline $\begin{array}{c}\text { Sollmann et al. } \\
{[46]}\end{array}$ & 2017 & $\begin{array}{l}100 \text { adult } \\
\text { patients }\end{array}$ & $\begin{array}{l}\text { LGG, HGG, } \\
\text { MET, Other }\end{array}$ & $\begin{array}{l}\text { Preoperative } \\
\text { motor mapping } \\
(110 \% \text { rMT for } \mathrm{uE} \text { and } \\
130 \% \text { for } \mathrm{lE} \text { muscles })\end{array}$ & - & $\begin{array}{l}\text { To investigate factors } \\
\text { that have impact on } \\
\text { MEP latencies }\end{array}$ & $\begin{array}{l}\text { - Common factors (relevant to APB, ADM, and FCR) for } \\
\text { MEP latency variability were sex and AED intake. } \\
\text { - Muscle-specific factors (relevant to APB, ADM, or FCR) } \\
\text { for MEP latency variability were tumor side, tumor } \\
\text { location, and rMT. }\end{array}$ \\
\hline $\begin{array}{c}\text { Sollmann et al. } \\
\text { [47] }\end{array}$ & 2017 & $\begin{array}{l}100 \text { adult } \\
\text { patients }\end{array}$ & $\begin{array}{l}\text { LGG, HGG, } \\
\text { MET, Other }\end{array}$ & $\begin{array}{l}\text { Preoperative } \\
\text { motor mapping } \\
(110 \% \text { rMT for uE and } \\
130 \% \text { for lE muscles })\end{array}$ & - & $\begin{array}{l}\text { To investigate factors } \\
\text { that influence the } \\
\text { determination of } \\
\text { the rMT }\end{array}$ & $\begin{array}{l}\text { - Edema and age at exam in the ADM model only jointly } \\
\text { reduced the unexplained variance for rMT determination. } \\
\text { - The other factors kept in the ADM model (sex, AED } \\
\text { intake, and motor deficit) and each of the factors kept in } \\
\text { the APB and FCR models independently and } \\
\text { significantly reduced the unexplained variance for } \\
\text { rMT determination. }\end{array}$ \\
\hline
\end{tabular}


Table 1. Cont.

\begin{tabular}{|c|c|c|c|c|c|c|c|}
\hline Author & Year & Cohort & $\begin{array}{l}\text { Tumor } \\
\text { Entities }\end{array}$ & $\begin{array}{l}\text { nTMS } \\
\text { Method }\end{array}$ & $\begin{array}{l}\text { Techniques for } \\
\text { Comparison }\end{array}$ & $\begin{array}{c}\text { Main } \\
\text { Objective }\end{array}$ & $\begin{array}{c}\text { Main } \\
\text { Findings }\end{array}$ \\
\hline Lam et al. [49] & 2019 & $\begin{array}{l}20 \text { adult } \\
\text { patients }\end{array}$ & $\mathrm{n} / \mathrm{a}$ & $\begin{array}{c}\text { Preoperative } \\
\text { motor mapping } \\
(105 \% \mathrm{rMT})\end{array}$ & - & $\begin{array}{l}\text { To investigate the } \\
\text { feasibility of increasing } \\
\text { the MEP threshold ( } 50 \\
\mu \mathrm{V} \text { vs. } 500 \mu \mathrm{V} \text { ) to } \\
\text { improve the robustness } \\
\text { of motor mapping }\end{array}$ & $\begin{array}{l}\text { - Both the standard }(50 \mu \mathrm{V}) \text { as well as the experimental } \\
(500 \mu \mathrm{V}) \mathrm{MEP} \text { threshold yielded motor maps in all patients. } \\
\text { No significant differences in motor area sizes were found } \\
\text { between the conventional }(50 \mu \mathrm{V}) \text { MEP threshold and the } \\
\text { experimental }(500 \mu \mathrm{V}) \mathrm{MEP} \text { threshold. } \\
\text { MEP latency time was significantly reduced for } \\
\text { recordings from } 500 \mu \mathrm{V} \text { compared with recordings from } \\
50 \mu \mathrm{V} \text { MEP thresholds. }\end{array}$ \\
\hline $\begin{array}{c}\text { Mirbagheri et al. } \\
{[50]}\end{array}$ & 2020 & $\begin{array}{l}12 \text { adult } \\
\text { patients (and } \\
\text { six healthy } \\
\text { volunteers) }\end{array}$ & $\mathrm{n} / \mathrm{a}$ & $\begin{array}{c}\text { Preoperative } \\
\text { motor mapping } \\
(105 \% \text { rMT for primary } \\
\text { motor areas, } \\
120 \% / 150 \% \text { for } \\
\text { non-primary motor } \\
\text { areas) }\end{array}$ & - & $\begin{array}{l}\text { To investigate whether } \\
\text { nTMS reliably elicits } \\
\text { MEPs outside of the } \\
\text { primary motor cortex }\end{array}$ & $\begin{array}{l}\text { - } 88.8 \% \text { of stimulations in suspected non-primary motor } \\
\text { areas did not result in motor-positive spots with MEPs } \\
\geq 50 \mu \mathrm{V} \text {. } \\
\text { - } \\
\text { Positive nTMS motor mapping in non-primary motor } \\
\text { areas was associated with higher SI and larger primary } \\
\text { motor areas. } \\
\text { Particularly when mapped with } 150 \% \mathrm{rMT} \text {, more MEP } \\
\text { artifacts occurred in patients than in healthy volunteers. }\end{array}$ \\
\hline $\begin{array}{c}\text { Lavrador et al. } \\
\text { [48] }\end{array}$ & 2020 & $\begin{array}{l}45 \text { adult } \\
\text { patients }\end{array}$ & LGG, HGG & $\begin{array}{l}\text { Preoperative } \\
\text { motor mapping } \\
(105 \% \mathrm{rMT})\end{array}$ & - & $\begin{array}{l}\text { To assess the excitability } \\
\text { of the motor system in } \\
\text { relation to } \\
\text { tumor grading }\end{array}$ & $\begin{array}{l}\text { - MEP latencies of IE muscles increased with an increase in } \\
\text { the WHO grading of the tumor. } \\
\text { - An association between the increase in the WHO grading } \\
\text { and a decreased rMT was observed for lE muscles. } \\
\text { - Higher WHO grading of the tumor and isocitrate } \\
\text { dehydrogenase wild-type tumors were associated with } \\
\text { the number of abnormal interhemispheric rMT ratios. }\end{array}$ \\
\hline
\end{tabular}

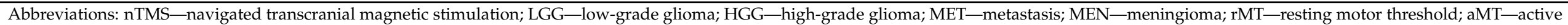

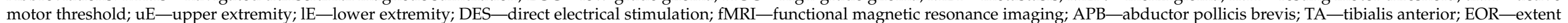

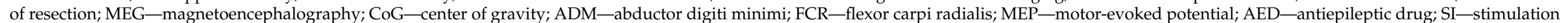
intensity; WHO-World Health Organization. 


\subsection{Fiber Tractography}

The motor-positive nTMS points can be used for seeding to obtain regions of interest (ROIs) for subsequent delineation of the corticospinal tract (CST) in the context of fiber tracking. The combination of nTMS motor maps at the cortical surface with diffusion MRI (dMRI) and tractography, i.e., the delineation of the primary motor cortex and its subcortical connections to the peripheral nervous system with visualization of the course of the CST, can provide a more complete picture than one of the techniques alone (Figure 4). In this regard, Table 2 outlines studies using data from nTMS motor mapping for tractography of the CST in patients with different kinds of brain neoplasms.

In a first tractography study using nTMS data, 30 patients harboring motor-eloquent brain tumors underwent presurgical nTMS motor mapping followed by nTMS-based tractography, using the nTMS motor-positive spots and the ipsilateral cerebral peduncle as ROIs [51]. Compared with the conventionally used approach with manual delineation of the suspected primary motor cortex and the ipsilateral cerebral peduncle as ROIs, the novel setup led to a lower number of fibers displayed, a reduced volume of the CST, and, most importantly, lower fractions of aberrant tracts most likely not belonging to the CST [51]. The approach of nTMS-based tractography of the CST was subsequently refined by investigating individually adapted adjustments for the fractional anisotropy (FA) that had to be defined for the deterministic tractography algorithm: the FA was increased stepwise until no fibers were displayed, followed by reducing the FA value by 0.01 , thus delineating only a thin fiber course; the obtained FA value was defined as $100 \%$ FA threshold (FAT), and nTMS-based tractography was then carried out with $50 \%$ and $75 \%$ FAT with motor-positive nTMS points and the manually delineated internal capsule or brainstem as ROIs [52]. This method influenced the surgical strategy in $46 \%$ of patients, in contrast to conventional tractography without nTMS data for ROI generation where an impact was only observed for $22 \%$ of patients [52].

Furthermore, a study among 20 patients with different entities of brain neoplasms achieved detailed somatotopic CST reconstruction derived from nTMS motor maps combined with $\mathrm{dMRI}$ for $\mathrm{uE}, \mathrm{lE}$, and face muscle representations, with a decreased number of fibers and a greater overlap between the motor cortex and the cortical end-region of the CST when compared with conventional tractography with only anatomical seeding [53]. Of note, the obtained CST course as well as the somatotopic organization were confirmed by DES mapping [53]. In another study on somatotopic reconstruction of the CST considering parts subserving $\mathrm{uE}, \mathrm{IE}$, and face muscles, a higher fraction of plausible fibers was observed for seeding at the anterior inferior pontine level when compared with seeding at the internal capsule, combined with nTMS-based seeding at the cortical level [54]. When setting somatotopic nTMS-based tractography in contrast to fMRI-based seeding, a higher plausibility was observed for the nTMS-based approach, and fMRI-originated tracts presented with a more posterior course relative to the nTMS-based reconstruction of tracts [55]. Recently, in a comprehensive study systematically comparing different setups for tractography (deterministic and probabilistic algorithms with variable ROI definitions) and correlating tractography with DES mapping and fMRI findings in 11 adult patients, highest accuracy of tractography was achieved when using seeding with a manually generated mask enclosing the precentral gyrus, but none of the applied setups showed clear superiority and nTMS- or fMRI-based tractography differed only slightly [56]. Yet, probabilistic tracking resulted in an optimized correlation with DES mapping when compared with the more commonly used deterministic tractography algorithm [56]. Upcoming work is needed to further investigate optimal settings and algorithms in representative cohort sizes to achieve results of CST tractography as close as possible to DES mapping results in order to assure accuracy and reliability of nTMS-based tractography. 


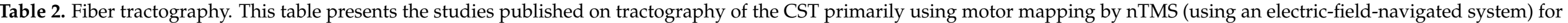
seeding in patients harboring brain neoplasms.

\begin{tabular}{|c|c|c|c|c|c|c|c|}
\hline Author & Year & Cohort & $\begin{array}{c}\text { Tumor } \\
\text { Entities }\end{array}$ & $\begin{array}{c}\text { dMRI } \\
\text { Acquisition }\end{array}$ & $\begin{array}{c}\text { Tractography } \\
\text { Specifics }\end{array}$ & $\begin{array}{c}\text { Main } \\
\text { Objective }\end{array}$ & $\begin{array}{c}\text { Main } \\
\text { Findings }\end{array}$ \\
\hline Krieg et al. [51] & 2012 & $\begin{array}{l}30 \text { adult } \\
\text { patients }\end{array}$ & $\begin{array}{l}\text { LGG, HGG, MET, } \\
\text { MEN, Other }\end{array}$ & $\begin{array}{c}6 \text { diffusion } \\
\text { directions, b-values: } \\
0-800 \mathrm{~s} / \mathrm{mm}^{2} \\
(3 \text { Tesla) }\end{array}$ & $\begin{array}{l}\text { Two ROIs: motor-positive } \\
\text { nTMS points and } \\
\text { ipsilateral brainstem } \\
\text { (conventional: manually } \\
\text { delineated motor cortex } \\
\text { and ipsilateral brainstem) } \\
\text { Deterministic tracking: FA } \\
\text { <0.2, FL } \sim 100 \mathrm{~mm} \text {, angular } \\
\text { threshold of } 30^{\circ}\end{array}$ & $\begin{array}{l}\text { To assess the feasibility of } \\
\text { nTMS-based tractography } \\
\text { in relation to conventional } \\
\text { seeding without } \\
\text { nTMS data }\end{array}$ & $\begin{array}{l}\text { - nTMS-based tractography resulted in a lower number of } \\
\text { aberrant tracts (i.e., tracts not belonging to the CST) when } \\
\text { compared with conventional seeding without nTMS. } \\
\text { The proximity of the tracts to the tumor was not different } \\
\text { between nTMS-based and conventional tractography for CST } \\
\text { reconstruction. } \\
\text { Conventional seeding showed to be user-dependent, whereas } \\
\text { nTMS-based tractography seemed to be less subjective. }\end{array}$ \\
\hline Frey et al. [52] & 2012 & $\begin{array}{l}50 \text { adult } \\
\text { patients }\end{array}$ & $\begin{array}{l}\text { LGG, HGG, MET, } \\
\text { MEN }\end{array}$ & $\begin{array}{c}23 \text { diffusion } \\
\text { directions, b-values: } \\
0-1000 \mathrm{~s} / \mathrm{mm}^{2} \\
\text { (3 Tesla) }\end{array}$ & $\begin{array}{l}\text { - One ROI: motor-positive } \\
\text { nTMS points } \\
\text { (conventional: manually } \\
\text { delineated internal capsule } \\
\text { or brainstem) } \\
\text { Deterministic tracking: } \\
\text { FA }=50 \% \text { and } \\
75 \% \text { FAT, FL }=110 \mathrm{~mm}, \\
\text { angular threshold of } 30^{\circ}\end{array}$ & $\begin{array}{l}\text { To assess the feasibility } \\
\text { and impact on surgery of } \\
\text { nTMS-based tractography } \\
\text { in relation to conventional } \\
\text { seeding without nTMS } \\
\text { data and to provide a new } \\
\text { algorithm for FA } \\
\text { determination }\end{array}$ & $\begin{array}{l}\text { - } \quad \text { nTMS-based tractography changed or modified the surgical } \\
\text { strategy in } 46 \% \text { of patients, whereas conventional tractography } \\
\text { would have changed the surgical strategy in only } 22 \% \\
\text { of patients. } \\
\text { Tractography facilitated intraoperative situs orientation and } \\
\text { application of DES in } 56 \% \text { of patients. } \\
\text { - Tracking at } 75 \% \text { FAT was considered most beneficial by } \\
\text { the neurosurgeons. }\end{array}$ \\
\hline Conti et al. [53] & 2014 & $\begin{array}{l}20 \text { adult } \\
\text { patients }\end{array}$ & $\begin{array}{l}\text { LGG, HGG, } \\
\text { MET, Other }\end{array}$ & $\begin{array}{c}32 \text { diffusion } \\
\text { directions } \\
\text { (3 Tesla) }\end{array}$ & $\begin{array}{l}\text { Two ROIs: motor-positive } \\
\text { nTMS points, subdivided } \\
\text { for uE, IE, and face } \\
\text { muscles, and ipsilateral } \\
\text { brainstem (conventional: } \\
\text { ipsilateral brainstem) } \\
\text { Deterministic tracking: } \\
\text { FA }=0.2, \mathrm{FL}=20 \mathrm{~mm}, \\
\text { angular threshold of } 45^{\circ}\end{array}$ & $\begin{array}{l}\text { To assess somatotopic } \\
\text { organization by } \\
\text { nTMS-based tractography } \\
\text { in relation to conventional } \\
\text { seeding without nTMS } \\
\text { data and to verify } \\
\text { nTMS-based tractography } \\
\text { by intraoperative DES }\end{array}$ & $\begin{array}{l}\text { Detailed somatotopic CST reconstruction was possible by } \\
\text { nTMS-based tractography with a greater overlap between the } \\
\text { motor cortex and the cortical end-region of the CST }(90.5 \pm 8.8 \% \\
\text { vs. } 58.3 \pm 16.6 \% \text { when compared with conventional tractography. } \\
\text { DES mapping confirmed the CST location and the somatotopic } \\
\text { reconstruction in all cases. } \\
\text { nTMS-based tractography of the CST appeared to be more } \\
\text { accurate, less user-dependent, and capable of providing reliable } \\
\text { CST delineation compared with conventional tractography. }\end{array}$ \\
\hline Weiss et al. [54] & 2015 & $\begin{array}{l}32 \text { adult } \\
\text { patients }\end{array}$ & $\begin{array}{l}\text { LGG, HGG, MET, } \\
\text { MEN, Other }\end{array}$ & $\begin{array}{l}30 \text { diffusion } \\
\text { directions, b-values: } \\
0-800 \mathrm{~s} / \mathrm{mm}^{2} \\
\text { (3 Tesla) }\end{array}$ & $\begin{array}{l}\text { Two ROIs: motor-positive } \\
\text { nTMS points, subdivided } \\
\text { for uE, IE, and face } \\
\text { muscles, and internal } \\
\text { capsule and /or anterior } \\
\text { inferior pontine level } \\
\text { Deterministic tracking: } \\
\text { FA }=75 \% \text { and } 100 \% \text { FAT, } \\
\text { FL }=1 \mathrm{~mm} \text {, angular } \\
\text { threshold of } 30^{\circ} \\
\end{array}$ & $\begin{array}{l}\text { To assess the impact of } \\
\text { subcortical seed regions } \\
\text { and of somatotopic } \\
\text { location of cortical seed } \\
\text { regions on plausibility of } \\
\text { tractography in relation to } \\
\text { clinical factors }\end{array}$ & $\begin{array}{l}\text { A higher proportion of plausible tracts was observed for seeding } \\
\text { at the anterior inferior pontine level when compared with } \\
\text { seeding at the internal capsule. } \\
\text { Low FAT and the presence of peritumoral edema within the } \\
\text { internal capsule led to less plausible tractography, and most } \\
\text { plausible tractography was obtained when the FAT ranged } \\
\text { above a cut-off of 0.105. } \\
\text { A strong effect of somatotopic location of the seed region was } \\
\text { observed, with the best plausibility present for tractography of } \\
\text { fibers subserving the bilateral uE muscle representations }(>95 \%) \text {. }\end{array}$ \\
\hline
\end{tabular}


Table 2. Cont.

\begin{tabular}{|c|c|c|c|c|c|c|c|}
\hline Author & Year & Cohort & $\begin{array}{l}\text { Tumor } \\
\text { Entities }\end{array}$ & $\begin{array}{c}\text { dMRI } \\
\text { Acquisition }\end{array}$ & $\begin{array}{l}\text { Tractography } \\
\text { Specifics }\end{array}$ & $\begin{array}{c}\text { Main } \\
\text { Objective }\end{array}$ & $\begin{array}{c}\text { Main } \\
\text { Findings }\end{array}$ \\
\hline Weiss et al. [55] & 2017 & $\begin{array}{l}18 \text { adult } \\
\text { patients }\end{array}$ & $\begin{array}{l}\text { LGG, HGG, MET, } \\
\text { MEN, Other }\end{array}$ & $\begin{array}{l}30 \text { diffusion } \\
\text { directions, b-values: } \\
0-800 \mathrm{~s} / \mathrm{mm}^{2} \\
(3 \text { Tesla) }\end{array}$ & $\begin{array}{l}\text { - Two ROIs: motor-positive } \\
\text { nTMS points, subdivided } \\
\text { for uE, lE, and face } \\
\text { muscles, and anterior } \\
\text { inferior pontine level } \\
\text { (fMRI-based: task-derived } \\
\text { activation map and } \\
\text { anterior inferior pons) } \\
\text { Deterministic tracking: } \\
\text { FA }=100 \% \mathrm{FAT}, \mathrm{FL}=1 \mathrm{~mm}, \\
\text { angular threshold of } 30^{\circ}\end{array}$ & $\begin{array}{l}\text { To assess the impact of the } \\
\text { modality used for } \\
\text { somatotopic location of } \\
\text { cortical seed regions on } \\
\text { plausibility of tractography }\end{array}$ & $\begin{array}{l}\text { - A higher plausibility was observed for nTMS-based } \\
\text { tractography compared with fMRI-based tractography, with } \\
\text { fMRI-originated tracts showing a significantly more posterior } \\
\text { course relative to the nTMS-based tracts. } \\
\text { nTMS motor mapping seems to be the method of choice to } \\
\text { identify seed regions for tractography of the CST in patients with } \\
\text { close vicinity of the primary motor cortex to a brain neoplasm. }\end{array}$ \\
\hline Münnich et al. [56] & 2019 & $\begin{array}{c}11 \text { adolescent or } \\
\text { adult } \\
\text { patients }\end{array}$ & $\begin{array}{l}\text { HGG, MET, } \\
\text { Other }\end{array}$ & $\begin{array}{l}20 \text { diffusion } \\
\text { directions, b-values: } \\
0-700 \mathrm{~s} / \mathrm{mm}^{2} \\
\quad(3 \text { Tesla })\end{array}$ & $\begin{array}{l}- \text { Several ROIs for } \\
\text { motor-positive nTMS } \\
\text { points, task-derived fMRI } \\
\text { activation maps, or } \\
\text { conventional seeding } \\
\text { Deterministic and } \\
\text { probabilistic tracking: } \\
\text { minimal } \\
\text { FA threshold }=0.05 / \epsilon \\
{[0.1 ; 0.45], \text { tracking step }} \\
\text { length }=1 \mathrm{~mm} / \in[0.5 ; 7] \\
\text { mm, maximum fiber } \\
\text { curvature }=0.3 / \in[0.2 ; 0.65]\end{array}$ & $\begin{array}{l}\text { To compare different } \\
\text { seeding setups and } \\
\text { tracking algorithms, and to } \\
\text { correlate tractography with } \\
\text { intraoperative DES and } \\
\text { MRI findings }\end{array}$ & $\begin{array}{l}\text { - The best accuracy of tractography was achieved using the } \\
\text { segmented precentral gyrus for seeding (marginal } \mathrm{R}^{2}=0.146 \text { ); } \\
\text { however, since the marginal } \mathrm{R}^{2} \text { of fMRI and nTMS motor } \\
\text { mapping differed very little, none of the methods showed } \\
\text { distinct superiority. } \\
\text { Both nTMS-based and fMRI-based tractography showed } \\
\text { significant correlations between distances and the SI of DES for } \\
\text { the CST, but only with respect to uE muscle representations. } \\
\text { The use of the probabilistic tracking algorithm led to a better } \\
\text { correlation between DES mapping and tractography. } \\
\text { Tractography demands for careful interpretation of its results by } \\
\text { considering all influencing variables (e.g., seeding approach and } \\
\text { tracking algorithm used). }\end{array}$ \\
\hline
\end{tabular}

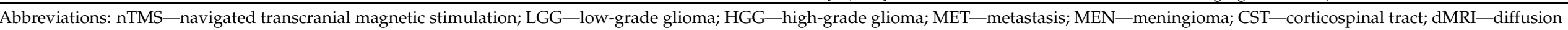

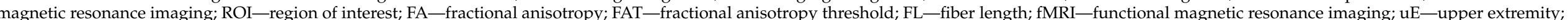

E-lower extremity; DES—direct electrical stimulation; SI—-stimulation intensity. 


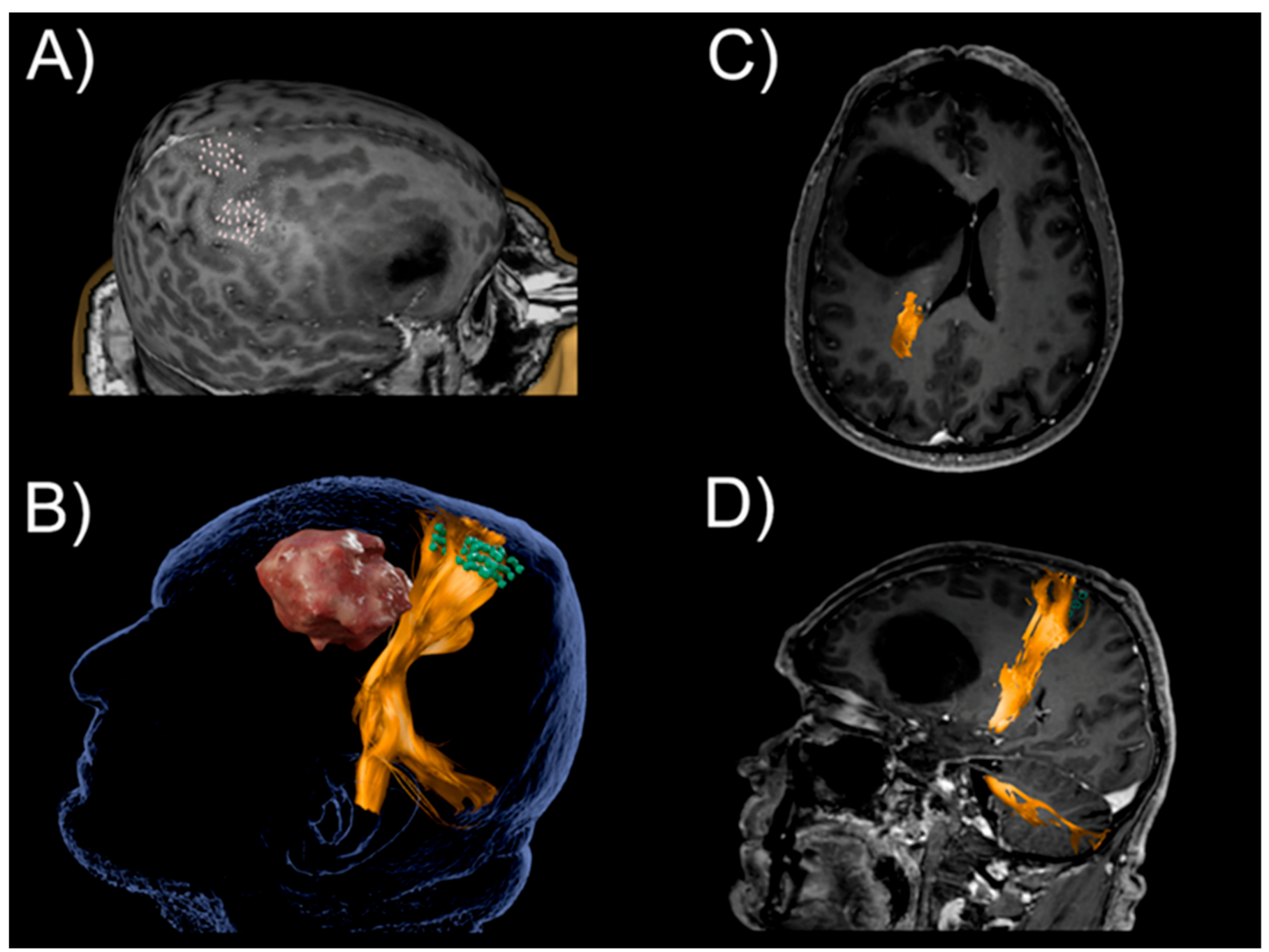

Figure 4. Exemplary patient case (right-hemispheric glioma in a 56-year-old male patient) for illustration of CST reconstruction using tractography based on motor maps derived from motor mapping with nTMS. (A) Motor map with binarization into motor-positive (white) and motor-negative (grey) stimulation points. (B) Tractography of the CST (orange) based on a ROI constituted of motor-positive nTMS points (green). (C) Fusion of T1-weighted imaging and tractography results (axial plane). (D) Fusion of T1-weighted imaging and tractography results (sagittal plane).

\subsection{Improvement of Clinical Outcome}

When added to the armamentarium of the preoperative workup of patients harboring brain neoplasms, the question arises whether nTMS motor mapping and derived nTMSbased tractography may be capable of improving the clinical outcome, as measured by an ideally increased EOR combined with lowered rates of functional perioperative decline. In this regard, Table 3 gives an overview of studies focused on clinical outcome.

An initial study compared 11 patients who underwent preoperative nTMS to 11 patients without nTMS motor mapping, revealing that preoperative nTMS motor mapping changed the treatment plan towards early and more extensive resection in 6 out of 11 patients [57]. Furthermore, one of four patients of the nTMS group with preoperative motor deficits improved by one year, whereas increased deficits were observed in three of the eight patients of the historical group not having surgery [57]. In two retrospective studies in considerably large cohorts of patients with different types of brain tumors, the utility of nTMS motor mapping and nTMS-based tractography of the CST may have facilitated a more extensive EOR, combined with tendencies towards better motor function after surgery $[58,59]$. 
Specifically, nTMS disproved suspected involvement of the primary motor cortex in $25.1 \%$ of the 250 enrolled patients, and it enabled expanding surgical indication in $14.8 \%$, thus facilitating planning of more extensive resections in $35.2 \%$ of patients [58]. Furthermore, the distinct add-on value of nTMS-based tractography of the CST has been evaluated in a study including 70 adult patients with different brain tumor entities, revealing that patients having nTMS-based tractography available are characterized by an improved risk-benefit profile, showed an increased EOR, and demonstrated reduced rates of worsening in motor function in cases of already preexisting preoperative motor deficits [60].

In a follow-up study investigating the role of nTMS motor mapping and nTMS-based tractography in 70 patients presenting with high-grade glioma (HGG), residual tumor tissue and unexpected tumor residuals were less frequent in the nTMS group compared with historical control patients, with patients of the nTMS group being more frequently eligible for postoperative radiotherapy and showing prolonged 3-, 6-, and 9-month survival rates [61]. A significantly higher EOR was subsequently confirmed by another study for patients with a diagnosis of glioblastoma multiforme (GBM), in which patients of the nTMS group showed a gross total resection (GTR) rate of $61 \%$ versus $45 \%$ for the non-nTMS group [62]. Analogously, in studies focusing on patients with intracranial MET, patients of the nTMS group showed a lower rate of residuals combined with comparatively low rates of perioperative decline of motor function $[63,64]$. Specifically, in a retrospective comparative study pooling patients with intracranial MET from three different neurosurgical centers, surgery-related paresis was clearly less frequent in patients of the nTMS group [64]. In 47 patients with MEN located in the rolandic area, nTMS motor mapping and tractography facilitated a modification of the surgical strategy in $42.5 \%$ of cases, and a new permanent motor deficit (i.e., deficit that did not resolve to the preoperative status within the follow-up interval) occurred in $8.5 \%$ of cases, which is at the lower edge of the range for motor deficits known from the literature of the pre-nTMS era [65]. Furthermore, the combination of sodium fluorescein-guided resection (FGR) with preoperative nTMS motor mapping and tractography has been explored recently, revealing a higher GTR rate for patients operated on using nTMS and FGR as well as lower rates of new surgery-related permanent motor deficits when compared with controls [66,67].

One study in 43 patients with LGG and HGG showed that $72 \%$ of patients had motorpositive nTMS points in areas frontal of the rolandic area and, thus, outside of the expected spatial dimensions of the primary motor cortex [68]. Interestingly, 10 of the 13 patients who underwent resection of motor-positive nTMS points presented with postoperative paresis (8 patients with a new permanent surgery-related paresis), suggesting that even motorpositive nTMS points within the superior or middle frontal gyrus should be considered carefully for resection planning and guidance to avoid perioperative functional decline [68]. Hence, nTMS motor mapping and derived tractography may help to understand individual functional anatomy, allowing for optimized resection that provides a high EOR and low rates of surgically induced motor function decline. 


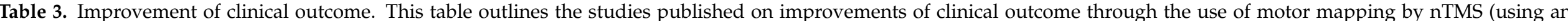
electric-field-navigated system) with or without additional nTMS-based tractography in patients harboring brain neoplasms.

\begin{tabular}{|c|c|c|c|c|c|c|c|c|}
\hline Author & Year & Cohort & $\begin{array}{c}\text { Group for } \\
\text { Comparison }\end{array}$ & $\begin{array}{l}\text { Tumor } \\
\text { Entities }\end{array}$ & $\begin{array}{l}\text { nTMS } \\
\text { Method }\end{array}$ & Outcome Parameters & $\begin{array}{c}\text { Main } \\
\text { Objective }\end{array}$ & $\begin{array}{c}\text { Main } \\
\text { Findings }\end{array}$ \\
\hline Picht et al. [57] & 2013 & $\begin{array}{l}11 \text { adult } \\
\text { patients }\end{array}$ & $\begin{array}{l}11 \text { historical } \\
\text { controls }\end{array}$ & $\begin{array}{c}\text { (suspected) LGG, } \\
\text { HGG }\end{array}$ & $\begin{array}{l}\text { Preoperative } \\
\text { motor mapping }\end{array}$ & $\begin{array}{ll}- & \text { Influence on } \\
\text { surgery } \\
-\quad \text { EOR/tumor } \\
\text { volume } \\
-\quad \begin{array}{l}\text { Motor function } \\
\text { (BMRC) }\end{array}\end{array}$ & $\begin{array}{l}\text { To assess the } \\
\text { impact of nTMS on } \\
\text { the treatment } \\
\text { strategy and } \\
\text { clinical outcome }\end{array}$ & $\begin{array}{l}\text { - In } 6 \text { out of } 11 \text { patients, nTMS changed the } \\
\text { treatment plan towards early and more } \\
\text { extensive resection. } \\
\text { - One of } 4 \text { patients of the nTMS group with } \\
\text { preoperative motor deficits improved by } \\
\text { one year, whereas increased motor deficits } \\
\text { were observed in } 3 \text { of the } 8 \text { patients of the } \\
\text { non-nTMS group not having surgery. } \\
\text { Median change of tumor volume from } \\
\text { baseline to one year was }-83 \% \text { in the nTMS } \\
\text { group and }+12 \% \text { in the non-nTMS group. }\end{array}$ \\
\hline Frey et al. [58] & 2014 & $\begin{array}{l}250 \text { adult } \\
\text { patients }\end{array}$ & $\begin{array}{l}115 \text { historical } \\
\text { controls }\end{array}$ & $\begin{array}{l}\text { LGG, HGG, } \\
\text { MET, Other }\end{array}$ & $\begin{array}{c}\text { Preoperative motor } \\
\text { mapping and } \\
\text { nTMS-based } \\
\text { tractography }\end{array}$ & $\begin{array}{ll}- & \begin{array}{l}\text { Influence on } \\
\text { surgery }\end{array} \\
- & \text { EOR/tumor } \\
& \text { volume } \\
- & \text { Motor function } \\
& \text { (BMRC) } \\
- & \text { KPS } \\
- & \text { PFS }\end{array}$ & $\begin{array}{l}\text { To assess the } \\
\text { impact of nTMS on } \\
\text { the treatment } \\
\text { strategy, } \\
\text { clinical outcome, } \\
\text { and survival }\end{array}$ & $\begin{array}{l}\text { nTMS disproved suspected involvement of } \\
\text { the primary motor cortex in } 25.1 \% \text {, } \\
\text { expanded surgical indication in } 14.8 \% \text {, and } \\
\text { led to planning of more extensive resections } \\
\text { in } 35.2 \% \text { and more restrictive resections in } \\
3.5 \% \text { of patients. } \\
\text { The rate of GTR was significantly higher in } \\
\text { the nTMS group ( } 42 \% \text { vs. } 59 \% \text { ), and PFS for } \\
\text { patients with LGG was better in the nTMS } \\
\text { group (at } 22.4 \text { months) than in the } \\
\text { non-nTMS group (at } 15.4 \text { months). } \\
\text { Integration of nTMS led to a non-significant } \\
\text { change of postoperative deficits from } 8.5 \% \\
\text { in the non-nTMS group to } 6.1 \% \text { in the } \\
\text { nTMS group. } \\
\text { Expanding surgical indications and EOR } \\
\text { based on nTMS might enable more patients } \\
\text { to undergo surgery and could lead to better } \\
\text { motor function outcome and improved PFS. }\end{array}$ \\
\hline
\end{tabular}


Table 3. Cont.

\begin{tabular}{|c|c|c|c|c|c|c|c|c|}
\hline Author & Year & Cohort & $\begin{array}{l}\text { Group for } \\
\text { Comparison }\end{array}$ & $\begin{array}{c}\text { Tumor } \\
\text { Entities }\end{array}$ & $\begin{array}{l}\text { nTMS } \\
\text { Method }\end{array}$ & Outcome Parameters & $\begin{array}{c}\text { Main } \\
\text { Objective }\end{array}$ & $\begin{array}{c}\text { Main } \\
\text { Findings }\end{array}$ \\
\hline $\begin{array}{l}\text { Krieg et al. } \\
\text { [59] }\end{array}$ & 2014 & $\begin{array}{l}100 \text { adult } \\
\text { patients }\end{array}$ & $\begin{array}{l}100 \text { historical } \\
\text { controls } \\
\text { (matching } \\
\text { criteria: tumor } \\
\text { location, } \\
\text { preoperative } \\
\text { paresis, and } \\
\text { histology) }\end{array}$ & $\begin{array}{l}\text { LGG, HGG, } \\
\text { MET, Other }\end{array}$ & $\begin{array}{l}\text { Preoperative } \\
\text { motor mapping } \\
\text { (110\% rMT for uE } \\
\text { and } 130 \% \text { for lE } \\
\text { muscles) and } \\
\text { nTMS-based } \\
\text { tractography }\end{array}$ & $\begin{array}{ll}- & \text { Influence on } \\
\text { surgery } \\
-\quad \text { EOR/tumor } \\
\text { volume } \\
-\quad \begin{array}{l}\text { Motor function } \\
\text { (BMRC) }\end{array}\end{array}$ & $\begin{array}{l}\text { To assess the } \\
\text { impact of nTMS on } \\
\text { the treatment } \\
\text { strategy, clinical } \\
\text { outcome, and } \\
\text { survival }\end{array}$ & 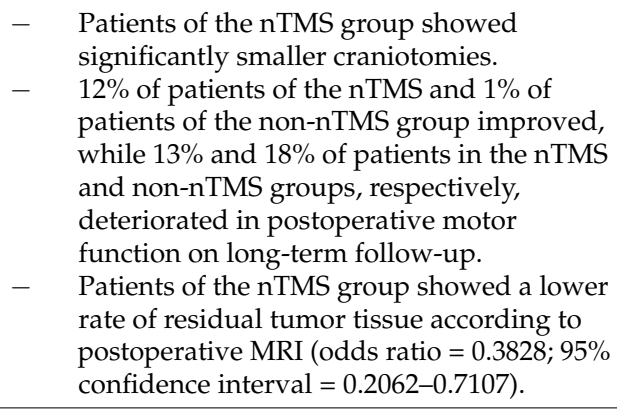 \\
\hline $\begin{array}{l}\text { Krieg et al. } \\
\text { [61] }\end{array}$ & 2015 & $\begin{array}{l}70 \text { adult } \\
\text { patients }\end{array}$ & $\begin{array}{l}70 \text { historical } \\
\text { controls } \\
\text { (matching } \\
\text { criteria: tumor } \\
\text { location, } \\
\text { preoperative } \\
\text { paresis, and } \\
\text { histology) }\end{array}$ & HGG & $\begin{array}{l}\text { Preoperative } \\
\text { motor mapping } \\
(110 \% \mathrm{rMT} \text { for } \mathrm{uE} \\
\text { and } 130 \% \text { for } \mathrm{lE} \\
\text { muscles) and } \\
\text { nTMS-based } \\
\text { tractography }\end{array}$ & $\begin{array}{ll}- & \text { Influence on } \\
\text { surgery } \\
-\quad & \text { Perioperative } \\
& \text { complications } \\
- & \text { Adjuvant } \\
\text { therapy } \\
-\quad \text { EOR/tumor } \\
\text { volume } \\
-\quad \text { Motor function } \\
\text { (BMRC) } \\
-\quad \text { KPS } \\
-\quad \text { PFS/overall } \\
\text { survival }\end{array}$ & $\begin{array}{l}\text { To assess the } \\
\text { impact of nTMS on } \\
\text { the treatment } \\
\text { strategy, } \\
\text { clinical outcome } \\
\text { including direct } \\
\text { perioperative } \\
\text { complications, } \\
\text { and survival }\end{array}$ & 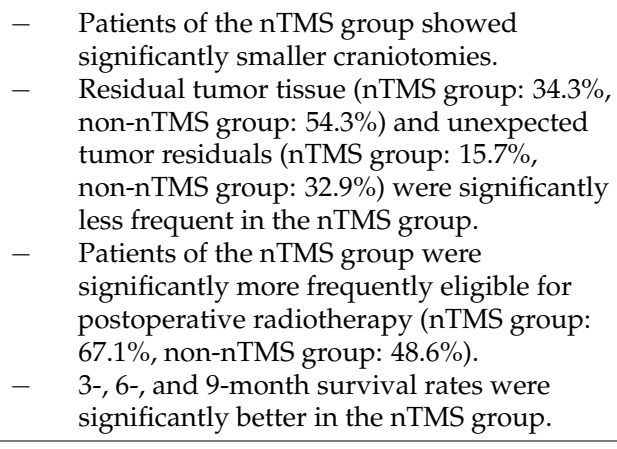 \\
\hline Picht et al. [62] & 2016 & $\begin{array}{l}93 \text { adult } \\
\text { patients }\end{array}$ & $\begin{array}{l}34 \text { controls } \\
\text { (with nTMS } \\
\text { mapping not } \\
\text { available) }\end{array}$ & $\begin{array}{l}\text { HGG (only } \\
\text { GBMs) }\end{array}$ & $\begin{array}{l}\text { Preoperative motor } \\
\text { mapping and } \\
\text { nTMS-based } \\
\text { tractography }\end{array}$ & $\begin{array}{ll}- & \begin{array}{l}\text { Influence on } \\
\text { surgery }\end{array} \\
- & \begin{array}{l}\text { Perioperative } \\
\text { complications }\end{array} \\
- & \text { EOR/tumor } \\
\text { volume } \\
-\quad \begin{array}{l}\text { Motor function } \\
\text { (BMRC) }\end{array}\end{array}$ & $\begin{array}{l}\text { To assess the } \\
\text { impact of nTMS on } \\
\text { the treatment } \\
\text { strategy and } \\
\text { clinical outcome } \\
\text { including direct } \\
\text { perioperative } \\
\text { complications (at } \\
\text { two campuses) }\end{array}$ & $\begin{array}{l}\text { - In } 10 \% \text { of patients of the nTMS group the } \\
\text { initial recommendation for biopsy or a } \\
\text { "wait and see" approach was changed to } \\
\text { resection because nTMS disproved the } \\
\text { suspected invasion of motor structures. } \\
\text { - Patients of the nTMS group showed a } \\
\text { significantly higher rate of GTR. } \\
\text { - A higher impact from nTMS was found in } \\
\text { patients with tumors located subcortically } \\
\text { when compared with tumors restricted to } \\
\text { the cortex. }\end{array}$ \\
\hline
\end{tabular}


Table 3. Cont

\begin{tabular}{|c|c|c|c|c|c|c|c|c|}
\hline Author & Year & Cohort & $\begin{array}{l}\text { Group for } \\
\text { Comparison }\end{array}$ & $\begin{array}{c}\text { Tumor } \\
\text { Entities }\end{array}$ & $\begin{array}{l}\text { nTMS } \\
\text { Method }\end{array}$ & Outcome Parameters & $\begin{array}{c}\text { Main } \\
\text { Objective }\end{array}$ & $\begin{array}{c}\text { Main } \\
\text { Findings }\end{array}$ \\
\hline $\begin{array}{l}\text { Hendrix et al. } \\
\text { [63] }\end{array}$ & 2016 & $\begin{array}{l}61 \text { adult } \\
\text { patients }\end{array}$ & - & $\begin{array}{l}\text { LGG, HGG, } \\
\text { MET, MEN, } \\
\text { Other }\end{array}$ & $\begin{array}{c}\text { Preoperative motor } \\
\text { mapping } \\
(110 \% \text { rMT })\end{array}$ & $\begin{array}{ll}- & \text { Influence on } \\
- & \text { surgery } \\
- & \text { EOR/tumor } \\
& \text { volume } \\
- & \text { Motor function } \\
& \text { (BMRC) }\end{array}$ & $\begin{array}{l}\text { To assess the } \\
\text { impact of nTMS on } \\
\text { the treatment } \\
\text { strategy and } \\
\text { clinical outcome }\end{array}$ & $\begin{array}{l}\text { Paresis resolved or improved in } 56.7 \% \text { of } \\
\text { patients one week after surgery, and } 89.5 \% \\
\text { of patients with postoperative paresis } \\
\text { improved during the follow-up interval. } \\
\text { - Only } 4.3 \% \text { of patients with a metastatic } \\
\text { lesion, but } 26.3 \% \text { of patients with a } \\
\text { non-metastatic lesion experienced } \\
\text { deterioration of motor function } \\
\text { after surgery. } \\
\text { All metastatic lesions were completely } \\
\text { resected compared with } 78.9 \% \text { of } \\
\text { non-metastatic lesions. }\end{array}$ \\
\hline $\begin{array}{c}\text { Krieg et al. } \\
\text { [64] }\end{array}$ & 2016 & $\begin{array}{l}120 \text { adult } \\
\text { patients }\end{array}$ & $\begin{array}{l}130 \text { historical } \\
\text { controls }\end{array}$ & MET & $\begin{array}{l}\text { Preoperative motor } \\
\text { mapping ( } 110 \% \text { rMT } \\
\text { for uE and } 130 \% \text { for } \\
\text { lE muscles) and } \\
\text { nTMS-based } \\
\text { tractography }\end{array}$ & $\begin{array}{ll}- & \text { Influence on } \\
- & \text { surgery } \\
- & \text { EOR/tumor } \\
& \text { volume } \\
- & \text { Motor function } \\
& (\text { BMRC) }\end{array}$ & $\begin{array}{l}\text { To assess the } \\
\text { impact of nTMS on } \\
\text { the treatment } \\
\text { strategy and } \\
\text { clinical outcome } \\
\text { (multi-centric with } \\
\text { three sites) }\end{array}$ & $\begin{array}{l}\text { - Patients of the nTMS group showed } \\
\text { significantly smaller craniotomies. } \\
\text { Patients of the nTMS group showed a lower } \\
\text { rate of residual tumor tissue after surgery } \\
\text { (odds ratio: } 0.3025,95 \% \text { confidence interval: } \\
\text { 0.1356- } 0.6749 \text { ). } \\
\text { Surgery-related paresis was significantly } \\
\text { less frequent in patients of the nTMS group } \\
\text { (nTMS group: improved: } 30.8 \% \text {, unchanged: } \\
\text { 65.8\%, worse: } 3.4 \% \text {, non-nTMS group: } \\
\text { improved: } 13.1 \% \text {, unchanged: } 73.8 \% \text {, worse: } \\
\text { 13.1\% of patients). }\end{array}$ \\
\hline $\begin{array}{l}\text { Moser et al. } \\
\text { [68] }\end{array}$ & 2017 & $\begin{array}{l}43 \text { adult } \\
\text { patients }\end{array}$ & - & LGG, HGG & $\begin{array}{l}\text { Preoperative } \\
\text { motor mapping } \\
\text { (110\% rMT for uE } \\
\text { and 130\% for } \\
\text { lE muscles) }\end{array}$ & $\begin{array}{ll}- & \text { Latency analyses } \\
- & \text { Motor function } \\
& \text { (BMRC) }\end{array}$ & $\begin{array}{c}\text { To assess the } \\
\text { impact of resection } \\
\text { of motor-positive } \\
\text { prerolandic nTMS } \\
\text { points on } \\
\text { clinical outcome }\end{array}$ & $\begin{array}{l}\text { - } 72 \% \text { of patients showed motor-positive } \\
\text { nTMS points in the prerolandic gyri and, } \\
\text { thus, outside of the anatomically suspected } \\
\text { extent of the primary motor cortex. } \\
\text { Out of the } 13 \text { patients who underwent } \\
\text { resection of motor-positive nTMS points, } \\
10 \text { patients showed postoperative paresis } \\
\text { (2 patients with transient and } 8 \text { patients } \\
\text { with permanent surgery-related paresis). } \\
\text { Motor-positive nTMS points within the } \\
\text { superior or middle frontal gyrus should be } \\
\text { considered carefully and can result in motor } \\
\text { deficits when affected during resection. }\end{array}$ \\
\hline
\end{tabular}


Table 3. Cont.

\begin{tabular}{|c|c|c|c|c|c|c|c|c|}
\hline Author & Year & Cohort & $\begin{array}{l}\text { Group for } \\
\text { Comparison }\end{array}$ & $\begin{array}{l}\text { Tumor } \\
\text { Entities }\end{array}$ & $\begin{array}{l}\text { nTMS } \\
\text { Method }\end{array}$ & Outcome Parameters & $\begin{array}{c}\text { Main } \\
\text { Objective }\end{array}$ & $\begin{array}{c}\text { Main } \\
\text { Findings }\end{array}$ \\
\hline Raffa et al. [60] & 2018 & $\begin{array}{l}70 \text { adult patients } \\
\text { (50\% also having } \\
\text { nTMS-based } \\
\text { fiber tracking) }\end{array}$ & $\begin{array}{l}35 \text { historical } \\
\text { controls }\end{array}$ & $\begin{array}{l}\text { LGG, HGG, } \\
\text { MET, Other }\end{array}$ & $\begin{array}{c}\text { Preoperative motor } \\
\text { mapping } \\
\text { (120\% rMT) and } \\
\text { nTMS-based } \\
\text { tractography }\end{array}$ & $\begin{array}{ll}- & \text { Influence on } \\
& \text { surgery } \\
- & \text { EOR/tumor } \\
& \text { volume } \\
- & \text { Motor function } \\
& \text { (BMRC) } \\
-\quad & \text { KPS }\end{array}$ & $\begin{array}{l}\text { To assess the } \\
\text { impact of nTMS } \\
\text { with or without } \\
\text { nTMS-based } \\
\text { tractography on } \\
\text { the treatment } \\
\text { strategy and } \\
\text { clinical outcome }\end{array}$ & 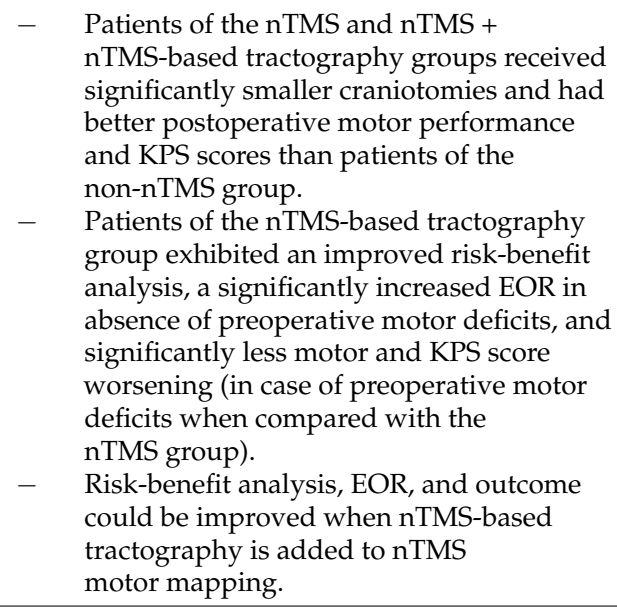 \\
\hline Raffa et al. [66] & 2019 & $\begin{array}{l}79 \text { adult } \\
\text { patients }\end{array}$ & $\begin{array}{l}55 \text { historical } \\
\text { controls }\end{array}$ & HGG & $\begin{array}{l}\text { Preoperative } \\
\text { motor mapping } \\
(120 \% \text { rMT }) \text { and } \\
\text { nTMS-based } \\
\text { tractography }\end{array}$ & $\begin{array}{ll}- & \text { EOR/tumor } \\
& \text { volume } \\
- & \text { Motor function } \\
& \text { (BMRC) }\end{array}$ & $\begin{array}{l}\text { To assess the } \\
\text { impact of nTMS } \\
\text { and nTMS-based } \\
\text { tractography with } \\
\text { sodium-fluorescein } \\
\text { guidance on } \\
\text { the treatment } \\
\text { strategy and } \\
\text { clinical outcome }\end{array}$ & $\begin{array}{l}\text { - In patients operated on considering nTMS + } \\
\text { FGR, the GTR rate was significantly higher } \\
\text { compared with controls (64.5\% vs. } 47.2 \%) \text {. } \\
\text { - } \quad \text { Surgery-related permanent motor deficits } \\
\text { were reduced in the nTMS + FGR group } \\
\text { compared with controls ( }(11.4 \% \text { vs. } 20 \%) .\end{array}$ \\
\hline Raffa et al. [67] & 2019 & $\begin{array}{l}41 \text { adult } \\
\text { patients }\end{array}$ & $\begin{array}{l}41 \text { historical } \\
\text { controls }\end{array}$ & HGG & $\begin{array}{c}\text { Preoperative motor } \\
\text { mapping } \\
(120 \% \text { rMT) and } \\
\text { nTMS-based } \\
\text { tractography }\end{array}$ & $\begin{array}{ll}- & \text { Influence on } \\
\text { surgery } \\
-\quad \text { EOR/tumor } \\
\text { volume } \\
-\quad \text { Motor function } \\
\text { (BMRC) } \\
-\quad \text { KPS }\end{array}$ & $\begin{array}{l}\text { To assess the } \\
\text { impact of nTMS } \\
\text { and nTMS-based } \\
\text { tractography with } \\
\text { sodium- } \\
\text { fluorescein } \\
\text { guidance on } \\
\text { the treatment } \\
\text { strategy and } \\
\text { clinical outcome }\end{array}$ & $\begin{array}{l}\text { - Use of nTMS motor mapping and } \\
\text { nTMS-based tractography reliably } \\
\text { identified the spatial tumor-to-function } \\
\text { relationship with an accuracy of } 92.7 \% \text {. } \\
\text { Patients of the nTMS group showed an } \\
\text { increased EOR and higher rate of GTR } \\
\text { (73.2\% vs. } 51.2 \%) \text {. } \\
\text { The number of cases with new } \\
\text { surgery-related permanent motor deficits } \\
\text { was lower in the nTMS group compared } \\
\text { with controls ( } 9.8 \% \text { vs. } 29.3 \%) \text {. } \\
\text { The number of cases with KPS worsening } \\
\text { was lower in the nTMS group compared } \\
\text { with controls (12.2\% vs. 31.7\%). }\end{array}$ \\
\hline
\end{tabular}


Table 3. Cont

\begin{tabular}{|c|c|c|c|c|c|c|c|c|}
\hline Author & Year & Cohort & $\begin{array}{l}\text { Group for } \\
\text { Comparison }\end{array}$ & $\begin{array}{c}\text { Tumor } \\
\text { Entities }\end{array}$ & $\begin{array}{l}\text { nTMS } \\
\text { Method }\end{array}$ & Outcome Parameters & $\begin{array}{c}\text { Main } \\
\text { Objective }\end{array}$ & $\begin{array}{c}\text { Main } \\
\text { Findings }\end{array}$ \\
\hline Raffa et al. [65] & 2019 & $\begin{array}{l}47 \text { adult } \\
\text { patients }\end{array}$ & - & MEN & $\begin{array}{l}\text { Preoperative } \\
\text { motor mapping and } \\
\text { nTMS-based } \\
\text { tractography }\end{array}$ & 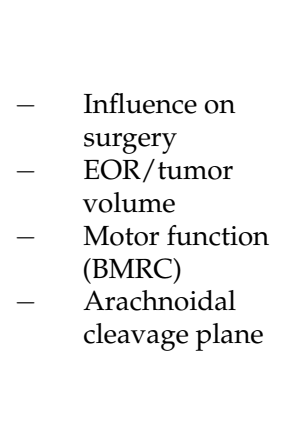 & $\begin{array}{l}\text { To analyze the role } \\
\text { of nTMS motor } \\
\text { mapping for } \\
\text { planning resection } \\
\text { of rolandic } \\
\text { meningiomas and } \\
\text { predicting } \\
\text { arachnoidal } \\
\text { cleavage plane. }\end{array}$ & $\begin{array}{l}\text { - Use of nTMS motor mapping and } \\
\text { nTMS-based tractography was considered } \\
\text { useful in } 89.3 \% \text { of patients and changed the } \\
\text { surgical strategy in } 42.5 \% \text { of patients. } \\
\text { A new permanent motor deficit occurred in } \\
\text { 8.5\% patients. } \\
\text { A higher rMT and the lack of an } \\
\text { intraoperative arachnoidal cleavage plane } \\
\text { were independent predictors of poor motor } \\
\text { function outcome. } \\
\text { A higher rMT and perilesional edema } \\
\text { predicted the lack of an arachnoidal } \\
\text { cleavage plane. }\end{array}$ \\
\hline
\end{tabular}

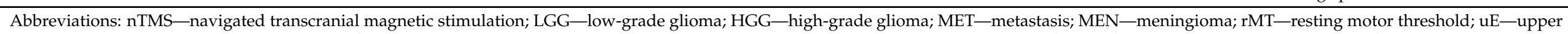

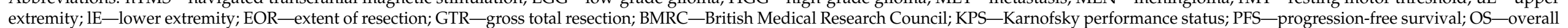
survival; FGR—-fluorescein-guided resection; GBM—glioblastoma multiforme. 


\subsection{Risk Stratification and Prediction}

Besides the role for preoperative planning and intraoperative resection guidance, nTMS motor mapping and tractography could also be efficiently used for risk stratification and prediction of the motor status in patients with brain neoplasms. This has already been acknowledged by a growing body of studies, which are summarized in Table 4 .

An early study characterized the neurophysiological status as derived from nTMS motor mapping in 100 patients, and already suggested that interhemispheric differences for MEP latencies may be considered as potential warning signs for the motor system at risk as comparatively similar latencies are commonly observed between the two hemispheres [69]. On a similar note, a high interhemispheric rMT ratio (i.e., the ratio between the two hemispheres regarding the rMT, which is commonly higher in a tumor-affected hemisphere) could suggest immanent deterioration of the functional motor status [69]. Furthermore, two studies in patients with various tumor entities investigated the role of nTMS-based tractography of the CST for risk stratification, evaluating the cut-off value for the lesion-to-CST distance that amounted to $8 \mathrm{~mm}$ and $12 \mathrm{~mm}$ to avoid new surgery-related permanent motor deficits, respectively $[70,71]$. Hence, patients that showed a lesion-to-CST distance above this cut-off value based on preoperative nTMS-based tractography were unlikely to suffer from surgery-related postoperative permanent paresis [70,71]. Moreover, statistically significant negative correlations were observed between the rMT value and lesion-to-CST distances in patients with a new surgery-related paresis, emphasizing the interplay between the SI used during motor mapping and results of nTMS-based tractography [71]. Correspondingly, motor function did not improve in cases with the rMT being significantly higher in the tumor-affected hemisphere than in the contralateral hemisphere, as expressed by an interhemispheric rMT ratio of $>110 \%$ [70]. In a study investigating patients harboring HGG, lower FA values within the tumor-affected CST and higher average apparent diffusion coefficient (ADC) values were significantly correlated to worsened postoperative motor function, thus further exploring the contribution of dMRI-derived metrics to risk modelling [72].

In an innovative approach investigating postoperative nTMS motor mapping-instead of standardly used presurgical mapping-compared with intraoperative neuromonitoring (IONM) for predicting recovery of motor function, it was revealed that IONM and postoperative nTMS motor mapping were equally predictive for long-term motor recovery [73]. Specifically, when postoperative motor mapping was able to elicit MEPs, motor strength recovered to a score of at least $4 / 5$ on the British Medical Research Council (BMRC) scale within one month after surgery, whereas when postoperative nTMS motor mapping did not elicit MEPs, the patient did not recover [73]. Furthermore, when implementing presurgical nTMS motor mapping and tractography in multi-modal neuroimaging with multi-sequence MRI and dedicated positron emission tomography (PET) protocols, it has been demonstrated that PET may be superior to contrast-enhanced T1-weighted MRI for proposing a motor deficit prior to surgery, and that the highest association with clinical impairment was revealed for the T2-weighted lesion overlap with functional brain tissue (i.e., the spatial overlap between the lesion volume on T2-weighted images of MRI and the functional primary motor cortex and/or CST volumes as derived from nTMS motor mapping and nTMS-based tractography) [74]. Future research may further explore the role of nTMS in multi-modal environments, given that data from various methods are frequently available for clinical needs prior to surgery. Opportunistic use of data from adjunct modalities (e.g., PET) as well as performance of dedicated longitudinal motor mapping (e.g., during the immediate postoperative course and during long-term follow-up examinations) could pave the way for a more efficient use of nTMS motor mapping and related tractography. 


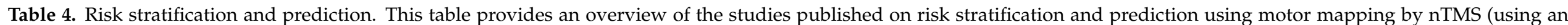
electric-field-navigated system) with or without additional nTMS-based tractography in patients harboring brain neoplasms.

\begin{tabular}{|c|c|c|c|c|c|c|c|}
\hline Author & Year & Cohort & $\begin{array}{l}\text { Tumor } \\
\text { Entities }\end{array}$ & $\begin{array}{l}\text { nTMS } \\
\text { Method }\end{array}$ & Tractography Specifics & $\begin{array}{c}\text { Main } \\
\text { Objective }\end{array}$ & $\begin{array}{l}\text { Main } \\
\text { Findings }\end{array}$ \\
\hline Picht et al. [69] & 2012 & $\begin{array}{l}100 \text { adult } \\
\text { patients }\end{array}$ & $\begin{array}{l}\text { LGG, HGG, } \\
\text { MET, MEN, } \\
\text { Other }\end{array}$ & $\begin{array}{l}\text { Preoperative } \\
\text { motor mapping } \\
(110 \% \mathrm{rMT})\end{array}$ & - & $\begin{array}{l}\text { To provide reference } \\
\text { values for parameters of } \\
\text { the functional status } \\
\text { and neurophysiological } \\
\text { measurements }\end{array}$ & $\begin{array}{l}\text { - The MEP latency was almost never different in the } \\
\text { tumor-affected hemisphere compared with the healthy } \\
\text { hemispheres; thus, interhemispheric differences for MEP } \\
\text { latencies may reflect a warning sign for functional } \\
\text { decline. } \\
\text { A high interhemispheric rMT ratio or a low } \\
\text { interhemispheric MEP amplitude ratio may suggest } \\
\text { immanent deterioration of the motor status. }\end{array}$ \\
\hline $\begin{array}{c}\text { Rosenstock et al. } \\
{[70]}\end{array}$ & 2017 & $\begin{array}{l}113 \text { adult } \\
\text { patients }\end{array}$ & LGG, HGG & $\begin{array}{c}\text { Preoperative } \\
\text { motor mapping } \\
\text { (105\% rMT for uE and } \\
\sim 130 \% \text { for lE muscles) } \\
\text { and nTMS-based } \\
\text { tractography }\end{array}$ & $\begin{array}{l}\text { Two ROIs: } \\
\text { motor-positive } \\
\text { nTMS points and } \\
\text { ipsilateral } \\
\text { brainstem } \\
\text { Deterministic } \\
\text { tracking: } \\
\text { FA }=75 \% \\
\text { FAT, FL }=110 \mathrm{~mm}, \\
\text { angular threshold } \\
\text { of } 30^{\circ}\end{array}$ & $\begin{array}{l}\text { To establish risk } \\
\text { stratification by } \\
\text { examining whether the } \\
\text { results of nTMS motor } \\
\text { mapping and its } \\
\text { neurophysiological data } \\
\text { predict postoperative } \\
\text { motor function outcome }\end{array}$ & $\begin{array}{l}\text { - No new surgery-related permanent motor deficit was } \\
\text { observed when the lesion-to-CST distance was }>8 \mathrm{~mm} \\
\text { and the precentral gyrus was not infiltrated by the tumor } \\
\text { mass. } \\
\text { - New postoperative motor deficits were associated with a } \\
\text { pathological excitability of the motor cortices (as } \\
\text { indicated by an interhemispheric rMT ratio of }<90 \% \text { or } \\
>110 \% \text { ). } \\
\text { Motor function did not improve in any patient when the } \\
\text { rMT was significantly higher in the tumor-affected } \\
\text { hemisphere than in the healthy hemisphere (related to an } \\
\text { interhemispheric rMT ratio of }>110 \% \text { ). }\end{array}$ \\
\hline
\end{tabular}


Table 4. Cont.

\begin{tabular}{|c|c|c|c|c|c|c|c|}
\hline Author & Year & Cohort & $\begin{array}{l}\text { Tumor } \\
\text { Entities }\end{array}$ & $\begin{array}{l}\text { nTMS } \\
\text { Method }\end{array}$ & Tractography Specifics & $\begin{array}{c}\text { Main } \\
\text { Objective }\end{array}$ & $\begin{array}{c}\text { Main } \\
\text { Findings }\end{array}$ \\
\hline $\begin{array}{c}\text { Rosenstock et al. } \\
\text { [72] }\end{array}$ & 2017 & $\begin{array}{l}30 \text { adult } \\
\text { patients }\end{array}$ & HGG & $\begin{array}{l}\text { Preoperative } \\
\text { motor mapping } \\
(105 \% \text { rMT for uE and } \\
130-150 \% \text { for } 1 \mathrm{E} \\
\text { muscles) and } \\
\text { nTMS-based } \\
\text { tractography }\end{array}$ & 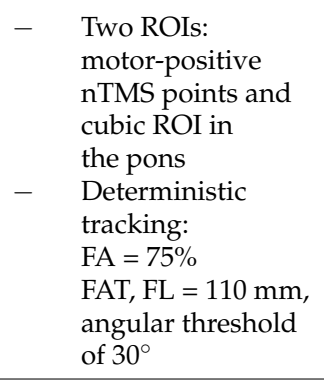 & $\begin{array}{l}\text { To analyze FA and ADC } \\
\text { within the CST in } \\
\text { different locations and } \\
\text { their usefulness for } \\
\text { predicting motor } \\
\text { function outcome }\end{array}$ & $\begin{array}{l}\text { - Lower FA within the tumor-affected CST as well as } \\
\text { higher average ADC values were significantly correlated } \\
\text { to worsened postoperative motor function. } \\
\text { - Segmental analyses within the CST indicated that the } \\
\text { extent of impairment of diffusion metrics correlates with } \\
\text { motor function deficits. }\end{array}$ \\
\hline $\begin{array}{l}\text { Sollmann et al. } \\
\text { [71] }\end{array}$ & 2018 & $\begin{array}{l}86 \text { adult } \\
\text { patients }\end{array}$ & $\begin{array}{l}\text { LGG, HGG, } \\
\text { MET }\end{array}$ & $\begin{array}{l}\text { Preoperative } \\
\text { motor mapping } \\
(110 \% \text { rMT for uE and } \\
130 \% \text { for lE muscles }) \\
\text { and nTMS-based } \\
\text { tractography }\end{array}$ & $\begin{array}{l}\text { Two ROIs: } \\
\text { motor-positive } \\
\text { nTMS points and } \\
\text { ipsilateral } \\
\text { brainstem } \\
\text { Deterministic } \\
\text { tracking: } \\
\text { FA }=50 \% \\
\text { FAT } / 75 \% \\
\text { FAT } / 100 \% \\
\text { FAT, } \mathrm{FL}=110 \mathrm{~mm}, \\
\text { angular threshold } \\
\text { of } 30^{\circ}\end{array}$ & $\begin{array}{l}\text { To explore whether } \\
\text { nTMS-based } \\
\text { tractography can be } \\
\text { used for individual } \\
\text { preoperative risk } \\
\text { evaluation for } \\
\text { surgery-related } \\
\text { motor impairment }\end{array}$ & $\begin{array}{l}\text { - For tractography with certain FATs, a significant } \\
\text { difference in lesion-to-CST distances was observed } \\
\text { between patients with HGGs who had no impairment } \\
\text { and those who developed surgery-related transient or } \\
\text { permanent motor function deficits. } \\
\text { As a cut-off value, no patient with a lesion-to-CST } \\
\text { distance } \geq 12 \text { mm showed a new surgery-related } \\
\text { permanent paresis. } \\
\text { Significant negative associations were observed between } \\
\text { the rMT and lesion-to-CST distances of patients with } \\
\text { surgery-related transient paresis or surgery-related } \\
\text { permanent paresis. }\end{array}$ \\
\hline Seidel et al. [73] & 2019 & $\begin{array}{l}13 \text { adult } \\
\text { patients }\end{array}$ & $\begin{array}{l}\text { LGG, HGG, } \\
\text { MET }\end{array}$ & $\begin{array}{l}\text { Postoperative motor } \\
\text { mapping (within } 14 \\
\text { days after surgery; } \\
\text { "MEP loss" if not } \\
5 / 10 \text { stimulations could } \\
\text { be elicited with } 70-100 \% \\
\text { of the MSO) }\end{array}$ & - & $\begin{array}{l}\text { To investigate the value } \\
\text { of postoperative nTMS } \\
\text { motor mapping } \\
\text { compared with } \\
\text { intraoperative MEP } \\
\text { monitoring for } \\
\text { predicting recovery of } \\
\text { motor function }\end{array}$ & $\begin{array}{l}\text { - Motor strength recovered to a score of at least } 4 / 5 \text { of the } \\
\text { BMRC scale within one month after surgery if } \\
\text { postoperative motor mapping elicited MEPs } \\
\text { (PPV = 90.9\%). } \\
\text { When postoperative nTMS motor mapping did not elicit } \\
\text { MEPs, the patient was unlikely to recover in terms of } \\
\text { motor function. } \\
\text { - Intraoperative MEP monitoring and postoperative nTMS } \\
\text { motor mapping were equally predictive for long-term } \\
\text { motor recovery. } \\
\text { - 2/3 of patients with intraoperative MEP alterations or } \\
\text { signal loss but positive postoperative nTMS motor } \\
\text { mapping demonstrated motor function recovery. }\end{array}$ \\
\hline
\end{tabular}

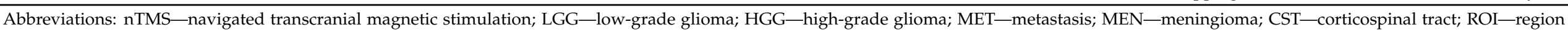

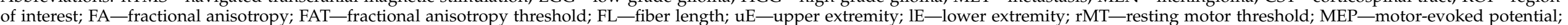

PET-positron emission tomography; MSO-maximum stimulator output. 


\subsection{Plasticity and Reallocation of Motor Function}

Repeated application of nTMS motor mapping and tractography has potential to provide insights into brain plasticity that is likely to occur to a certain degree due to the presence and growth of a brain tumor. Few studies have already tried to investigate the role of nTMS motor mapping in this regard, and these studies are outlined in Table 5.

The non-invasive character of nTMS makes possible the acquisition of data from multiple time points, ideally spanning from the preoperative to the postoperative and follow-up interval. Correspondingly, an early explorative study in five patients and five controls used preoperative motor mapping by nTMS as well as mapping during follow-up examinations, revealing a shift of CoGs over a mean interval of 18 months of $6.8 \pm 3.4 \mathrm{~mm}$ and a shift of motor hotspots of $8.7 \pm 5.1 \mathrm{~mm}$ for the dominant hemispheres [75]. In a case report on a patient with a LGG that was situated within the frontal lobe and affected the suspected primary motor cortex, motor representation shifted from the precentral to the postcentral gyrus over an interval of 18 months according to serial nTMS motor mappings, which was confirmed by DES mapping during re-resection [76].

In general, a connection between the distinct location of the motor map as enclosed by nTMS as well as its extent and tumor location has been demonstrated in the sense of tumor location-dependent changes in the distribution of polysynaptic MEP latencies and spread of motor maps, especially along the anterior-posterior direction [77]. In the further course, it was revealed that in a majority of patients with mixed tumor entities, MEP counts, when elicited by nTMS to the precentral gyrus, were higher than average, potentially reflecting robust and less variable motor representations within the primary motor cortex [78]. Additionally, patients with tumors affecting the postcentral gyrus and other parietal areas primarily showed high MEP counts when stimulation by nTMS was delivered to the postcentral gyrus [78]. Hence, functional reorganization patterns seem to be reflected by a reorganization within anatomical constraints, such as of the postcentral gyrus [78]. Using again serial nTMS motor mappings from presurgical and follow-up sessions, the initial observation of CoG or motor hotspot shifts have been confirmed in further series including 22 and 20 patients with different tumor entities, respectively [79,80]. Additionally, motor representations appeared to shift more clearly toward the tumor mass if the lesion was anterior to the rolandic region than if it was located posterior to the rolandic region, and a preferential regrowth pattern of tumor recurrence towards the primary motor cortex and/or CST as defined by nTMS-based motor mapping and tractography has been suggested by exploratory approaches $[80,81]$. 


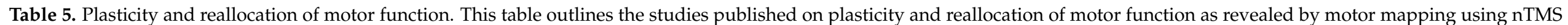
(using an electric-field-navigated system) with or without additional nTMS-based tractography in patients harboring brain neoplasms.

\begin{tabular}{|c|c|c|c|c|c|c|}
\hline Author & Year & Cohort & $\begin{array}{c}\text { Tumor } \\
\text { Entities }\end{array}$ & $\begin{array}{l}\text { nTMS } \\
\text { Method }\end{array}$ & $\begin{array}{c}\text { Main } \\
\text { Objective }\end{array}$ & $\begin{array}{c}\text { Main } \\
\text { Findings }\end{array}$ \\
\hline Forster et al. [75] & 2012 & $\begin{array}{l}5 \text { adult patients } \\
\text { (and } 5 \text { healthy } \\
\text { volunteers) }\end{array}$ & LGG, HGG & $\begin{array}{c}\text { Preoperative and } \\
\text { follow-up } \\
\text { motor mapping } \\
\text { (110\% rMT for uE and } \mathrm{lE} \\
\text { muscles; interval } \\
\text { between mappings: } \\
18 \text { months on average) } \\
\text { (two motor mappings in } \\
\text { healthy volunteers) }\end{array}$ & $\begin{array}{l}\text { To investigate cortical } \\
\text { motor representation } \\
\text { after resection of } \\
\text { perirolandic WHO grade } \\
\text { II and III gliomas }\end{array}$ & $\begin{array}{l}\text { - Shift of CoGs over time was } 0.7 \pm 0.3 \mathrm{~cm} \text { in the } \\
\text { dominant and } 0.8 \pm 0.4 \mathrm{~cm} \text { in the } \\
\text { non-dominant hemisphere. } \\
-\quad \text { Shift of motor hotspots amounted to } \\
0.9 \pm 0.5 \mathrm{~cm} \text { for the dominant and } 0.8 \pm 0.5 \mathrm{~cm} \\
\text { in the non-dominant hemisphere. } \\
-\quad \text { In one patient CoG and motor hotspot shifts } \\
\text { significantly differed from the control group of } \\
\text { healthy volunteers. }\end{array}$ \\
\hline $\begin{array}{c}\text { Takahashi et al. } \\
\text { [76] }\end{array}$ & 2013 & 20-year-old man & LGG & $\begin{array}{l}\text { Preoperative and } \\
\text { follow-up } \\
\text { motor mapping } \\
\text { (110\% for uE muscles; } \\
\text { interval between } \\
\text { mappings: } 18 \text { months) }\end{array}$ & $\begin{array}{l}\text { To confirm induced } \\
\text { brain plasticity by nTMS } \\
\text { motor mapping }\end{array}$ & $\begin{array}{l}\text { - Primary motor representation as determined } \\
\text { by nTMS motor mapping shifted from the } \\
\text { precentral to the postcentral gyrus over time, } \\
\text { which was confirmed by DES mapping. } \\
\text { - Plastic changes in primary motor } \\
\text { representations permitted complete tumor } \\
\text { removal without neurological decline. }\end{array}$ \\
\hline
\end{tabular}


Table 5. Cont.

\begin{tabular}{|c|c|c|c|c|c|c|}
\hline Author & Year & Cohort & $\begin{array}{c}\text { Tumor } \\
\text { Entities }\end{array}$ & $\begin{array}{l}\text { nTMS } \\
\text { Method }\end{array}$ & $\begin{array}{c}\text { Main } \\
\text { Objective }\end{array}$ & $\begin{array}{l}\text { Main } \\
\text { Findings }\end{array}$ \\
\hline $\begin{array}{c}\text { Conway et al. } \\
\text { [80] }\end{array}$ & 2017 & 22 adult patients & LGG, HGG & $\begin{array}{l}\text { Preoperative and } \\
\text { follow-up motor } \\
\text { mapping (110\% rMT for } \\
\mathrm{uE} \text { and } \geq 130 \% \text { for } 1 \mathrm{E} \\
\text { muscles; interval } \\
\text { between mappings: } \\
3-42 \text { months) }\end{array}$ & $\begin{array}{l}\text { To demonstrate the } \\
\text { frequency of plastic } \\
\text { reshaping and reveal } \\
\text { clues to the patterns } \\
\text { of reorganization }\end{array}$ & 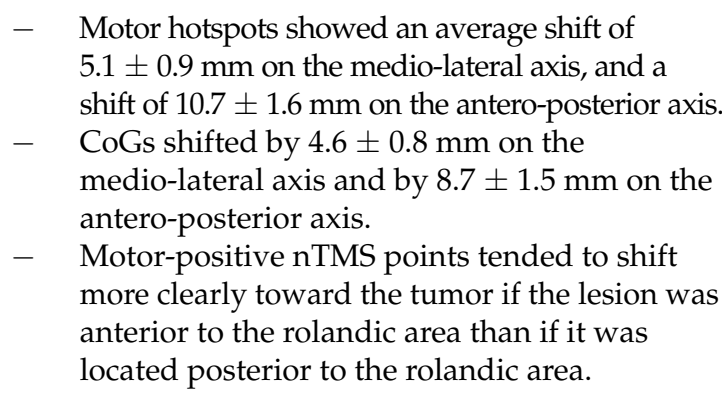 \\
\hline $\begin{array}{c}\text { Bulubas et al. } \\
\text { [78] }\end{array}$ & 2018 & 100 adult patients & $\begin{array}{l}\text { LGG, HGG, MET, } \\
\text { Other }\end{array}$ & $\begin{array}{l}\text { Preoperative motor } \\
\text { mapping } \\
\text { (110\% rMT for uE and } \\
130 \% \text { for } \mathrm{lE} \text { muscles) }\end{array}$ & $\begin{array}{l}\text { To investigate the spatial } \\
\text { distributions of motor } \\
\text { sites to reveal } \\
\text { tumor-induced brain } \\
\text { plasticity in patients } \\
\text { with brain tumors }\end{array}$ & 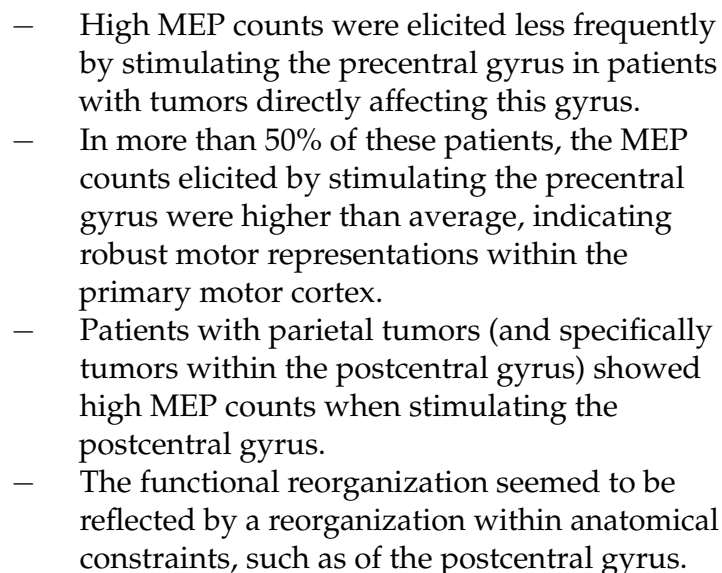 \\
\hline
\end{tabular}


Table 5. Cont.

\begin{tabular}{|c|c|c|c|c|c|c|}
\hline Author & Year & Cohort & $\begin{array}{l}\text { Tumor } \\
\text { Entities }\end{array}$ & $\begin{array}{l}\text { nTMS } \\
\text { Method }\end{array}$ & $\begin{array}{c}\text { Main } \\
\text { Objective }\end{array}$ & $\begin{array}{l}\text { Main } \\
\text { Findings }\end{array}$ \\
\hline Barz et al. [79] & 2018 & $\begin{array}{l}20 \text { adolescent } \\
\text { to adult } \\
\text { patients (and } \\
12 \text { healthy } \\
\text { volunteers) }\end{array}$ & LGG, HGG, Other & $\begin{array}{c}\text { Preoperative and } \\
\text { follow-up } \\
\text { motor mapping } \\
(110 \% \text { rMT for uE and } \mathrm{lE} \\
\text { muscles; interval } \\
\text { between mappings: } \\
26.1 \pm 24.8 \text { months and } \\
46.3 \pm 25.4 \text { months) } \\
\text { (two motor mappings in } \\
\text { healthy volunteers) }\end{array}$ & $\begin{array}{l}\text { To evaluate motor cortex } \\
\text { reorganization in } \\
\text { patients after } \\
\text { perirolandic } \\
\text { glioma surgery }\end{array}$ & $\begin{array}{l}\text { - Pre- and postoperatively pooled CoGs from the } \\
\text { areas of the dominant APB muscle and } \\
\text { non-dominant lE representation area differed } \\
\text { significantly from those of healthy individuals. } \\
\text { - During the follow-up period, reorganization of } \\
\text { all muscle representation areas occurred in } \\
3 \text { patients, and significant shifts of uE muscle } \\
\text { representations were detected in another } \\
3 \text { patients. }\end{array}$ \\
\hline $\begin{array}{l}\text { Sollmann et al. } \\
\text { [81] }\end{array}$ & 2018 & 60 adult patients & HGG & $\begin{array}{l}\text { Preoperative motor } \\
\text { mapping (110\% rMT for } \\
\mathrm{uE} \text { and } \geq 130 \% \text { for } \mathrm{lE} \\
\text { muscles) and } \\
\text { nTMS-based } \\
\text { tractography } \\
\text { (and fMRI for a } \\
\text { subsample of the cohort) }\end{array}$ & $\begin{array}{l}\text { To evaluate whether } \\
\text { brain tumor relapse has } \\
\text { a preference to grow } \\
\text { towards motor-eloquent } \\
\text { brain structures }\end{array}$ & $\begin{array}{l}\text { - } 69.0 \% \text { of patients without residual tumor, } \\
64.3 \% \text { with residual tumor away from motor } \\
\text { areas, and } 66.7 \% \text { with residual tumor facing } \\
\text { motor areas showed tumor recurrence that was } \\
\text { directed towards motor eloquence. } \\
\text { Average growth towards was highest for } \\
\text { patients with residual tumor already facing } \\
\text { motor areas, suggesting a preference in growth } \\
\text { patterns towards (reshaping) motor areas. }\end{array}$ \\
\hline
\end{tabular}

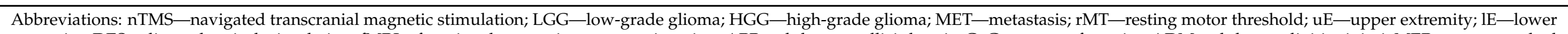

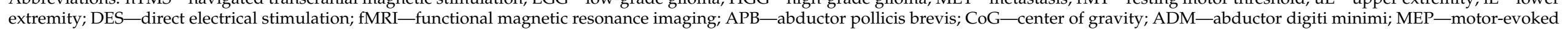
potential; WHO-World Health Organization. 


\subsection{Integration into the Clinical Environment}

For broad application of nTMS motor mapping and derived nTMS-based tractography in neuro-surgical oncology, seamless integration into existing hospital infrastructure and processes is key for acceptance and optimal use of generated data. In this regard, a structured workflow has already been proposed [82]. It starts with admission of the patient and when the indication for mapping is made and includes, amongst other steps, transfer of nTMS data to a hospital-intern picture archiving and communication system (PACS) as well as reporting within dedicated masks for the hospital-intern electronic patient charts [82].

An example of inter-disciplinary integration into different systems requiring nTMS data transfer is represented by the versatile use of the motor maps for planning and treatment purposes in radiosurgery and radiotherapy [83-87]. The first published approach achieved easy and reliable integration of nTMS, fMRI, and tractography data for radiosurgery treatment planning, which led to an average radiation dose reduction of $17 \%$ to functional brain areas in a cohort with mixed entities of pathologies [83]. Another study approved flawless integration of specifically nTMS data for radiosurgery, which influenced the radiosurgical planning procedure by improving risk-benefit balancing in all cases, achieved dose plan modifications in $81.9 \%$, facilitated treatment indication in $63.7 \%$, and reduced radiation doses in $72.7 \%$ of cases [86]. Compared with radiosurgery plans without nTMS data, treatment plans with integration of nTMS data demonstrated a significant decrease in dose to eloquent cortex volume, which was achievable without a reduction of the dose applied to intracranial MET [87]. Moreover, integration of nTMS motor maps with radiotherapy planning software for hypofractioned stereotactic treatment regimens for patients diagnosed with intracranial MET has been proposed, and by constraining the dose applied to the nTMS motor maps outside the planning target volume (PTV) to 15 Gy, the mean dose was significantly reduced from 23.0 Gy to $18.9 \mathrm{~Gy}$, while the mean dose of the PTV increased [85]. Analogously, in patients with HGG, mean dose to the nTMS motor maps was significantly reduced by $14.3 \%$ when constraining the dose to nTMS motor areas, while the dose to the PTV was not compromised [84].

Furthermore, integrating nTMS motor mapping in clinical workflows has provided initial evidence for the usefulness of the method for planning of a stereotactic tumor biopsy, performing endoscopic cystoventriculostomy, or facilitating a transparietal approach to the trigone of the lateral ventricle in patients with brain neoplasms [88-90]. In a special environment such as the intensive care unit with critically ill patients, an approach for safe and reliable use of nTMS motor mapping has been described recently, yet preliminarily in patients suffering from other diseases than brain tumors (e.g., central cord syndrome after trauma, ischemic or hemorrhagic stroke) [91]. In particular, the use of computed tomography (CT) instead of MRI data may help to establish nTMS motor mapping also in special environments with patients who may only be eligible to undergo CT due to specific infrastructural constraints (e.g., non-availability of timely imaging by MRI) or medical conditions (e.g., specific implanted devices as contraindications for MRI) [91,92]. While this underlines the broad applicability of nTMS motor mapping, which requires little patient interaction while creating valuable data on the motor system in a non-invasive way, high accuracy has to be ensured and other imaging sources than MRI have to be regarded as second-line alternatives in selected cases.

\section{Methodological Considerations on Application of nTMS Motor Mapping}

\subsection{Current Practices and Protocols}

Previous large-scale studies have converged to feasible routines for nTMS motor mapping in clinical practice [93]. As an example, the usual SI is normalized to the rMT, and $110 \%$ rMT has become the standard, though also $105 \%$ rMT is often used. Alternative methods, such as using Mills-Nithi upper threshold (UT), exist as well [93].

There is large variance in the motor mapping protocols since the studies intend to answer specific research questions. On a similar note, the terminology used is not always clear and uniform. New methods and analysis tools have emerged. In addition to formerly 
used metrics, new and parallel map measures (e.g., area and volume in defining the extent of motor maps) are increasingly used and reported, which brings variance to the studies and makes them more difficult to compare with each other. For instance, motor map topography based on counting the number of discrete peaks, which in turn was based on MEP amplitudes, was introduced in 2017 [94]. Another measure that seems to be interesting and reliable and may also have clinical relevance is the overlap of the motor representation of muscles, though its potential meaning is not yet fully understood [95-97].

When it comes to quantitative mapping, a lot of research on quantitative parameters derived from nTMS motor mapping is ongoing. Despite many motor mapping results in patients (such as greater or smaller area of motor maps, closeness of CoGs, or location and shift of CoGs) have already been published, there is clear need of comparison data on healthy volunteers as a basis against which to evaluate cortical reorganization in clinical populations [98,99]. In addition, the normativity of hemispheric side-to-side differences needs to be ensured before comparison between potentially affected and non-affected hemispheres takes place. Fine-scale topography seems to be complex and variable between subjects. To understand it better, multi-modal approaches would be important to better track and understand nTMS-induced effects across the brain [100,101]. Furthermore, instead of mapping single muscles, the importance of groups of muscles, their synergy, and the role of movements and their relation to posture and biomechanics have been pointed out [102].

It should not be forgotten that the steps during initial mapping to locate a motor hotspot, sometimes called coarse mapping or technical mapping, are an important part of the examination to define the precise and correct hotspot. Regarding motor areas of $1 E$ muscle representations, a double-cone coil is recommended to reach deeper [103]. Different coil types hinder direct comparison between studies. The coil orientation may also have impact, which partly depends on the area of interest $(\mathrm{uE}, \mathrm{lE}$, or face muscle representations) [104-106]. The need for preactivation of muscles is a special issue that needs to be taken into account, particularly for $\mathrm{lE}$ and face muscle representations [106]. Another important issue is that when mapping the extent of several muscle representations within a limb, the rMT is usually only determined for one specific small hand muscle (abductor pollicis brevis (APB) or first dorsal interosseous (FDI) muscle), and this is used as a reference for motor mapping of representations of other muscles as well. This could perhaps be tackled by targeted post-hoc analysis [95]. For the 1E, there is much more variance when choosing the muscle of primary interest, which should preferably also have the lowest rMT. The clinical importance is, however, mostly unknown.

In the analysis of motor mapping data, large variability in MEP amplitudes is a challenge. Another challenge is that the amplitudes are often small. The usual response criterion for an accepted MEP in rest is often $50 \mu \mathrm{V}$ [26], but lower amplitude criteria have been successfully applied [107]. Some of the measures need to be normalized to the maximum recorded MEP amplitude. Mapping-related biomarkers of sensorimotor plasticity could be used in the study of pathophysiology of different diseases and an important application is rehabilitation. Based on these reflections on the current status and routine procedures for nTMS motor mapping, in the following we outline the most important quantitative parameters and methods for ensuring feasible accuracy of nTMS motor mapping.

\subsection{Selecting Stimulation Intensity}

The proper SI used in quantitative mapping is conventionally and fundamentally dependent on the rMT, which can be determined in several ways [47,108-112]. These days, the most convenient and most widespread method is adaptive threshold hunting (ATH), which estimates the threshold SI in an iterative fashion with excellent confidence [109,110,113-115].

Selection of the SI used in motor mapping overall is a crucial part of the experimental design, as the SI defines the amplitude and spread of the responses, and the spatial accuracy of individual stimuli [25]. In general, the map size increases with the SI [24,25]. A common 
practice is to use a SI that is related to the individual rMT by percentage increase, i.e., $110 \%$ of the rMT. A workshop report including recommendations for nTMS motor mapping in patients harboring brain tumors suggest the use of $105 \%$ rMT when mapping the $\mathrm{uE}$ muscle representations and $110 \%$ (with additional $20 \mathrm{~V} / \mathrm{m}$ ) to map the representations of IE muscle representations [93]. While these are practical solutions easily applied for clinical practice, they are likely to cause protocol-induced variation to the results. The individual input-output characteristics vary with factors such as age $[116,117]$. Furthermore, they are then also affecting the outcome of the mapping, as the used supra-threshold SI is dependent on those characteristics $[24,25,107,118,119]$.

From a risk-benefit perspective, the risks in selection of the SI are the following: (1) too low SI will not activate the cortex that contains motor functions in mapped areas (and, as a result, false-negative responses are gained), and (2) too high SI that excites neurons outside the stimulated target region (resulting in a response that is falsely positive, i.e., positive responses not associated with the stimulated target). Provided that the fluctuation in cortical excitability is normal, and muscles are maintained in rest, the benefits corresponding with the above-mentioned risks are that with (1) low SI if the stimulation of a cortical target is producing a response, it can be assumed with high confidence as a true-positive response, and with (2) high SI the probability of inducing a response is greater (Figure 5), and it is likely that if there is no response the stimulated target is a truenegative response. Therefore, in selecting the SI, the risks and benefits should be weighted regarding the information that is needed to be acquired. In preoperative motor mapping in patients with brain tumors, a motor map that only shows a minimum number of falsepositive stimulation points is warranted in order to avoid overestimation of the extent of the motor map. Such overestimation could lead to incomplete tumor resection given that false-positive spots are unnecessarily spared from resection due to anticipated, but faulty "true" motor function representations. However, high fractions of false-negative points would put the patient at a theoretically higher risk of functional deterioration in cases in which such points are included in the surgical resection. Correspondingly, Thordstein et al. speculated that using a low SI could include an additional risk since the activation area of a muscle could be distributed non-continuously along the motor cortex $[107,120]$.

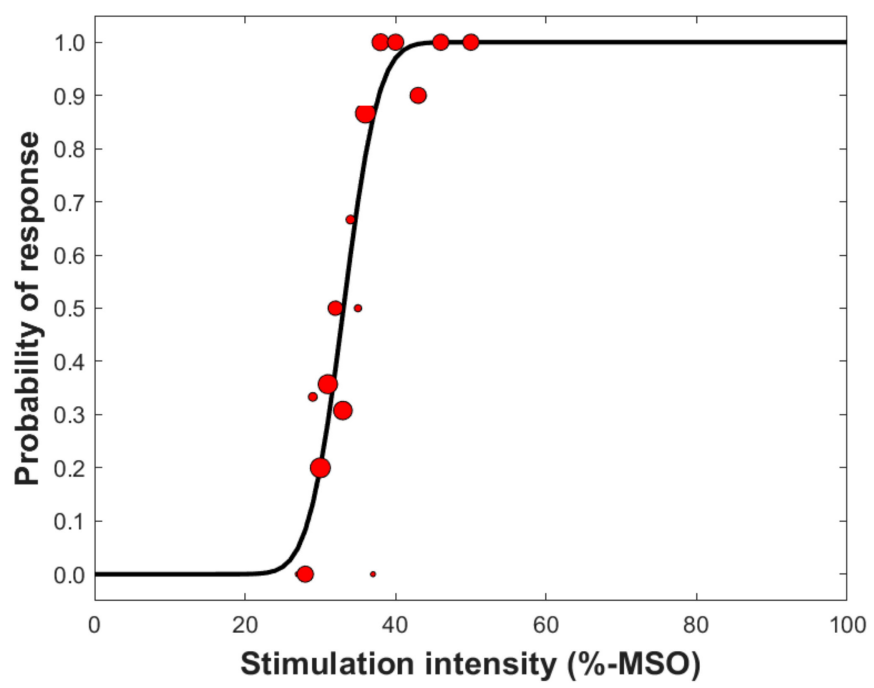

Figure 5. Example of the cumulative distribution function (black line) fitted to the experimental data of one subject. The red dots indicate the probability of response based on repeated MEP trials. The number of repetitions at each SI (given as \%-MSO) is reflected in the marker size, which has been used to weight the fitting of the cumulative distribution function.

When using a SI that is at supra-threshold level normalized to the rMT (e.g., 110\% rMT), it is unclear what the individual likelihood for induction of a response is (Figure 6). 
However, it may largely avoid false-negative stimulation points within the motor map by arbitrarily creating some sort of a "safety margin" around unequivocally motor-positive stimulation spots. Certainly, the likelihood for producing a response at the motor hotspot where the rMT was determined is greater than $50 \%$-but is it $60 \%$ or $95 \%$ ? This dilemma makes it difficult to estimate the real accuracy of individual motor mapping if the inputoutput characteristics are unknown. Alternative techniques for determining the mapping intensity based on a threshold value that relies on greater probability of responses than $50 \%$ has been suggested as an alternative way to determine the SI [25]. Specifically, Kallioniemi and Julkunen proposed that the use of the so-called Mills-Nithi UT could be used directly as the SI for mapping, and demonstrated that it indeed reduces the inter-individual variation in the quantified motor map size $[25,108]$. The core principle in using the UT instead of a SI normalized to the rMT seems justified as with UT the probability of a response is $\sim 90 \%$, hence reducing the dependence of mapping outcome from the individual input-output characteristics. However, there are drawbacks in that methodology: (1) the confidence in the estimated UT is likely lower than for the rMT that is determined using ATH $[109,110]$, and (2) it may take a few minutes more time to determine the UT [25].

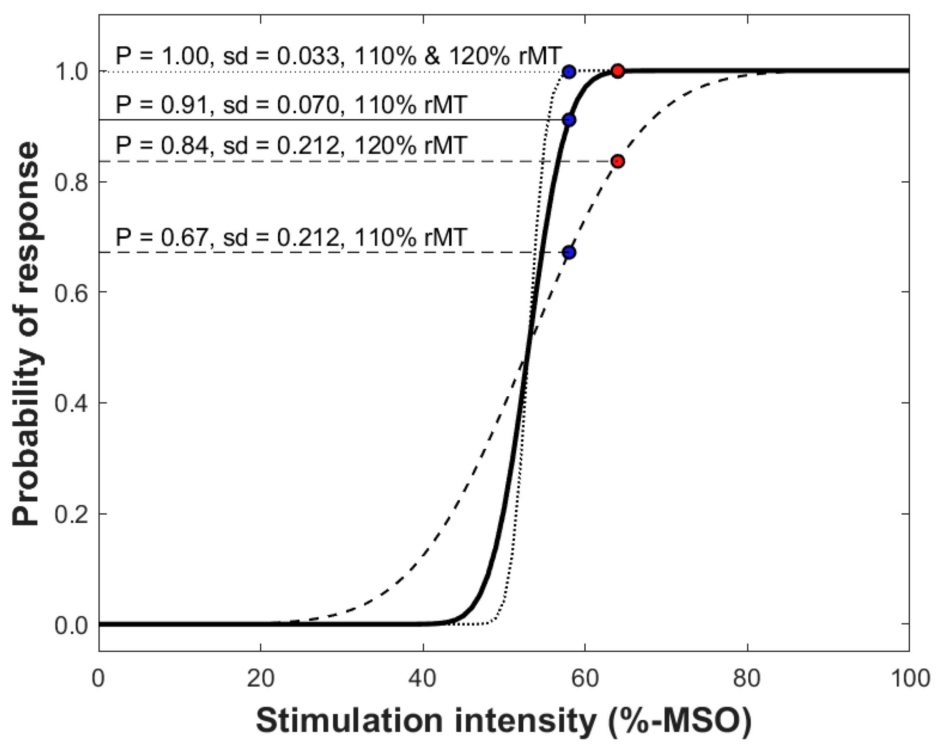

Figure 6. Demonstration of the cumulative distribution function representing the probability of inducing a response at different SIs. As the slope, represented as relative spread [110], can differ between subjects, the use of the SI related to the rMT can induce differences to the absolute size of the motor map [25]. In the plot, mean relative spread (solid black line) and the minimum (dotted black line) and maximum (dashed black line) found in the study population were used to compare probabilities of inducing a response at 110\% rMT (blue dots) and 120\% rMT (red dots). At a low relative spread, 110\% and $120 \%$ rMT produce an MEP at the stimulation target with a probability close to $100 \%$, but with the high relative spread, the probabilities of MEPs at the target at $110 \%$ and $120 \% \mathrm{rMT}$ are $68 \%$ and $83 \%$, respectively.

To demonstrate the variability of motor maps due to uncertainty in response occurrence probability, we simulated motor maps based on experimental motor mapping data by assuming that $10 \%$ of the responses were falsely negative to estimate the general confidence of motor mapping based on uncertainties related to response occurrence (Figure 7). The simulation demonstrated that despite the uncertainty, the SI-dependent differences in the motor map area were still apparent, and the shape and extent of the motor maps were maintained from simulation to simulation. Unlike the area of the motor map, the location of CoGs does not appear to depend on the SI [24]. It was demonstrated by Thickbroom et al. that when moving the coil from one cortical location to another, the shape of the 
input-output curve does not change significantly, only the offset that is the crucial part being represented as the rMT [121].

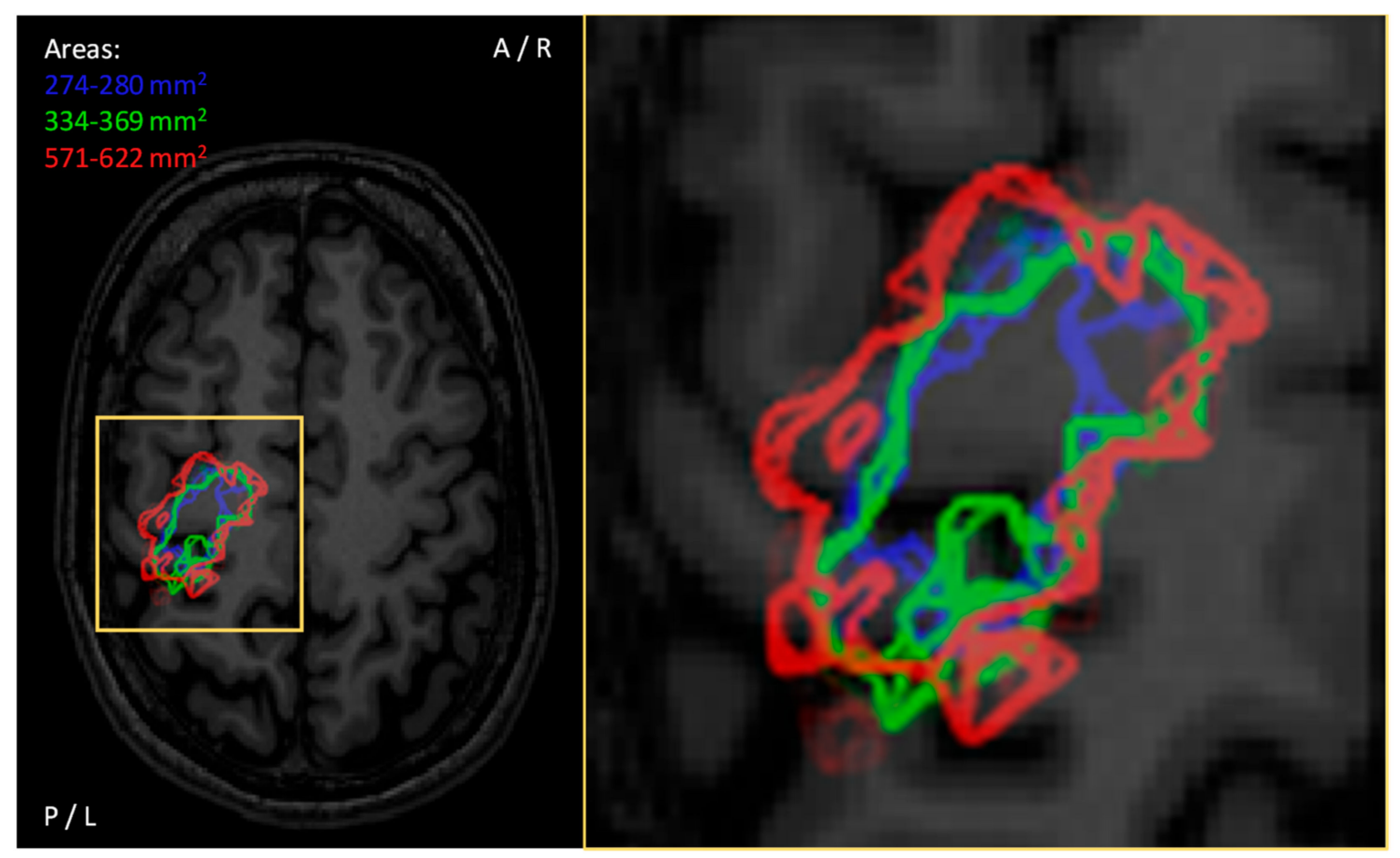

Figure 7. Visualization of the motor map resulting from mapping with three SIs (blue: 110\% of the rMT, green: Mills-Nithi UT method [108], red: 120\% rMT). Data from each of the experiments were bootstrapped 1000 times, assuming that $10 \%$ of the responses observed were false negative. The image is visualized in neurological projection. The stimulations were placed on average $0.4 \mathrm{~mm}$ apart. The $95 \%$ confidence limits are indicated for quantified areas in the images.

The SI is commonly represented as a percentage of the maximum stimulator output (\%-MSO), by definition making it dependent on the maximal stimulator performance that is highly dependent on the used instrumentation including the characteristics of stimulation coils and the stimulating pulse [122-128]. This means that when comparing the used SIs between individuals, one has to consider the characteristics of the instrumentation. In addition, the SI, when represented as \%-MSO, is not considering the individual distance of the stimulated cortex from the stimulating coil that is placed on the scalp [129-133]. To account for individual coil-to-cortex distance by estimating the cortically-induced EF by stimulation, an EF estimate could be used [134-136]. However, the EF estimate may not account for differences in pulse characteristics [137]; yet it could reduce the difference in representing SIs as EFs between stimulator manufactures differ [126]. Nevertheless, when applying EFs in different individuals, there exists a challenge to determine the anatomic location where the EF should be estimated, as the exact location of response induction has not been unambiguously determined since the activation by stimulation is not limited to the crown of specific layers of the cortex, but, instead, the coil distance-dependent EF affects a large part of the cortex $[29,105,138]$.

Recently, Nazarova et al. mapped the representations of multiple muscles simultaneously to distinguish between muscle representations of the individual muscles [98]. As previously suggested, they observed that the use of a single SI may be a possible limitation as the different muscles could potentially have different rMTs [98]. Previously, it has been observed that the different somatotopically adjacent muscle representations could have different excitability profiles $[95,107,118]$. Albeit, at the group level the effect size may be minor or acceptable, at the individual level the clinical significance for such different profiles may be crucial $[95,119,139-141]$. This means that if a muscle has a lower rMT for activation and a steeper rise for the input-output curve than the other mapped muscles, 
the motor map will be biased due to the responses of that muscle, and will mostly present the representation area of that specific muscle over the other mapped muscles. Therefore, when determining quantitative characteristics for a group of muscles, the mapped outcome may be biased with certain muscles due to the differences in the individual muscle rMTs, and perhaps also due to individual motor hotspots.

Furthermore, the coil-to-cortex distance varies with stimulated cortical regions, which may require adjustment of the applied SI [130,131,135,136,142-144]. Because of the differences between target sites, the SI needs to be adjusted by taking into account the differences in coil-to-cortex distances, the secondary field caused by charge accumulation at conductivity discontinuities, and the coil orientation, and adjustment based only on the SI or primary EF is not sufficient [135].

\subsection{Stimulation Grid}

To enable quantitative mapping and to set the spatial density for stimulation targets and, thus, spatial accuracy of the quantitative mapping, stimulation grids are frequently used [27,145-147]. The grids are especially crucial for non-navigated estimation of motor maps $[145,146]$. However, they are also used in nTMS approaches where the underlying anatomy is visible $[27,147]$. The use of the grids enables straightforward calculation of the motor map size, i.e., by calculation of the number of active squares (producing acceptable responses when that square is stimulated) within the grid [118]. The definition of the active grid square varies in terms of interpreting a response (e.g., response/no response, maximum MEP amplitude, mean MEP amplitude, MEP count, etc.). In nTMS, the size of the grid squares affects the accuracy of the motor map that can be related to anatomical structures. The accuracy is limited also by the resolution of the underlying structural MRI and the accuracy of the neuronavigation system [1]. If using a grid as aid for enabling homogeneous spacing between the stimuli, the selection of the grid size should consider the required spatial resolution of the motor map. Figure 8 demonstrates how the size of a stimulation grid square could affect the appearance of a motor map. The larger grid squares result in bulk-shaped motor maps with the grid potentially overestimating the true map size, while reduction of the grid square size converges towards the true motor map size. However, the smallest grid squares produce lower map size than the reference value because the original data were gathered with inferior density and there might be no data for all grid squares (Figure 9).

It may soon be obsolete to consider motor mapping in terms of grids and grid targets, as modern nTMS motor mapping could potentially be performed in a quantitative fashion without the use of grids as long as quality criteria are set [148]. This means that the placement of stimuli is anatomically guided with denser placement of stimuli at specific regions, e.g., in the vicinity of anatomically interesting landmarks or at the edges of a motor map. This also means that the spatial and regional accuracy within the motor map may vary, while the extent of the motor map could be more accurately defined. The effects could be inverse for the accuracy of the CoGs, and for calculation of CoGs the coverage of each individual stimulus target in the motor map needs to be accounted for and be weighted in the calculation [27].

\subsection{Number of Stimuli Required (per Target Location)}

The accuracy of the motor mapping has been shown to relate to the number of stimuli used [26]. The number of stimulated responses within each grid square varies, as does the size of the grid squares $[26,118,140,145,147,149-153]$. Previous studies have investigated the required number of stimuli in a stimulation grid, having observed that two or more stimuli should be used to improve the confidence in the resulting motor map parameters $[26,154]$. Specifically, Cavaleri et al. reported that at least two responses induced by targeting each grid square were required for reliable calculation of the $\mathrm{CoG}$ and motor map volume in non-navigated TMS with a grid square size of $10 \mathrm{~mm}$ [154]. The used stimulus grid, or the density of the stimulus target spacing plays an essential role when defining the parameters 
of the motor map. In essence, the CoG location is dependent on the grid square size, as it is the case with the cortical area (Figure 9). The larger the grid square is, the less accurate is the CoG location or the motor area (Figure 9).
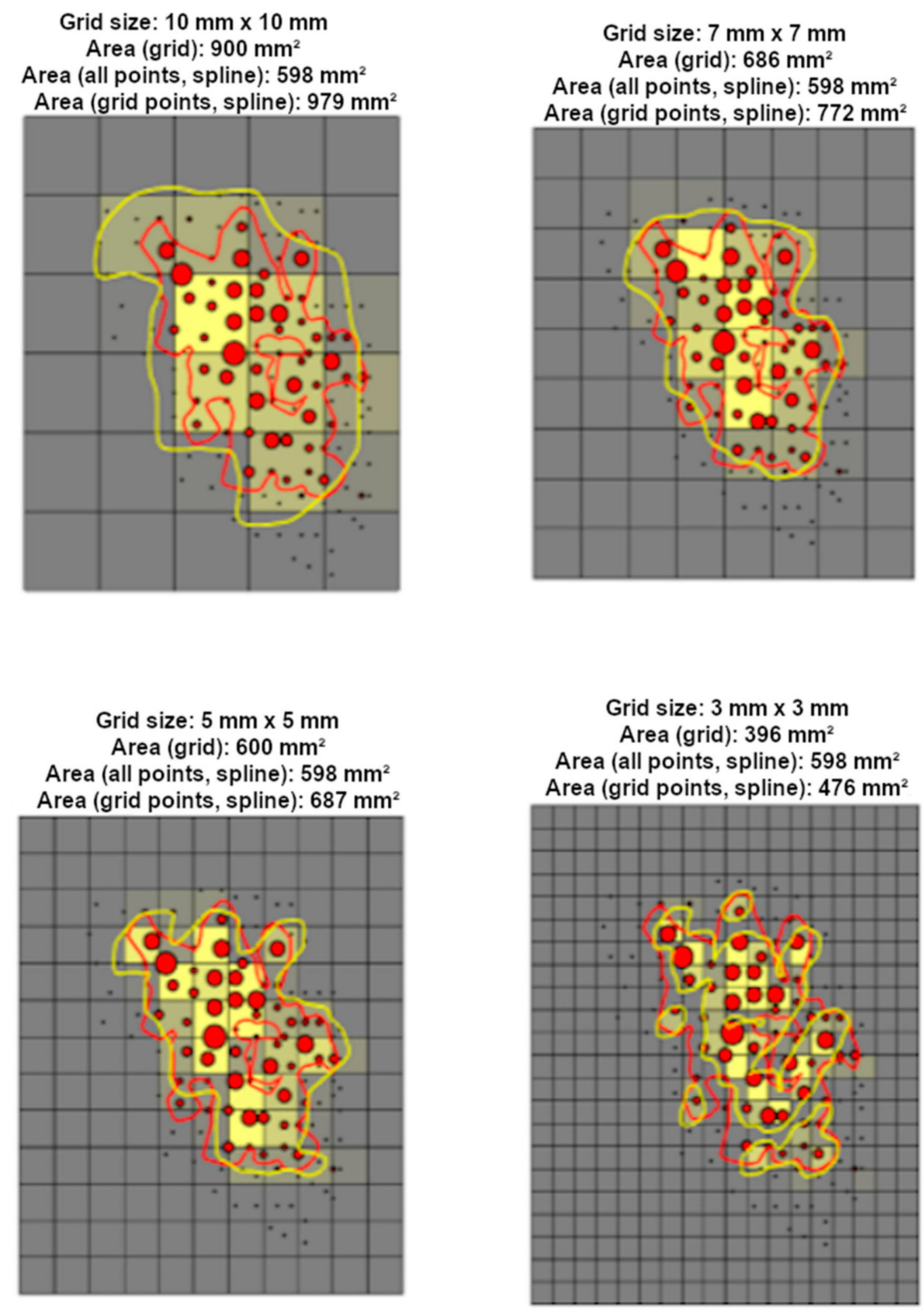

Figure 8. Demonstration of the use of a grid in calculating the area of the motor map. The original individual responses are presented as red-filled dots, with the dot size reflecting the MEP amplitude. The black dots are 0-amplitude responses. Average MEP amplitudes were calculated within grid squares in different size grids. The resulting average MEP amplitude size is reflected in the yellow color of the grid squares. The area of the motor map was evaluated based on the sum of the grid square areas with average MEP amplitudes of at least $50 \mu \mathrm{V}$, and by using spline interpolation (yellow line). The corresponding motor map areas are displayed above the grids with the grid sizes. For comparison, the motor map area is displayed for the original responses with spline interpolation, indicated by the red line in each plot.

When using nTMS, the conventional grid squares (e.g., $10 \times 10 \mathrm{~mm}$ or $15 \times 15 \mathrm{~mm}$ in size) are likely to include more stimuli. This is demonstrated in Figure 10, placing a stimulus grid of typical size over the mapped region and demonstrating that several stimuli are placed within the grid squares [146,149]. In fact, due to the spatial averaging caused by the large number of MEPs recorded during the mapping, the inherent variability effect 
in MEPs may be reduced, and placing multiple stimuli per location is compensated by closer spacing of the stimulus locations $[95,155]$. Chernyavskiy et al. showed that with an increasing number of stimuli included in the motor map, the accuracy is improved in nTMS mapping without application of a grid, as the coverage of a single response in a motor map and, hence, the contribution a response for the total motor map is decreased [155].
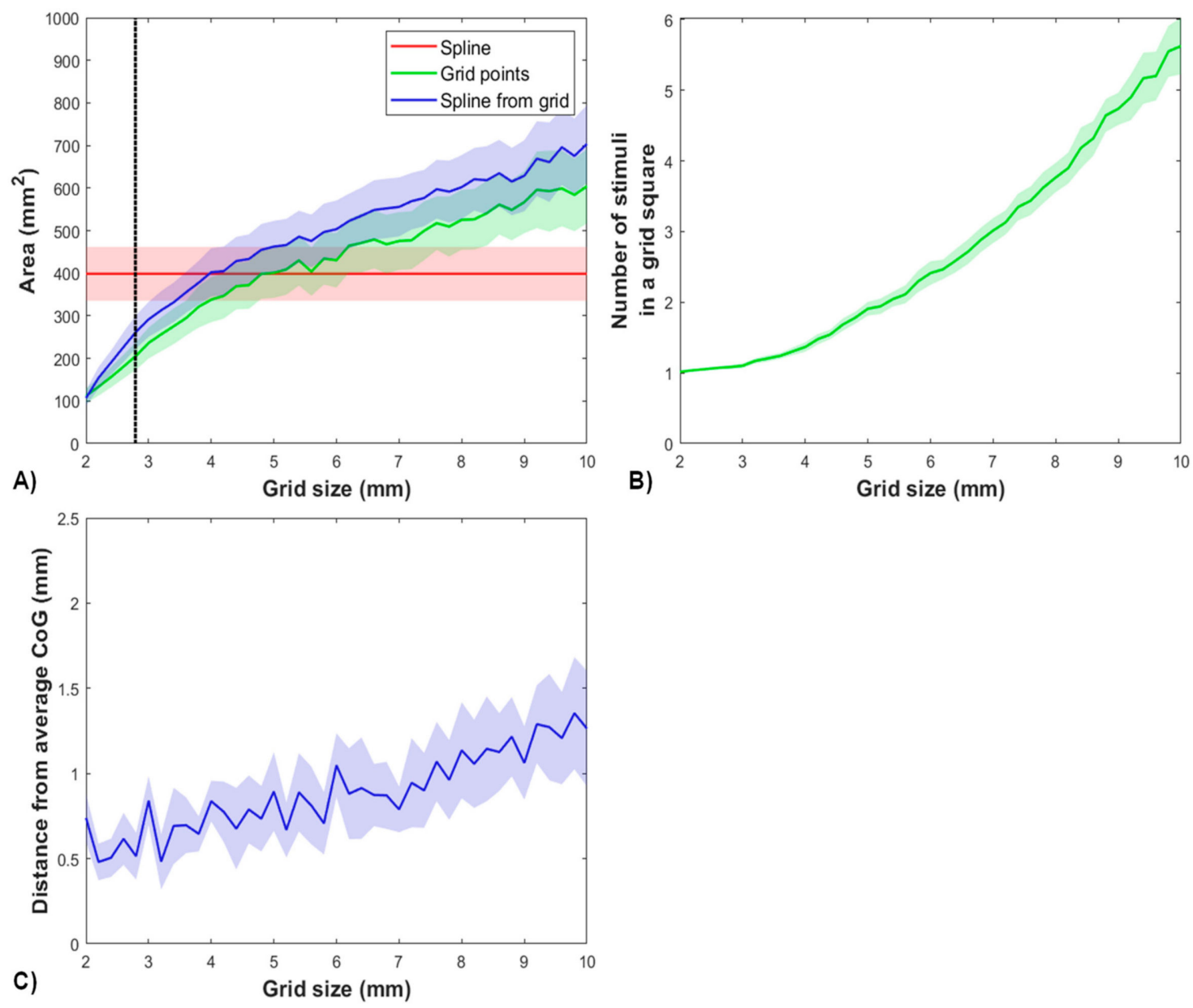

Figure 9. (A) The effect of grid size on the resulting motor areas with different methods of calculation. As a comparison, there is the area calculated with the spline interpolation $(\mathrm{red})$, which is independent of the grid size, but is instead dependent on the local spacing of the stimuli. The area calculated from active grid squares is presented in green and, for ease of comparison, the spline interpolation area calculated from the active grid sites is shown in blue. The shaded areas indicate the $95 \%$ confidence interval within the study population, which was 24 mapping experiments at $110 \%$ of rMT. (B) The average number of stimuli falling within each grid square is shown as a function of grid size, with the shaded area indicating the $95 \%$ confidence interval within the study population. (C) The effect of grid size on the CoG location is shown, with the shaded area indicating the $95 \%$ confidence interval within the study population.

Often, when utilizing stimulation grids, a few stimuli may be repeated per grid to reduce the effect of MEP amplitude variation. However, then the number of stimuli is in a different scale than the number of required stimuli needed to obtain the average MEP amplitude confidently. To reach for a reliable and stable value of the MEP amplitude, previous studies have found that at least 20 repeated trials should be averaged $[156,157]$. However, these confidences are not fully comparable, since the overall data on MEP amplitudes within the motor maps are more extensive than in studies assessing single-target MEP amplitudes. Thus, the effect of individual grid square MEP amplitudes variability affects less the binarized map parameters such as the area, and, hence, the "spatial filtering" reduces the apparent MEP variability. Obviously, parameters utilizing absolute MEP amplitudes such as the map volume could be more affected. 


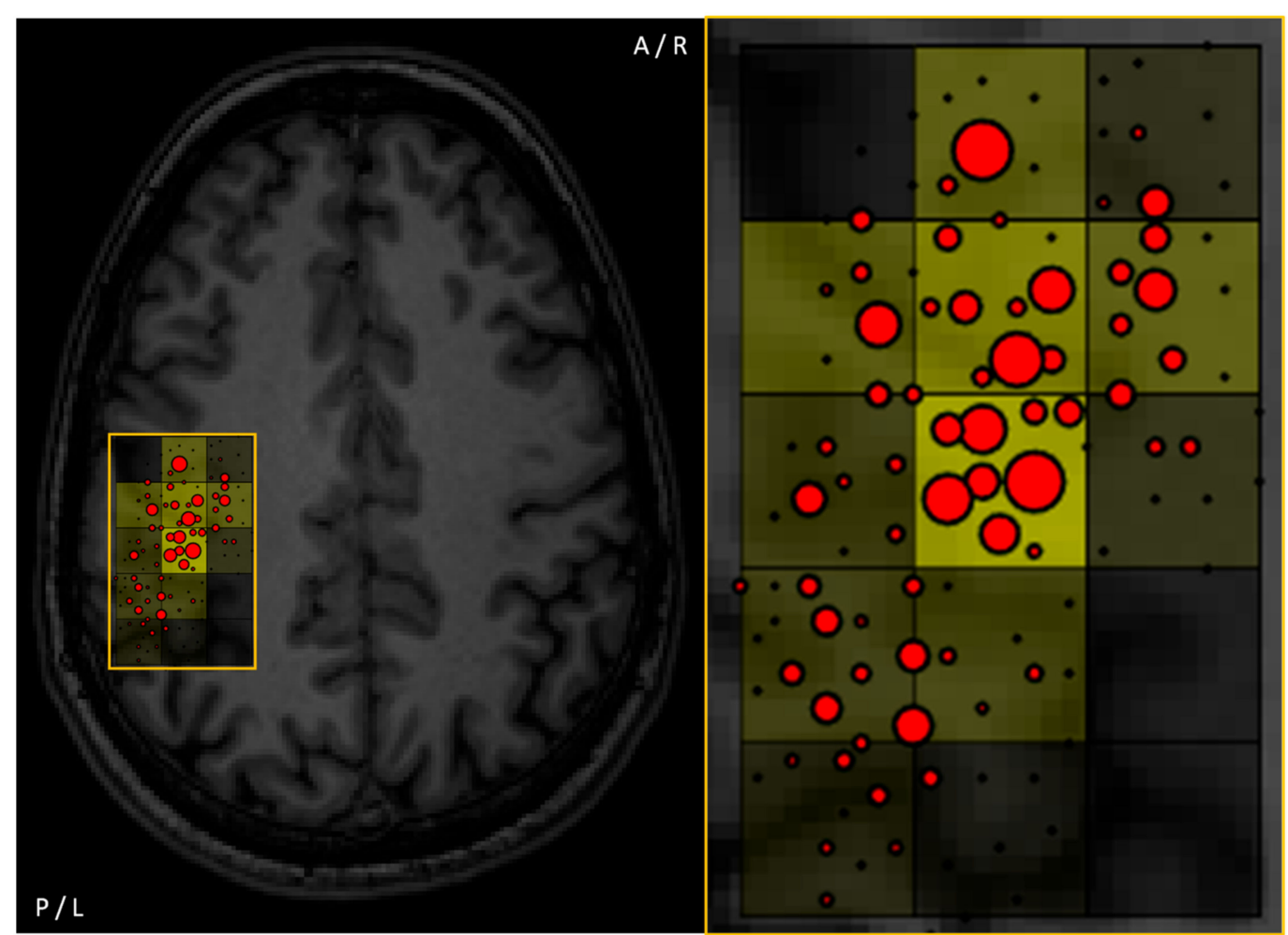

Figure 10. The visualized grid square size used was $10 \mathrm{~mm} \times 10 \mathrm{~mm}$, which is a quite commonly used size [146,149]. The stimulations were placed on average $2.6 \mathrm{~mm}$ apart. The individual stimulus locations are shown with red dots, the size of which is indicative of the associated MEP amplitude (the larger the amplitude, the larger the dot). The yellow colors in the grid squares indicate the size of the mean MEP amplitude for the MEPs induced by stimulating points within the grid square (the brighter the color, the higher the mean MEP amplitude).

\subsection{Coil Orientation with Respect to Anatomy}

The degrees of freedom (DOF) of the stimulation coil include the coil location, orientation and tilt, while additionally, one system-dependent DOF is also the previously discussed SI. The coil tilt affects the efficiency of dose delivery on the cortex [158,159]. With respect to the underlying cortical anatomy, the coil orientation affects the observed response (i.e., suboptimal coil orientation may result in MEPs with low amplitude or a non-response) [105,160-162]. Balslev et al. showed with non-navigated TMS that a $45^{\circ}$ angle with respect to the interhemispheric midline is generally the optimal coil orientation [163]. Further, the optimal coil orientation has been observed from experiments and simulations to be perpendicular to the gyral wall $[104,105,135,138,160,164]$. While there may not be group-level differences in the optimal coil orientation, the individually quantified parameters, such as the motor area, may depend on it [106].

The microanatomy of the gyrus may also affect the efficacy of nTMS, i.e., how aligned are the stimulations and the activated neuronal structures, and how organized or anisotropic are the activated individual neurons in their population [138,165]. While these factors cannot be directly visualized during application of nTMS, they may take relevant effect on the mapping outcome.

\subsection{Other Quantitative Parameters in Motor Maps}

Other quantitative parameters commonly used to characterize motor maps based on MEP amplitudes include the motor hotspot, CoG, motor area, and motor map volume. The motor hotspot location typically is defined by the location of the maximum MEP amplitude response $\left(x_{\max } ; y_{\max }\right)$ or the "optimal location" for stimulation $[28,29,166-168]$. The motor hotspot is not only used to characterize the location of the motor representation, but is also used as the location where the rMT is determined and around which the motor 
mapping is extended [169]. Considering the definition of the motor hotspot, Reijonen et al. characterized a hotspot as a region instead of a unique target and found that if the definition is based on MEP amplitudes within individualized motor maps, the hotspot is on average $13 \mathrm{~mm}^{2}$ in size, and if the hotspot is defined on the basis of the stimulation-induced $\mathrm{EF}$, the size is on average $26 \mathrm{~mm}^{2}$ [29]. These hotspot definitions consider the accuracy of the definition of the hotspot, including within-session neuronavigation system accuracy. Specifically, with nTMS, it has been shown that intra- and inter-observer variability for motor hotspot determination are on average $\leq 1 \mathrm{~cm}$, with values ranging within the calculated precision of the used system [170].

The CoG is defined as the amplitude-weighted location in coordinates representing the location in the motor representation area where the center of motor activation lies, and is represented by the following equation:

$$
x_{\mathrm{CoG}}=\sum M_{i} x_{i} / \sum M_{i} ; y_{\mathrm{CoG}}=\sum M_{i} y_{i} / \sum M_{i}
$$

where CoG location is defined in two dimensions with the Cartesian coordinates $x_{\mathrm{CoG}}$ and $y_{\mathrm{CoG}}$, individual MEP amplitudes, and $M_{i}$ corresponding to single stimulation targets $\left(x_{i} ; y_{i}\right)[171]$. The CoG locations are dependent on the muscle representation mapped $[95,118,172]$. The intersession repeatability of the CoG has been demonstrated to be good to excellent $[28,31,98,118]$. In our simulations, we found that the SI has a minor effect on the CoG location, as does the chance of false-negative responses (Figure 11).

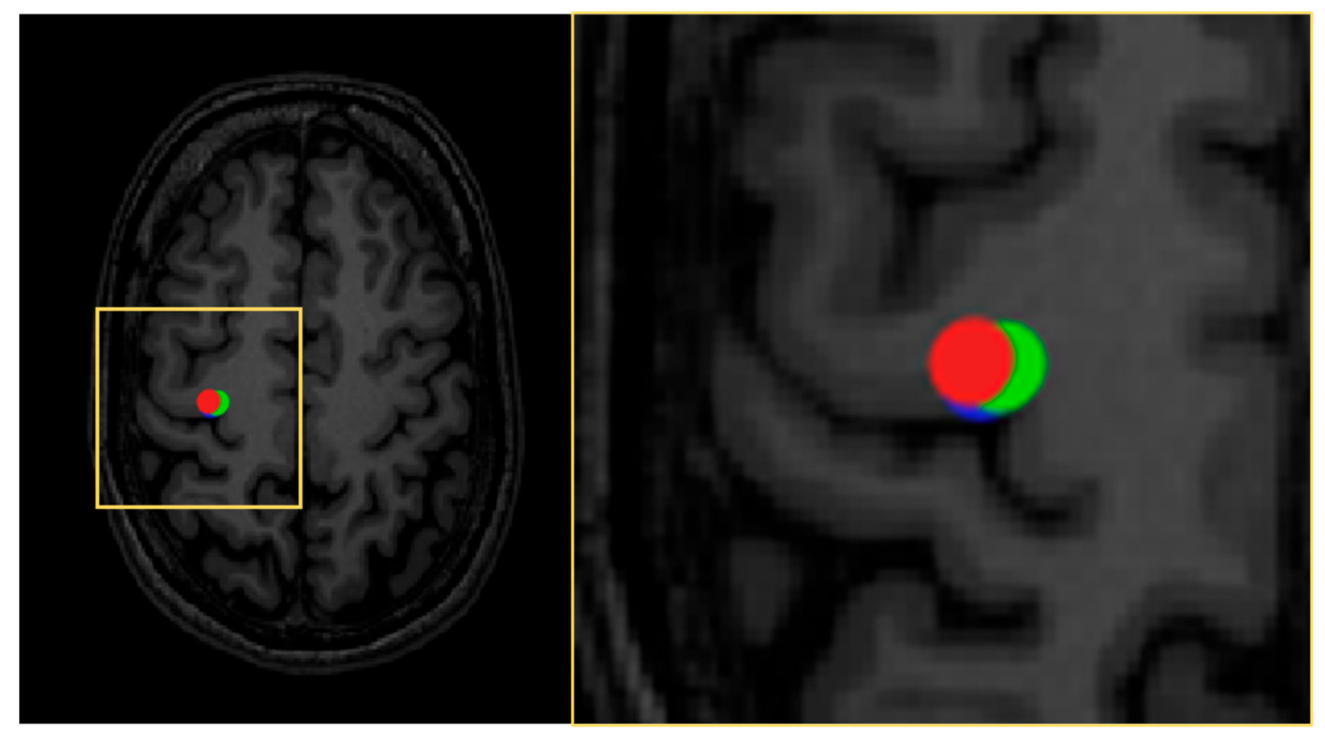

Figure 11. Visualization of CoGs based on motor maps with three SIs (blue: $110 \%$ of the rMT, green: Mills-Nithi UT method [108], red: 120\% rMT). Data from each of the experiments were bootstrapped 1000 times, assuming that $10 \%$ of the responses observed were false negative. The dots indicate a product of $1000 \mathrm{CoG}$ locations each. The image is visualized in neurological projection.

If the spacing of the stimulus targets is not homogeneous within the motor map (i.e., when a stimulus grid is not used), then the response amplitudes $M_{i}$ need to be weighted by their stimulus targets coverage in the motor map $A_{i}$ [27]:

$$
x_{\mathrm{CoG}}=\sum M_{i} A_{i} x_{i} / \sum M_{i} A_{i} ; y_{\mathrm{CoG}}=\sum M_{i} A_{i} y_{i} / \sum M_{i} A_{i}
$$

The volume of a motor map is usually defined in a grid by summing the MEP amplitudes associated with the grid squares that exceed a given response threshold [24,30,31]:

$$
\text { Volume }=\sum M_{i}
$$


where the index $i$ refers to each grid element. Alternatively, the volume of the motor map has been determined as the volume of an interpolated amplitude surface on the cortex [96]. The repeatability of the motor map volumes has been demonstrated to be between poor and good [30,31].

The area has been defined in different ways. When using a simulation grid, previous studies have multiplied the grid square area with the number of active stimulation sites within the grid $[118,147,173]$. With nTMS, recent studies have utilized different means for calculating the area, such as spline interpolation or Voronoi tessellation [25,27,95,153,155,173-176]. These analysis techniques of the representation are not directly comparable, as they include systematic differences [173]. Previous studies have shown that the motor map area may suffer from poor to excellent session-to-session/within-session repeatability [27,30,31,98,118]. Here, we simulated the session-to-session repeatability of a motor map by assuming the potential of false-negative motor responses to find that the quantitative size is well-preserved within the sessions as are the shapes and locations, while minor session-to-session differences were observed in the motor map area (Figure 12). The set amplitude criterion also affects the motor area, and commonly the amplitude criterion of $50 \mu \mathrm{V}$ is used (Figure 13).
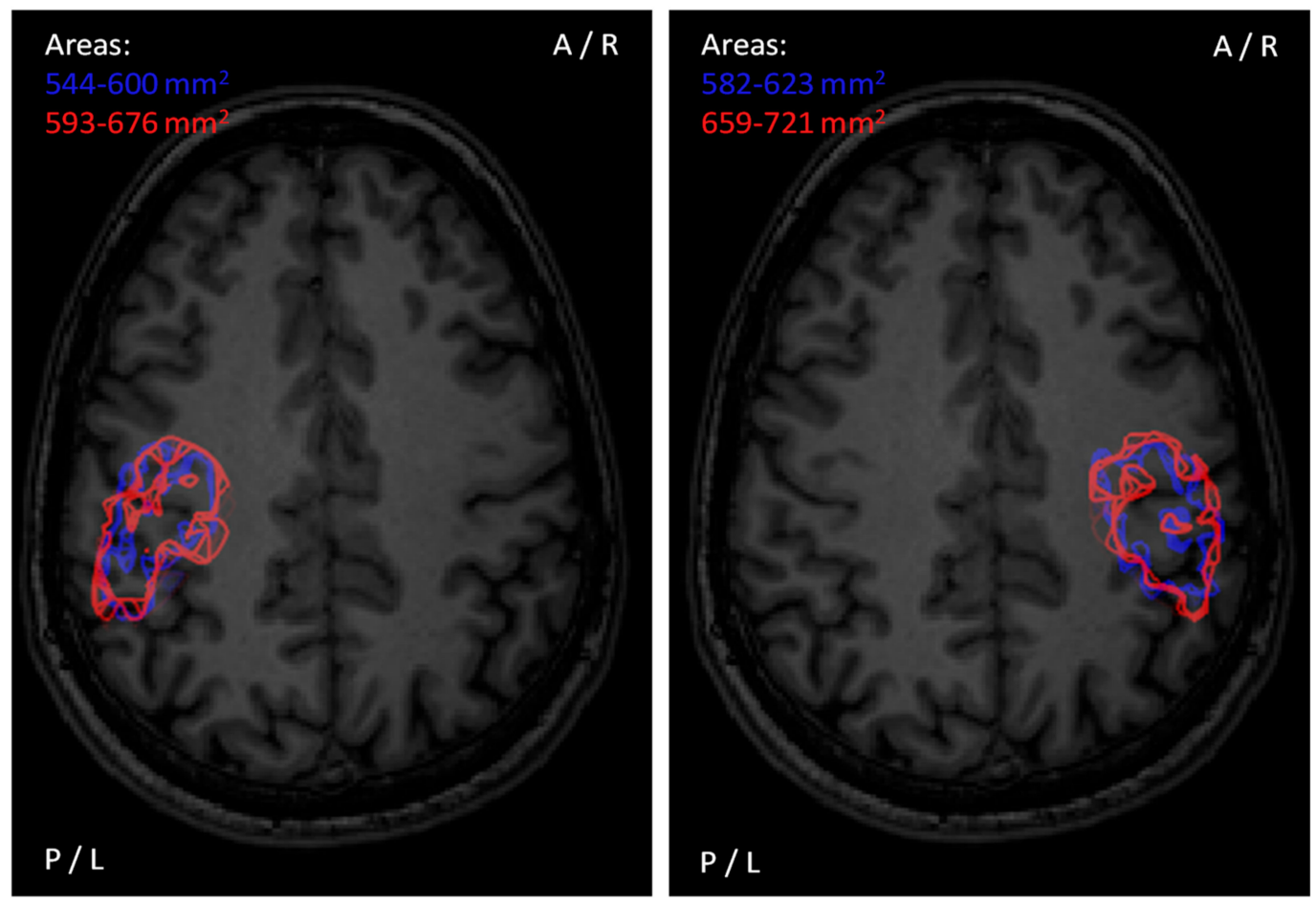

Figure 12. Visualization of motor map outlines of the FDI muscle representation in repeated measurements. Data from each of the experiments were bootstrapped 1000 times, assuming that $10 \%$ of the responses observed were false negative. The image is visualized in neurological projection. The blue maps were mapped a bit more densely (mean distance between stimulus locations was $2.6 \mathrm{~mm}$ on both hemispheres, as a $3.0 \mathrm{~mm}$ grid was used as aid) than the red maps (mean distance between stimulus locations was $2.7 \mathrm{~mm}$ and $3.0 \mathrm{~mm}$ on the left and right hemisphere, respectively, without a stimulation grid). The $95 \%$ confidence limits are indicated for quantified areas in the images.

Sinitsyn et al. found, based on their experiments comparing multiple techniques and multiple stimuli/grid squares in calculating the motor map areas, that area weighted by the probability of an MEP within a grid square appeared overall best in terms of accuracy [26]. As the SI applied with respect to the rMT determines the probability of an MEP in each grid square, the reliable determination of the probability would likely require multiple repetitions per grid square, or for one stimulus per grid square the probability would be 0 or 1 . 


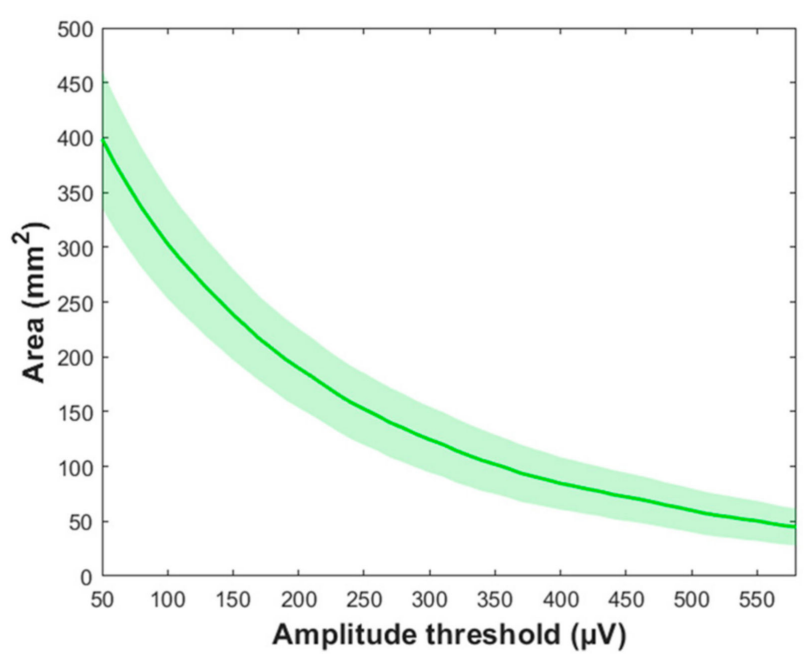

Figure 13. Effect of amplitude criterion for accepted MEPs measured on the resulting motor map size as determined using spline interpolation [27]. In the figure, 24 cortical mapping experiments for locating and outlining the FDI muscle representation were used to calculate the mean (green line) and 95\% confidence interval (green area) for the motor area at different amplitude threshold criteria for accepted MEPs.

\section{Perspectives and Future Directions}

Over the past decade, nTMS has found its way into clinical routine, particularly for motor mapping among patients with motor-eloquent brain neoplasms since the method combines spatially resolved identification of brain function with high accuracy even in cases with deranged anatomo-functional architecture. The good agreement between preoperative nTMS motor mapping and intraoperative DES mapping as the reference method seems one of the key factors contributing to the current role of nTMS motor mapping in neurooncological surgery [35-42]. Furthermore, motor maps derived from nTMS can be used for seeding to achieve function-based tractography, which enables the identification of the spatial course of critical subcortical structures such as the CST [51-56]. However, the initial application for preoperative planning and intraoperative resection guidance in patients harboring functionally eloquent brain neoplasms has been greatly expanded over the years, thus enabling researchers to also address basic research questions in the context of a brain tumor as the use case, spanning from risk stratification for motor function to plasticity and reshaping of functional anatomy [69-73,77-81].

The key to successful integration of nTMS motor mapping and derived tractography into the clinical workflow is closely related to feasibility aspects and potential difficulties when embedding these approaches in existing environments. In this context, seamless integration into pre-existing infrastructure (e.g., hospital information system or PACS) can be achieved by standardized data export and transfer from the nTMS system [82]. However, it has to be noted that performing the mapping procedure in the most accurate fashion requires some training and time ( 60 to 90 min per patient, excluding preparation and depending on factors such as the extent of motor mapping and patient cooperation) [6]. Thus, trained personnel and dedicated time slots for mapping purposes may be required in the clinical setting, which are not always granted under economic and time constraints. However, alternatives to nTMS motor mapping for the preoperative workup in patients harboring brain neoplasms (e.g., fMRI or MEG) also come with expenses and may only be available in specialized centers. Given that an overall better agreement between nTMS motor mapping and DES mapping has been observed in comparative studies with fMRI or MEG, efforts during the preoperative setup with nTMS seem justified [35-42].

Further potential of nTMS motor mapping lies in the interdisciplinary use of derived data. Particularly, radiotherapists may take advantage of such maps to modify treatment plans with the aim of limiting dose exposure to motor-eloquent cortex, as shown in first 
studies on the matter [83-87]. Integration of functional data derived from nTMS motor mapping could also be achieved for case discussions of interdisciplinary tumor boards and forwarded to follow-up treatment, which may make use of such information for rehabilitation strategies. In this context, a first example in patients suffering from acute surgery-related paresis of $\mathrm{uE}$ muscles after glioma resection provides evidence for the beneficial use of nTMS as a therapeutic tool in neuro-oncology, with the exact site of stimulation being determined based on nTMS motor maps [177]. Specifically, the combination of low-frequency nTMS with physical therapy for seven consecutive days after surgery improved motor function outcome according to the Fugl-Meyer assessment performed postoperatively and until the 3-months follow-up examinations [177].

Additionally, nTMS data could also be efficiently used in multi-modal scenarios. For instance, the combination of motor mapping with mapping of other functions such as language and derived tractography of motor- and language-related subcortical pathways has already been achieved in a few studies, which may help to gain a broader picture of functional anatomy in patients harboring large or critically situated neoplasms that most likely do not solely affect the motor system $[178,179]$. Further, to understand better the distinct effects of nTMS on the brain's connectivity profile, combinations of nTMS application with pre- and post-stimulation $\mathrm{fMRI}$ acquisitions and functional connectivity analyses are possible and have shown promising results in healthy volunteers $[100,101]$. Most notably, it has been revealed that modulation by nTMS critically depends on the connectivity profile of the target region, with imaging biomarkers derived from fMRI possibly playing a role to improve sensitivity of nTMS for research and clinical applications [100]. Based on such data, it seems likely that in patients with brain neoplasms, the impact and effects of nTMS also depend on a connectivity profile that may fluctuate over time or due to yet unidentified parameters, possibly interfering with the mapping outcome. Yet, multi-modal scenarios specifically in patients with motor-eloquent brain tumors may also exert difficulties on data acquisition, processing, and interpretation of data, which need to be addressed prior to routine application. For fMRI, presence of particularly high-grade tumors with increased cerebral blood flow characteristics can negatively interfere with signal interpretation $[180,181]$. Thus, combinations of fMRI with nTMS in such patients need to be considered carefully to avoid errors in calculations of connectivity characteristics.

Regarding dMRI, images can suffer from geometric image distortions compared with anatomical MRI, which may introduce spatial inaccuracies when dMRI data is linearly projected on conventional T1- or T2-weighted sequences and used for tractography. This may be retrospectively corrected for by non-linear, semi-elastic image fusion, thus potentially enabling tractography with improved accuracy and clinical feasibility [182]. Expanding on this, intraoperative MRI-based elastic image fusion for anatomically accurate tractography of the CST using nTMS motor maps has been achieved, correlating well with IONM and disproving the severity of brain shift in selected cases [183,184]. Furthermore, most work on nTMS-based fiber tracking of the CST has used standard deterministic algorithms implemented in commercially available packages for clinical use (e.g., fiber assignment by continuous tracking (FACT) algorithms) [51,52,54,55,70-72]. Using a FACT algorithm, fiber bundles are reconstructed in a voxel-by-voxel fashion with respect to the direction of the main eigenvector, which works purely data-based (no interpolation function) and needs only comparatively low computation time $[185,186]$. However, on the other hand, FACT algorithms create some predictable inherent errors, which limit the accuracy of the method and could lead to error-prone or incomplete tractography results [186-189]. Probabilistic approaches disperse trajectories more than deterministic methods and may delineate a greater proportion of white matter tracts, particularly when combined with more advanced dMRI sequences [189]. Additionally, the potential value of diffusion measures besides mere delineation of the spatial course of the CST by nTMS-based tractography may be of merit. One study has shown that the extent of impairment of diffusion metrics (such as FA and ADC) correlates with motor function deficits according to segmental analyses within the CST [72]. Hence, supplementing nTMS-based tractography of the CST with diffusion 
metrics may improve the predictive power for postoperative motor impairment, but other parameters such as mean diffusivity (MD) have not yet been routinely considered. As such, MD is a quantitative measure of the mean motion of water and reflects the rotationally invariant magnitude of water diffusion, which could also be representative of structural integrity of white matter [190]. Future work may explore the potential benefits of further, even more elaborate quantitative markers of white matter structure, composition, and integrity, which can be derived from advanced dMRI techniques such as high angular resolution diffusion imaging, multi-shell imaging, diffusion kurtosis imaging, neurite orientation dispersion, and density imaging [191-193].

The continuous optimization of the nTMS system technique has recently enabled a novel paired-pulse nTMS (pp-nTMS) paradigm for biphasic pulse wave application to induce short-interval intracortical facilitation [194-196]. Use of pp-nTMS may increase efficacy of motor mapping in patients with brain tumors as accurate motor maps are achieved even in cases where conventional single-pulse mapping fails (e.g., due to tumoraffected motor structures or edema) $[174,175]$. Further, pp-nTMS would result in a lower rMT, thus allowing motor mapping with lower SI but without clinically relevant constraints for motor map extent or location $[174,175]$. Particularly in patients with brain tumors, the rMT can be frequently high in the tumor-affected hemisphere, and accurate mapping with a lower SI related to a lower determined rMT could permit successful use of nTMS even in the most demanding cases. This may also be highly relevant for other applications of nTMS in patients with brain tumors, such as language mapping [197-201]. In such applications, a higher SI is often used and stimulation is more widespread and, thus, can entail discomfort that negatively interferes with the mapping outcome. However, studies using pp-nTMS for other purposes than motor mapping are currently lacking.

From a methodological perspective, the presently used motor mapping approach is focused on determining the volume, area, coil locations, or corresponding cortical EF maximum locations associated with motor responses. However, as the EF induced by nTMS is not ideally focused, the spread of the EF also stimulates adjacent areas and, thus, when stimulating an area in the cortex adjacent to the target muscle representation area, the target muscle may activate even though the representation area was not targeted. Hence, quantitative mapping at present cannot precisely capture the true representation size of the motor representation area, and may over- or underestimate it. Previous studies have shown that inclusion of the EF information in generating the motor maps may aid in localizing the motor representation [202-204]. Specifically, minimum norm estimation (MNE) has recently been employed for estimating the true representation area of muscles by accounting for the EF spread and the input-output characteristics of the MEP values [204]. Figure 14 demonstrates the application of MNE in a single subject in comparison with the outlined cortical maximum EF locations with associated positive responses. A quite similar method to MNE was presented by Weise et al., also utilizing the input-output characteristics of the MEPs [203]. The practical difference between these methods arises from the number of coil locations applied and how the input-output characteristics are estimated spatially. 


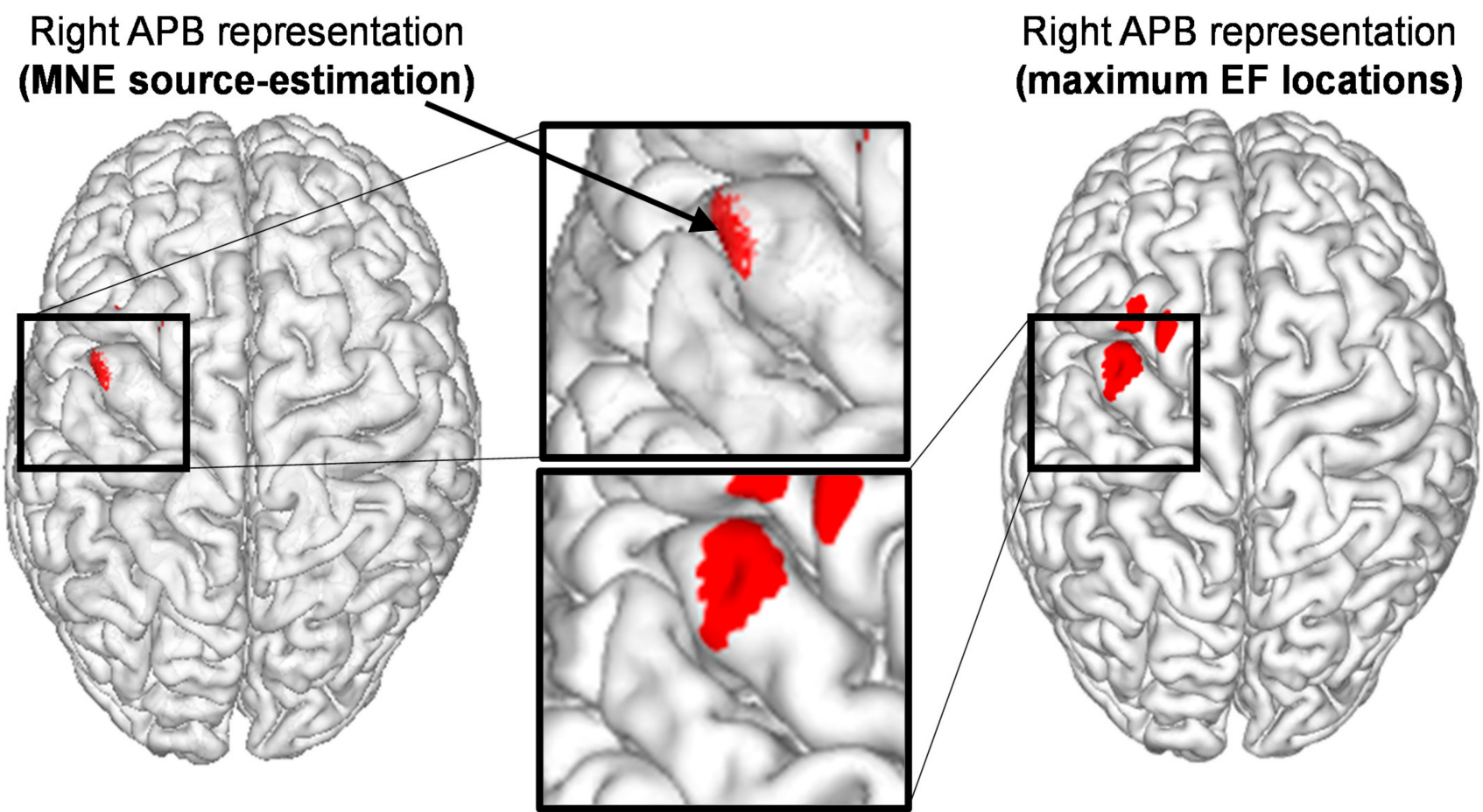

Figure 14. The MNE method (left) utilizes the spread of the EF at each stimulation point in addition to the MEP amplitude to estimate the source of motor activation, as opposed to the more conventional motor mapping approach not considering the spread of the EF associated with each stimulus (right) [204]. The active stimulation sites in the conventional motor map were outlined using the spline interpolation method [27].

In essence, one challenge for more accurate clinical motor mapping with nTMS in the future may be the accurate inclusion of the EF information to estimate the source of the induced MEPs. Currently, there are no clinically validated tools classified as medical devices available for source estimation utilizing EF spread, and the tools that are currently available require special skills and are not feasible for clinical routines. However, the development seems to be heading in the right direction. With tools such as the SimNIBS, EF simulations have been made quite straightforward, albeit the pipelines feasible for clinical mapping applications are still lacking $[205,206]$. Furthermore, the shape of the motor map may be evaluated by the aspect ratio (i.e., the ratio between map extension along the EF direction and perpendicular to it) [195]. This means that if the aspect ratio is 1 , the shape of the motor map is approximated as circular, if the ratio is $>1$, the map is elongated along the EF direction, and with an aspect ratio $<1$, the motor map is elongated to the direction perpendicular to the EF direction. With single-pulse nTMS, the aspect ratio tends to be $>1[174,175,195]$.

Despite increasing acceptance of nTMS motor mapping in clinical routine, it cannot be emphasized enough that the value of the method stands and falls with its accuracy. In this regard, many parameters such as the location of the motor hotspot and $\mathrm{CoG}$, and area and volume of the motor map are associated with the applied SI, which needs to be determined with highest diligence. Therefore, with the increase in applications of nTMS, methods for ensuring feasible accuracy become more and more important. In the context of quantitative mapping, awareness of the relevant parameters and control over them is warranted to assure best practices and reliable mapping outcomes. Specifically, quantitative mapping has the potential to derive parameters related to the motor maps of the patients that could impact diagnostics, prognostics, and follow-up examinations by enabling spatial and spatio-temporal metrics related to cortical motor function. Major future development efforts should be put to understanding the correlations between motor 
mapping, interpretation of stimulation targets, and resulting responses in relation to their origin in the cortex by consideration of the physical effects of induced EFs.

\title{
5. Conclusions
}

The technique of nTMS is increasingly used particularly for preoperative motor mapping in patients harboring brain tumors, which is due to its sufficient accuracy and reliability in a clinical setup. The combination of nTMS motor mapping with tractography as well as the option of serial mapping over time profoundly expands its role beyond a mere surgical planning tool. Development of quantitative motor mapping can include further applications while the accuracy of current mapping modalities can be improved by standardized protocols and increased consideration of EF information.

Author Contributions: All authors declare that they have made substantial contributions to the conception and design of the work and have drafted the work or substantively revised it. All authors approved the submitted version. All authors have read and agreed to the published version of the manuscript.

Funding: This research was supported by the Academy of Finland (grant no: 322423). L.S. was funded by UEF in a research project funded by Business Finland (grant no: 2956/31/2018) and State Research Funding (grant no: 1689/2020).

Institutional Review Board Statement: Not applicable.

Informed Consent Statement: Not applicable.

Acknowledgments: The authors would like to thank Axel Schroeder for his support during the generation of figures to illustrate the motor mapping procedure by nTMS and fiber tracking.

Conflicts of Interest: P.J. has a shared patent with, and has received consulting fees from Nexstim Plc (Helsinki, Finland), a manufacturer of navigated TMS systems. N.S. received honoraria from Nexstim Plc (Helsinki, Finland). S.M.K. is a consultant for Nexstim Plc (Helsinki, Finland) and Spineart Deutschland $\mathrm{GmbH}$ (Frankfurt, Germany) and received honoraria from Medtronic (Meerbusch, Germany) and Carl Zeiss Meditec (Oberkochen, Germany). S.M.K. received research grants and is a consultant for Brainlab AG (Munich, Germany). The funders had no role in the design of the study; in the collection, analyses, or interpretation of data; in the writing of the manuscript, or in the decision to publish the results.

\author{
Abbreviations \\ ADC Apparent diffusion coefficient \\ ADM Abductor digiti minimi \\ AED Antiepileptic drug \\ aMT Active motor threshold \\ APB Abductor pollicis brevis \\ ATH Adaptive threshold hunting \\ BMRC British Medical Research Council \\ CoG Center of gravity \\ CST Corticospinal tract \\ CT Computed tomography \\ DES Direct electrical stimulation \\ DOF Degrees of freedom \\ dMRI Diffusion magnetic resonance imaging \\ EF Electric field \\ EOR Extent of resection \\ FA Fractional anisotropy \\ FACT Fiber assignment by continuous tracking \\ FAT Fractional anisotropy threshold \\ FCR Flexor carpi radialis \\ FDI First dorsal interosseous \\ FGR Fluorescein-guided resection
}




\begin{tabular}{ll} 
FL & Fiber length \\
fMRI & Functional MRI \\
GBM & Glioblastoma multiforme \\
GTR & Gross total resection \\
HGG & High-grade glioma \\
IONM & Intraoperative neuromonitoring \\
IR & Infrared \\
KPS & Karnofsky performance status \\
lE & Lower extremity \\
LGG & Low-grade glioma \\
MD & Mean diffusivity \\
MEG & Magnetoencephalography \\
MEN & Meningioma \\
MEP & Motor-evoked potential \\
MET & Metastasis \\
MNE & Minimum norm estimation \\
MSO & Maximum stimulator output \\
nTMS & Navigated transcranial magnetic stimulation \\
PACS & Picture archiving and communication system \\
PET & Positron emission tomography \\
PFS & Progression-free survival \\
pp-nTMS & Paired-pulse navigated transcranial magnetic stimulation \\
PTV & Planning target volume \\
rMT & Resting motor threshold \\
ROI & Region of interest \\
SI & Stimulation intensity \\
TA & Tibialis anterior \\
uE & Upper extremity \\
UT & Upper threshold \\
WHO & World Health Organization \\
& \\
\hline
\end{tabular}

\section{References}

1. Ruohonen, J.; Karhu, J. Navigated transcranial magnetic stimulation. Clin. Neurophysiol. 2010, 40, 7-17. [CrossRef]

2. Krings, T.; Buchbinder, B.R.; Butler, W.E.; Chiappa, K.H.; Jiang, H.J.; Rosen, B.R.; Cosgrove, G.R. Stereotactic transcranial magnetic stimulation: Correlation with direct electrical cortical stimulation. Neurosurgery 1997, 41, 1319-1326. [CrossRef]

3. Krings, T.; Naujokat, C.; von Keyserlingk, D.G. Representation of cortical motor function as revealed by stereotactic transcranial magnetic stimulation. Electroencephalogr. Clin. Neurophysiol. 1998, 109, 85-93. [CrossRef]

4. Krings, T.; Chiappa, K.H.; Foltys, H.; Reinges, M.H.; Cosgrove, G.R.; Thron, A. Introducing navigated transcranial magnetic stimulation as a refined brain mapping methodology. Neurosurg. Rev. 2001, 24, 171-179. [CrossRef]

5. Ruohonen, J.; Ilmoniemi, R.J. Modeling of the stimulating field generation in TMS. Electroencephalogr. Clin. Neurophysiol. Suppl. 1999, 51, 30-40.

6. Sollmann, N.; Goblirsch-Kolb, M.F.; Ille, S.; Butenschoen, V.M.; Boeckh-Behrens, T.; Meyer, B.; Ringel, F.; Krieg, S.M. Comparison between electric-field-navigated and line-navigated TMS for cortical motor mapping in patients with brain tumors. Acta Neurochir. 2016, 158, 2277-2289. [CrossRef]

7. Bijsterbosch, J.D.; Barker, A.T.; Lee, K.H.; Woodruff, P.W. Where does transcranial magnetic stimulation (TMS) stimulate? Modelling of induced field maps for some common cortical and cerebellar targets. Med. Biol. Eng. Comput. 2012, 50, 671-681. [CrossRef]

8. Lefaucheur, J.P.; Picht, T. The value of preoperative functional cortical mapping using navigated TMS. Clin. Neurophysiol. 2016, 46, 125-133. [CrossRef]

9. Haddad, A.F.; Young, J.S.; Berger, M.S.; Tarapore, P.E. Preoperative applications of navigated transcranial magnetic stimulation. Front. Neurol. 2020, 11, 628903. [CrossRef]

10. Raffa, G.; Scibilia, A.; Conti, A.; Ricciardo, G.; Rizzo, V.; Morelli, A.; Angileri, F.F.; Cardali, S.M.; Germano, A. The role of navigated transcranial magnetic stimulation for surgery of motor-eloquent brain tumors: A systematic review and meta-analysis. Clin. Neurol. Neurosurg. 2019, 180, 7-17. [CrossRef]

11. Picht, T. Current and potential utility of transcranial magnetic stimulation in the diagnostics before brain tumor surgery. CNS Oncol. 2014, 3, 299-310. [CrossRef]

12. Duffau, H.; Mandonnet, E. The "onco-functional balance" in surgery for diffuse low-grade glioma: Integrating the extent of resection with quality of life. Acta Neurochir. 2013, 155, 951-957. [CrossRef] 
13. Pope, W.B.; Sayre, J.; Perlina, A.; Villablanca, J.P.; Mischel, P.S.; Cloughesy, T.F. MR imaging correlates of survival in patients with high-grade gliomas. AJNR Am. J. Neuroradiol. 2005, 26, 2466-2474.

14. Molinaro, A.M.; Hervey-Jumper, S.; Morshed, R.A.; Young, J.; Han, S.J.; Chunduru, P.; Zhang, Y.; Phillips, J.J.; Shai, A.; Lafontaine, M.; et al. Association of maximal extent of resection of contrast-enhanced and non-contrast-enhanced tumor with survival within molecular subgroups of patients with newly diagnosed glioblastoma. JAMA Oncol. 2020. [CrossRef]

15. Brown, P.D.; Maurer, M.J.; Rummans, T.A.; Pollock, B.E.; Ballman, K.V.; Sloan, J.A.; Boeve, B.F.; Arusell, R.M.; Clark, M.M.; Buckner, J.C. A prospective study of quality of life in adults with newly diagnosed high-grade gliomas: The impact of the extent of resection on quality of life and survival. Neurosurgery 2005, 57, 495-504. [CrossRef]

16. Haj, A.; Doenitz, C.; Schebesch, K.M.; Ehrensberger, D.; Hau, P.; Putnik, K.; Riemenschneider, M.J.; Wendl, C.; Gerken, M.; Pukrop, T.; et al. Extent of resection in newly diagnosed glioblastoma: Impact of a specialized neuro-oncology care center. Brain Sci. 2017, 8, 5. [CrossRef]

17. Ammirati, M.; Vick, N.; Liao, Y.L.; Ciric, I.; Mikhael, M. Effect of the extent of surgical resection on survival and quality of life in patients with supratentorial glioblastomas and anaplastic astrocytomas. Neurosurgery 1987, 21, 201-206. [CrossRef]

18. Hervey-Jumper, S.L.; Berger, M.S. Evidence for Improving Outcome Through Extent of Resection. Neurosurg. Clin. N. Am. 2019, 30, 85-93. [CrossRef]

19. Szelenyi, A.; Bello, L.; Duffau, H.; Fava, E.; Feigl, G.C.; Galanda, M.; Neuloh, G.; Signorelli, F.; Sala, F.; Workgroup for intraoperative management in low-grade glioma surgery within the european low-grade glioma. Intraoperative electrical stimulation in awake craniotomy: Methodological aspects of current practice. Neurosurg. Focus 2010, 28, E7. [CrossRef]

20. Duffau, H. Lessons from brain mapping in surgery for low-grade glioma: Insights into associations between tumour and brain plasticity. Lancet. Neurol. 2005, 4, 476-486. [CrossRef]

21. De Witt Hamer, P.C.; Robles, S.G.; Zwinderman, A.H.; Duffau, H.; Berger, M.S. Impact of intraoperative stimulation brain mapping on glioma surgery outcome: A meta-analysis. J. Clin. Oncol. 2012, 30, 2559-2565. [CrossRef]

22. Mandonnet, E.; Winkler, P.A.; Duffau, H. Direct electrical stimulation as an input gate into brain functional networks: Principles, advantages and limitations. Acta Neurochir. 2010, 152, 185-193. [CrossRef]

23. Hervey-Jumper, S.L.; Berger, M.S. Maximizing safe resection of low- and high-grade glioma. J. Neurooncol. 2016, 130, 269-282. [CrossRef]

24. Van de Ruit, M.; Grey, M.J. The TMS map scales with increased stimulation intensity and muscle activation. Brain Topogr. 2016, 29, 56-66. [CrossRef]

25. Kallioniemi, E.; Julkunen, P. Alternative stimulation intensities for mapping cortical motor area with navigated TMS. Brain Topogr. 2016, 29, 395-404. [CrossRef]

26. Sinitsyn, D.O.; Chernyavskiy, A.Y.; Poydasheva, A.G.; Bakulin, I.S.; Suponeva, N.A.; Piradov, M.A. Optimization of the navigated TMS mapping algorithm for accurate estimation of cortical muscle representation characteristics. Brain Sci. 2019, 9, 88. [CrossRef]

27. Julkunen, P. Methods for estimating cortical motor representation size and location in navigated transcranial magnetic stimulation. J. Neurosci. Methods 2014, 232, 125-133. [CrossRef]

28. Wolf, S.L.; Butler, A.J.; Campana, G.I.; Parris, T.A.; Struys, D.M.; Weinstein, S.R.; Weiss, P. Intra-subject reliability of parameters contributing to maps generated by transcranial magnetic stimulation in able-bodied adults. Clin. Neurophysiol. 2004, 115, 1740-1747. [CrossRef]

29. Reijonen, J.; Pitkanen, M.; Kallioniemi, E.; Mohammadi, A.; Ilmoniemi, R.J.; Julkunen, P. Spatial extent of cortical motor hotspot in navigated transcranial magnetic stimulation. J. Neurosci. Methods 2020, 346, 108893. [CrossRef]

30. Ngomo, S.; Leonard, G.; Moffet, H.; Mercier, C. Comparison of transcranial magnetic stimulation measures obtained at rest and under active conditions and their reliability. J. Neurosci. Methods 2012, 205, 65-71. [CrossRef]

31. Kraus, D.; Gharabaghi, A. Neuromuscular plasticity: Disentangling stable and variable motor maps in the human sensorimotor cortex. Neural. Plast. 2016, 2016, 7365609. [CrossRef] [PubMed]

32. Coburger, J.; Musahl, C.; Weissbach, C.; Bittl, M. Navigated transcranial magnetic stimulation-guided resection of a left parietal tumor: Case report. Minim. Invasive Neurosurg. 2011, 54, 38-40. [CrossRef] [PubMed]

33. Picht, T.; Schmidt, S.; Woitzik, J.; Suess, O. Navigated brain stimulation for preoperative cortical mapping in paretic patients: Case report of a hemiplegic patient. Neurosurgery 2011, 68, E1475-E1480. [CrossRef] [PubMed]

34. Coburger, J.; Karhu, J.; Bittl, M.; Hopf, N.J. First preoperative functional mapping via navigated transcranial magnetic stimulation in a 3-year-old boy. J. Neurosurg. Pediatrics 2012, 9, 660-664. [CrossRef]

35. Picht, T.; Schmidt, S.; Brandt, S.; Frey, D.; Hannula, H.; Neuvonen, T.; Karhu, J.; Vajkoczy, P.; Suess, O. Preoperative functional mapping for rolandic brain tumor surgery: Comparison of navigated transcranial magnetic stimulation to direct cortical stimulation. Neurosurgery 2011, 69, 581-588. [CrossRef]

36. Coburger, J.; Musahl, C.; Henkes, H.; Horvath-Rizea, D.; Bittl, M.; Weissbach, C.; Hopf, N. Comparison of navigated transcranial magnetic stimulation and functional magnetic resonance imaging for preoperative mapping in rolandic tumor surgery. Neurosurg. Rev. 2013, 36, 65-76. [CrossRef]

37. Forster, M.T.; Hattingen, E.; Senft, C.; Gasser, T.; Seifert, V.; Szelenyi, A. Navigated transcranial magnetic stimulation and functional magnetic resonance imaging: Advanced adjuncts in preoperative planning for central region tumors. Neurosurgery 2011, 68, 1317-1325. [CrossRef] 
38. Krieg, S.M.; Shiban, E.; Buchmann, N.; Gempt, J.; Foerschler, A.; Meyer, B.; Ringel, F. Utility of presurgical navigated transcranial magnetic brain stimulation for the resection of tumors in eloquent motor areas. J. Neurosurg. 2012, 116, 994-1001. [CrossRef]

39. Krieg, S.M.; Shiban, E.; Buchmann, N.; Meyer, B.; Ringel, F. Presurgical navigated transcranial magnetic brain stimulation for recurrent gliomas in motor eloquent areas. Clin. Neurophysiol. 2013, 124, 522-527. [CrossRef]

40. Mangraviti, A.; Casali, C.; Cordella, R.; Legnani, F.G.; Mattei, L.; Prada, F.; Saladino, A.; Contarino, V.E.; Perin, A.; DiMeco, F. Practical assessment of preoperative functional mapping techniques: Navigated transcranial magnetic stimulation and functional magnetic resonance imaging. Neurol. Sci. 2013, 34, 1551-1557. [CrossRef]

41. Weiss Lucas, C.; Nettekoven, C.; Neuschmelting, V.; Oros-Peusquens, A.M.; Stoffels, G.; Viswanathan, S.; Rehme, A.K.; Faymonville, A.M.; Shah, N.J.; Langen, K.J.; et al. Invasive versus non-invasive mapping of the motor cortex. Hum. Brain Mapp. 2020, 41, 3970-3983. [CrossRef]

42. Tarapore, P.E.; Tate, M.C.; Findlay, A.M.; Honma, S.M.; Mizuiri, D.; Berger, M.S.; Nagarajan, S.S. Preoperative multimodal motor mapping: A comparison of magnetoencephalography imaging, navigated transcranial magnetic stimulation, and direct cortical stimulation. J. Neurosurg. 2012, 117, 354-362. [CrossRef]

43. Picht, T.; Schulz, J.; Hanna, M.; Schmidt, S.; Suess, O.; Vajkoczy, P. Assessment of the influence of navigated transcranial magnetic stimulation on surgical planning for tumors in or near the motor cortex. Neurosurgery 2012, 70, 1248-1257. [CrossRef]

44. Rizzo, V.; Terranova, C.; Conti, A.; Germano, A.; Alafaci, C.; Raffa, G.; Girlanda, P.; Tomasello, F.; Quartarone, A. Preoperative functional mapping for rolandic brain tumor surgery. Neurosci. Lett. 2014, 583, 136-141. [CrossRef]

45. Zdunczyk, A.; Fleischmann, R.; Schulz, J.; Vajkoczy, P.; Picht, T. The reliability of topographic measurements from navigated transcranial magnetic stimulation in healthy volunteers and tumor patients. Acta Neurochir. 2013, 155, 1309-1317. [CrossRef] [PubMed]

46. Sollmann, N.; Bulubas, L.; Tanigawa, N.; Zimmer, C.; Meyer, B.; Krieg, S.M. The variability of motor evoked potential latencies in neurosurgical motor mapping by preoperative navigated transcranial magnetic stimulation. BMC Neurosci. 2017, 18, 5. [CrossRef] [PubMed]

47. Sollmann, N.; Tanigawa, N.; Bulubas, L.; Sabih, J.; Zimmer, C.; Ringel, F.; Meyer, B.; Krieg, S.M. Clinical factors underlying the inter-individual variability of the resting motor threshold in navigated transcranial magnetic stimulation motor mapping. Brain Topogr. 2017, 30, 98-121. [CrossRef]

48. Lavrador, J.P.; Gioti, I.; Hoppe, S.; Jung, J.; Patel, S.; Gullan, R.; Ashkan, K.; Bhangoo, R.; Vergani, F. Altered motor excitability in patients with diffuse gliomas involving motor eloquent areas: The impact of tumor grading. Neurosurgery 2020, 88, 183-192. [CrossRef] [PubMed]

49. Lam, S.; Lucente, G.; Schneider, H.; Picht, T. TMS motor mapping in brain tumor patients: More robust maps with an increased resting motor threshold. Acta Neurochir. 2019, 161, 995-1002. [CrossRef]

50. Mirbagheri, A.; Schneider, H.; Zdunczyk, A.; Vajkoczy, P.; Picht, T. NTMS mapping of non-primary motor areas in brain tumour patients and healthy volunteers. Acta Neurochir. 2020, 162, 407-416. [CrossRef]

51. Krieg, S.M.; Buchmann, N.H.; Gempt, J.; Shiban, E.; Meyer, B.; Ringel, F. Diffusion tensor imaging fiber tracking using navigated brain stimulation-A feasibility study. Acta Neurochir. 2012, 154, 555-563. [CrossRef] [PubMed]

52. Frey, D.; Strack, V.; Wiener, E.; Jussen, D.; Vajkoczy, P.; Picht, T. A new approach for corticospinal tract reconstruction based on navigated transcranial stimulation and standardized fractional anisotropy values. NeuroImage 2012, 62, 1600-1609. [CrossRef] [PubMed]

53. Conti, A.; Raffa, G.; Granata, F.; Rizzo, V.; Germano, A.; Tomasello, F. Navigated transcranial magnetic stimulation for "somatotopic" tractography of the corticospinal tract. Neurosurgery 2014, 10 (Suppl. 4), 542-554. [CrossRef] [PubMed]

54. Weiss, C.; Tursunova, I.; Neuschmelting, V.; Lockau, H.; Nettekoven, C.; Oros-Peusquens, A.M.; Stoffels, G.; Rehme, A.K.; Faymonville, A.M.; Shah, N.J.; et al. Improved nTMS- and DTI-derived CST tractography through anatomical ROI seeding on anterior pontine level compared to internal capsule. NeuroImage. Clin. 2015, 7, 424-437. [CrossRef]

55. Weiss Lucas, C.; Tursunova, I.; Neuschmelting, V.; Nettekoven, C.; Oros-Peusquens, A.M.; Stoffels, G.; Faymonville, A.M.; Jon, S.N.; Langen, K.J.; Lockau, H.; et al. Functional MRI vs. navigated TMS to optimize M1 seed volume delineation for DTI tractography. A prospective study in patients with brain tumours adjacent to the corticospinal tract. NeuroImage. Clin. 2017, 13, 297-309. [CrossRef] [PubMed]

56. Munnich, T.; Klein, J.; Hattingen, E.; Noack, A.; Herrmann, E.; Seifert, V.; Senft, C.; Forster, M.T. Tractography verified by intraoperative magnetic resonance imaging and subcortical stimulation during tumor resection near the corticospinal tract. Oper. Neurosurg. (Hagerstown) 2019, 16, 197-210. [CrossRef] [PubMed]

57. Picht, T.; Schulz, J.; Vajkoczy, P. The preoperative use of navigated transcranial magnetic stimulation facilitates early resection of suspected low-grade gliomas in the motor cortex. Acta Neurochir. 2013, 155, 1813-1821. [CrossRef]

58. Frey, D.; Schilt, S.; Strack, V.; Zdunczyk, A.; Rosler, J.; Niraula, B.; Vajkoczy, P.; Picht, T. Navigated transcranial magnetic stimulation improves the treatment outcome in patients with brain tumors in motor eloquent locations. Neuro-oncol. 2014, 16, 1365-1372. [CrossRef]

59. Krieg, S.M.; Sabih, J.; Bulubasova, L.; Obermueller, T.; Negwer, C.; Janssen, I.; Shiban, E.; Meyer, B.; Ringel, F. Preoperative motor mapping by navigated transcranial magnetic brain stimulation improves outcome for motor eloquent lesions. Neuro-oncol. 2014, 16, 1274-1282. [CrossRef] 
60. Raffa, G.; Conti, A.; Scibilia, A.; Cardali, S.M.; Esposito, F.; Angileri, F.F.; La Torre, D.; Sindorio, C.; Abbritti, R.V.; Germano, A.; et al. The impact of diffusion tensor imaging fiber tracking of the corticospinal tract based on navigated transcranial magnetic stimulation on surgery of motor-eloquent brain lesions. Neurosurgery 2018, 83, 768-782. [CrossRef]

61. Krieg, S.M.; Sollmann, N.; Obermueller, T.; Sabih, J.; Bulubas, L.; Negwer, C.; Moser, T.; Droese, D.; Boeckh-Behrens, T.; Ringel, F.; et al. Changing the clinical course of glioma patients by preoperative motor mapping with navigated transcranial magnetic brain stimulation. BMC Cancer 2015, 15, 231. [CrossRef]

62. Picht, T.; Frey, D.; Thieme, S.; Kliesch, S.; Vajkoczy, P. Presurgical navigated TMS motor cortex mapping improves outcome in glioblastoma surgery: A controlled observational study. J. Neurooncol. 2016, 126, 535-543. [CrossRef] [PubMed]

63. Hendrix, P.; Senger, S.; Griessenauer, C.J.; Simgen, A.; Schwerdtfeger, K.; Oertel, J. Preoperative navigated transcranial magnetic stimulation in patients with motor eloquent lesions with emphasis on metastasis. Clin. Anat. 2016, 29, 925-931. [CrossRef] [PubMed]

64. Krieg, S.M.; Picht, T.; Sollmann, N.; Bahrend, I.; Ringel, F.; Nagarajan, S.S.; Meyer, B.; Tarapore, P.E. Resection of motor eloquent metastases aided by preoperative nTMS-based motor maps-comparison of two observational cohorts. Front. Oncol. 2016, 6, 261. [CrossRef] [PubMed]

65. Raffa, G.; Picht, T.; Scibilia, A.; Rosler, J.; Rein, J.; Conti, A.; Ricciardo, G.; Cardali, S.M.; Vajkoczy, P.; Germano, A. Surgical treatment of meningiomas located in the rolandic area: The role of navigated transcranial magnetic stimulation for preoperative planning, surgical strategy, and prediction of arachnoidal cleavage and motor outcome. J. Neurosurg. 2019, 1-12. [CrossRef]

66. Raffa, G.; Picht, T.; Angileri, F.F.; Youssef, M.; Conti, A.; Esposito, F.; Cardali, S.M.; Vajkoczy, P.; Germano, A. Surgery of malignant motor-eloquent gliomas guided by sodium-fluorescein and navigated transcranial magnetic stimulation: A novel technique to increase the maximal safe resection. J. Neurosurg. Sci. 2019, 63, 670-678. [CrossRef]

67. Raffa, G.; Scibilia, A.; Conti, A.; Cardali, S.M.; Rizzo, V.; Terranova, C.; Quattropani, M.C.; Marzano, G.; Ricciardo, G.; Vinci, S.L.; et al. Multimodal Surgical Treatment of High-Grade Gliomas in the Motor Area: The impact of the combination of navigated transcranial magnetic stimulation and fluorescein-guided resection. World Neurosurg. 2019, 128, e378-e390. [CrossRef]

68. Moser, T.; Bulubas, L.; Sabih, J.; Conway, N.; Wildschutz, N.; Sollmann, N.; Meyer, B.; Ringel, F.; Krieg, S.M. Resection of navigated transcranial magnetic stimulation-positive prerolandic motor areas causes permanent impairment of motor function. Neurosurgery 2017, 81, 99-110. [CrossRef]

69. Picht, T.; Strack, V.; Schulz, J.; Zdunczyk, A.; Frey, D.; Schmidt, S.; Vajkoczy, P. Assessing the functional status of the motor system in brain tumor patients using transcranial magnetic stimulation. Acta Neurochirur. 2012, 154, 2075-2081. [CrossRef]

70. Rosenstock, T.; Grittner, U.; Acker, G.; Schwarzer, V.; Kulchytska, N.; Vajkoczy, P.; Picht, T. Risk stratification in motor area-related glioma surgery based on navigated transcranial magnetic stimulation data. J. Neurosurg. 2017, 126, 1227-1237. [CrossRef]

71. Sollmann, N.; Wildschuetz, N.; Kelm, A.; Conway, N.; Moser, T.; Bulubas, L.; Kirschke, J.S.; Meyer, B.; Krieg, S.M. Associations between clinical outcome and navigated transcranial magnetic stimulation characteristics in patients with motor-eloquent brain lesions: A combined navigated transcranial magnetic stimulation-diffusion tensor imaging fiber tracking approach. J. Neurosurg. 2018, 128, 800-810. [CrossRef] [PubMed]

72. Rosenstock, T.; Giampiccolo, D.; Schneider, H.; Runge, S.J.; Bahrend, I.; Vajkoczy, P.; Picht, T. Specific DTI seeding and diffusivityanalysis improve the quality and prognostic value of TMS-based deterministic DTI of the pyramidal tract. NeuroImage. Clin. 2017, 16, 276-285. [CrossRef] [PubMed]

73. Seidel, K.; Hani, L.; Lutz, K.; Zbinden, C.; Redmann, A.; Consuegra, A.; Raabe, A.; Schucht, P. Postoperative navigated transcranial magnetic stimulation to predict motor recovery after surgery of tumors in motor eloquent areas. Clin. Neurophysiol. 2019, 130, 952-959. [CrossRef]

74. Neuschmelting, V.; Weiss Lucas, C.; Stoffels, G.; Oros-Peusquens, A.M.; Lockau, H.; Shah, N.J.; Langen, K.J.; Goldbrunner, R.; Grefkes, C. Multimodal imaging in malignant brain tumors: Enhancing the preoperative risk evaluation for motor deficits with a combined hybrid MRI-PET and navigated transcranial magnetic stimulation approach. AJNR Am. J. Neuroradiol. 2016, 37, 266-273. [CrossRef] [PubMed]

75. Forster, M.T.; Senft, C.; Hattingen, E.; Lorei, M.; Seifert, V.; Szelenyi, A. Motor cortex evaluation by nTMS after surgery of central region tumors: A feasibility study. Acta Neurochir. 2012, 154, 1351-1359. [CrossRef] [PubMed]

76. Takahashi, S.; Vajkoczy, P.; Picht, T. Navigated transcranial magnetic stimulation for mapping the motor cortex in patients with rolandic brain tumors. Neurosur. Focus 2013, 34, E3. [CrossRef] [PubMed]

77. Bulubas, L.; Sabih, J.; Wohlschlaeger, A.; Sollmann, N.; Hauck, T.; Ille, S.; Ringel, F.; Meyer, B.; Krieg, S.M. Motor areas of the frontal cortex in patients with motor eloquent brain lesions. J. Neurosurg. 2016, 1-12. [CrossRef]

78. Bulubas, L.; Sollmann, N.; Tanigawa, N.; Zimmer, C.; Meyer, B.; Krieg, S.M. Reorganization of motor representations in patients with brain lesions: A navigated transcranial magnetic stimulation study. Brain Topogr. 2018, 31, 288-299. [CrossRef] [PubMed]

79. Barz, A.; Noack, A.; Baumgarten, P.; Seifert, V.; Forster, M.T. Motor cortex reorganization in patients with glioma assessed by repeated navigated transcranial magnetic stimulation- A longitudinal study. World Neurosurg. 2018, 112, e442-e453. [CrossRef] [PubMed]

80. Conway, N.; Wildschuetz, N.; Moser, T.; Bulubas, L.; Sollmann, N.; Tanigawa, N.; Meyer, B.; Krieg, S.M. Cortical plasticity of motor-eloquent areas measured by navigated transcranial magnetic stimulation in patients with glioma. J. Neurosurg. 2017, 1-11. [CrossRef] 
81. Sollmann, N.; Laub, T.; Kelm, A.; Albers, L.; Kirschke, J.S.; Combs, S.E.; Meyer, B.; Krieg, S.M. Predicting brain tumor regrowth in relation to motor areas by functional brain mapping. Neurooncol. Pract. 2018, 5, 82-95. [CrossRef] [PubMed]

82. Sollmann, N.; Meyer, B.; Krieg, S.M. Implementing functional preoperative mapping in the clinical routine of a neurosurgical department: Technical note. World Neurosurg. 2017, 103, 94-105. [CrossRef]

83. Conti, A.; Pontoriero, A.; Ricciardi, G.K.; Granata, F.; Vinci, S.; Angileri, F.F.; Pergolizzi, S.; Alafaci, C.; Rizzo, V.; Quartarone, A.; et al. Integration of functional neuroimaging in CyberKnife radiosurgery: Feasibility and dosimetric results. Neurosur. Focus 2013, 34, E5. [CrossRef] [PubMed]

84. Diehl, C.D.; Schwendner, M.J.; Sollmann, N.; Oechsner, M.; Meyer, B.; Combs, S.E.; Krieg, S.M. Application of presurgical navigated transcranial magnetic stimulation motor mapping for adjuvant radiotherapy planning in patients with high-grade gliomas. Radiother. Oncol. 2019, 138, 30-37. [CrossRef]

85. Schwendner, M.J.; Sollmann, N.; Diehl, C.D.; Oechsner, M.; Meyer, B.; Krieg, S.M.; Combs, S.E. The role of navigated transcranial magnetic stimulation motor mapping in adjuvant radiotherapy planning in patients with supratentorial brain metastases. Front. Oncol. 2018, 8, 424. [CrossRef]

86. Picht, T.; Schilt, S.; Frey, D.; Vajkoczy, P.; Kufeld, M. Integration of navigated brain stimulation data into radiosurgical planning: Potential benefits and dangers. Acta Neurochir. 2014, 156, 1125-1133. [CrossRef]

87. Tokarev, A.S.; Rak, V.A.; Sinkin, M.V.; Evdokimova, O.L.; Stepanov, V.N.; Koynash, G.V.; Krieg, S.M.; Krylov, V.V. Appliance of navigated transcranial magnetic stimulation in radiosurgery for brain metastases. J. Clin. Neurophysiol. 2020, 37, 50-55. [CrossRef]

88. Hendrix, P.; Senger, S.; Griessenauer, C.J.; Simgen, A.; Linsler, S.; Oertel, J. Preoperative navigated transcranial magnetic stimulation and tractography in transparietal approach to the trigone of the lateral ventricle. J. Clin. Neurosci. 2017, 41, 154-161. [CrossRef] [PubMed]

89. Hendrix, P.; Senger, S.; Griessenauer, C.J.; Simgen, A.; Linsler, S.; Oertel, J. Preoperative navigated transcranial magnetic stimulation and tractography to guide endoscopic cystoventriculostomy: A technical note and case report. World Neurosurg. 2018, 109, 209-217. [CrossRef] [PubMed]

90. Bartek, J., Jr.; Cooray, G.; Islam, M.; Jensdottir, M. Stereotactic brain biopsy in eloquent areas assisted by navigated transcranial magnetic stimulation: A technical case report. Oper. Neurosurg. 2019, 17, E124-E129. [CrossRef]

91. Schramm, S.; Haddad, A.F.; Chyall, L.; Krieg, S.M.; Sollmann, N.; Tarapore, P.E. Navigated TMS in the ICU: Introducing motor mapping to the critical care setting. Brain Sci. 2020, 10, 1005. [CrossRef] [PubMed]

92. Ferreira Pinto, P.; Nigri, F.; Caparelli-Daquer, E.M.; Viana, J.D.S. Computed tomography-guided navigated transcranial magnetic stimulation for preoperative brain motor mapping in brain lesion resection: A case report. Surg. Neurol. Int. 2019, 10, 134. [CrossRef]

93. Krieg, S.M.; Lioumis, P.; Makela, J.P.; Wilenius, J.; Karhu, J.; Hannula, H.; Savolainen, P.; Lucas, C.W.; Seidel, K.; Laakso, A.; et al. Protocol for motor and language mapping by navigated TMS in patients and healthy volunteers; workshop report. Acta Neurochir. 2017, 159, 1187-1195. [CrossRef] [PubMed]

94. Te, M.; Baptista, A.F.; Chipchase, L.S.; Schabrun, S.M. Primary motor cortex organization is altered in persistent patellofemoral pain. Pain Med. 2017, 18, 2224-2234. [CrossRef]

95. Saisanen, L.; Kononen, M.; Niskanen, E.; Lakka, T.; Lintu, N.; Vanninen, R.; Julkunen, P.; Maatta, S. Primary hand motor representation areas in healthy children, preadolescents, adolescents, and adults. Neuroimage 2021, 228. [CrossRef] [PubMed]

96. Novikov, P.A.; Nazarova, M.A.; Nikulin, V.V. TMSmap—Software for quantitative analysis of TMS mapping results. Front. Hum. Neurosci. 2018, 12, 239. [CrossRef] [PubMed]

97. Melgari, J.M.; Pasqualetti, P.; Pauri, F.; Rossini, P.M. Muscles in "concert": Study of primary motor cortex upper limb functional topography. PLoS ONE 2008, 3, e3069. [CrossRef] [PubMed]

98. Nazarova, M.; Novikov, P.; Ivanina, E.; Kozlova, K.; Dobrynina, L.; Nikulin, V.V. Mapping of multiple muscles with transcranial magnetic stimulation: Absolute and relative test-retest reliability. Hum. Brain Mapp. 2021, 42, 2508-2528. [CrossRef] [PubMed]

99. Davies, J.L. Using transcranial magnetic stimulation to map the cortical representation of lower-limb muscles. Clin. Neurophysiol. Pract. 2020, 5, 87-99. [CrossRef]

100. Castrillon, G.; Sollmann, N.; Kurcyus, K.; Razi, A.; Krieg, S.M.; Riedl, V. The physiological effects of noninvasive brain stimulation fundamentally differ across the human cortex. Sci. Adv. 2020, 6, eaay2739. [CrossRef]

101. Zhang, H.; Sollmann, N.; Castrillon, G.; Kurcyus, K.; Meyer, B.; Zimmer, C.; Krieg, S.M. Intranetwork and internetwork effects of navigated transcranial magnetic stimulation using low- and high-frequency pulse application to the dorsolateral prefrontal cortex: A combined rTMS-fMRI approach. J. Clin. Neurophysiol. 2020, 37, 131-139. [CrossRef] [PubMed]

102. Tsao, H.; Galea, M.P.; Hodges, P.W. Reorganization of the motor cortex is associated with postural control deficits in recurrent low back pain. Brain 2008, 131, 2161-2171. [CrossRef] [PubMed]

103. Groppa, S.; Oliviero, A.; Eisen, A.; Quartarone, A.; Cohen, L.G.; Mall, V.; Kaelin-Lang, A.; Mima, T.; Rossi, S.; Thickbroom, G.W.; et al. A practical guide to diagnostic transcranial magnetic stimulation: Report of an IFCN committee. Clin. Neurophysiol. 2012, 123, 858-882. [CrossRef] [PubMed]

104. Richter, L.; Neumann, G.; Oung, S.; Schweikard, A.; Trillenberg, P. Optimal coil orientation for transcranial magnetic stimulation. PLoS ONE 2013, 8, e60358. [CrossRef] [PubMed] 
105. Reijonen, J.; Saisanen, L.; Kononen, M.; Mohammadi, A.; Julkunen, P. The effect of coil placement and orientation on the assessment of focal excitability in motor mapping with navigated transcranial magnetic stimulation. J. Neurosci. Methods 2020, 331, 108521. [CrossRef]

106. Saisanen, L.; Julkunen, P.; Kemppainen, S.; Danner, N.; Immonen, A.; Mervaala, E.; Maatta, S.; Muraja-Murro, A.; Kononen, M. Locating and outlining the cortical motor representation areas of facial muscles with navigated transcranial magnetic stimulation. Neurosurgery 2015, 77, 394-405. [CrossRef]

107. Thordstein, M.; Saar, K.; Pegenius, G.; Elam, M. Individual effects of varying stimulation intensity and response criteria on area of activation for different muscles in humans. A study using navigated transcranial magnetic stimulation. Brain Stimul. 2013, 6, 49-53. [CrossRef]

108. Mills, K.R.; Nithi, K.A. Corticomotor threshold to magnetic stimulation: Normal values and repeatability. Muscle Nerve 1997, 20, 570-576. [CrossRef]

109. Awiszus, F. TMS and threshold hunting. Suppl. Clin. Neurophysiol. 2003, 56, 13-23.

110. Julkunen, P. Mobile application for adaptive threshold hunting in transcranial magnetic stimulation. IEEE Trans. Neural. Syst. Rehabil. Eng. 2019, 27, 1504-1510. [CrossRef]

111. Engelhardt, M.; Schneider, H.; Gast, T.; Picht, T. Estimation of the resting motor threshold (RMT) in transcranial magnetic stimulation using relative-frequency and threshold-hunting methods in brain tumor patients. Acta Neurochir. 2019, 161, 1845-1851. [CrossRef]

112. Tranulis, C.; Gueguen, B.; Pham-Scottez, A.; Vacheron, M.N.; Cabelguen, G.; Costantini, A.; Valero, G.; Galinovski, A. Motor threshold in transcranial magnetic stimulation: Comparison of three estimation methods. Neurophysiol. Clin. 2006, 36, 1-7. [CrossRef]

113. Dissanayaka, T.; Zoghi, M.; Farrell, M.; Egan, G.; Jaberzadeh, S. Comparison of Rossini-Rothwell and adaptive threshold-hunting methods on the stability of TMS induced motor evoked potentials amplitudes. J. Neurosci. Res. 2018, 96, 1758-1765. [CrossRef] [PubMed]

114. Ah Sen, C.B.; Fassett, H.J.; El-Sayes, J.; Turco, C.V.; Hameer, M.M.; Nelson, A.J. Active and resting motor threshold are efficiently obtained with adaptive threshold hunting. PLoS ONE 2017, 12, e0186007. [CrossRef] [PubMed]

115. Silbert, B.I.; Patterson, H.I.; Pevcic, D.D.; Windnagel, K.A.; Thickbroom, G.W. A comparison of relative-frequency and thresholdhunting methods to determine stimulus intensity in transcranial magnetic stimulation. Clin. Neurophysiol. 2013, 124, 708-712. [CrossRef] [PubMed]

116. Saisanen, L.; Julkunen, P.; Lakka, T.; Lindi, V.; Kononen, M.; Maatta, S. Development of corticospinal motor excitability and cortical silent period from mid-childhood to adulthood-A navigated TMS study. Neurophysiol. Clin. 2018, 48, 65-75. [CrossRef] [PubMed]

117. Pitcher, J.B.; Doeltgen, S.H.; Goldsworthy, M.R.; Schneider, L.A.; Vallence, A.M.; Smith, A.E.; Semmler, J.G.; McDonnell, M.N.; Ridding, M.C. A comparison of two methods for estimating $50 \%$ of the maximal motor evoked potential. Clin. Neurophysiol. 2015, 126, 2337-2341. [CrossRef]

118. Malcolm, M.P.; Triggs, W.J.; Light, K.E.; Shechtman, O.; Khandekar, G.; Gonzalez Rothi, L.J. Reliability of motor cortex transcranial magnetic stimulation in four muscle representations. Clin. Neurophysiol. 2006, 117, 1037-1046. [CrossRef]

119. Saisanen, L.; Kononen, M.; Julkunen, P.; Maatta, S.; Vanninen, R.; Immonen, A.; Jutila, L.; Kalviainen, R.; Jaaskelainen, J.E.; Mervaala, E. Non-invasive preoperative localization of primary motor cortex in epilepsy surgery by navigated transcranial magnetic stimulation. Epilepsy Res. 2010, 92, 134-144. [CrossRef]

120. Schieber, M.H. Constraints on somatotopic organization in the primary motor cortex. J. Neurophysiol. 2001, 86, $2125-2143$. [CrossRef]

121. Thickbroom, G.W.; Sammut, R.; Mastaglia, F.L. Magnetic stimulation mapping of motor cortex: Factors contributing to map area. Electroencephalogr. Clin. Neurophysiol. 1998, 109, 79-84. [CrossRef]

122. Thielscher, A.; Kammer, T. Electric field properties of two commercial figure-8 coils in TMS: Calculation of focality and efficiency. Clin. Neurophysiol. 2004, 115, 1697-1708. [CrossRef] [PubMed]

123. Sommer, M.; Alfaro, A.; Rummel, M.; Speck, S.; Lang, N.; Tings, T.; Paulus, W. Half sine, monophasic and biphasic transcranial magnetic stimulation of the human motor cortex. Clin. Neurophysiol. 2006, 117, 838-844. [CrossRef]

124. Hannah, R.; Rothwell, J.C. Pulse duration as well as current direction determines the specificity of transcranial magnetic stimulation of motor cortex during contraction. Brain Stimul. 2017, 10, 106-115. [CrossRef]

125. Saisanen, L.; Julkunen, P.; Niskanen, E.; Danner, N.; Hukkanen, T.; Lohioja, T.; Nurkkala, J.; Mervaala, E.; Karhu, J.; Kononen, M. Motor potentials evoked by navigated transcranial magnetic stimulation in healthy subjects. J. Clin. Neurophysiol. 2008, 25, 367-372. [CrossRef] [PubMed]

126. Danner, N.; Julkunen, P.; Kononen, M.; Saisanen, L.; Nurkkala, J.; Karhu, J. Navigated transcranial magnetic stimulation and computed electric field strength reduce stimulator-dependent differences in the motor threshold. J. Neurosci. Methods 2008, 174, 116-122. [CrossRef]

127. Nieminen, J.O.; Koponen, L.M.; Ilmoniemi, R.J. Experimental characterization of the electric field distribution induced by TMS devices. Brain Stimul. 2015, 8, 582-589. [CrossRef]

128. Zacharias, L.R.; Peres, A.S.C.; Souza, V.H.; Conforto, A.B.; Baffa, O. Method to assess the mismatch between the measured and nominal parameters of transcranial magnetic stimulation devices. J. Neurosci. Methods 2019, 322, 83-87. [CrossRef] [PubMed] 
129. McConnell, K.A.; Nahas, Z.; Shastri, A.; Lorberbaum, J.P.; Kozel, F.A.; Bohning, D.E.; George, M.S. The transcranial magnetic stimulation motor threshold depends on the distance from coil to underlying cortex: A replication in healthy adults comparing two methods of assessing the distance to cortex. Biol. Psychiatry 2001, 49, 454-459. [CrossRef]

130. Stokes, M.G.; Chambers, C.D.; Gould, I.C.; Henderson, T.R.; Janko, N.E.; Allen, N.B.; Mattingley, J.B. Simple metric for scaling motor threshold based on scalp-cortex distance: Application to studies using transcranial magnetic stimulation. J. Neurophysiol. 2005, 94, 4520-4527. [CrossRef] [PubMed]

131. Stokes, M.G.; Chambers, C.D.; Gould, I.C.; English, T.; McNaught, E.; McDonald, O.; Mattingley, J.B. Distance-adjusted motor threshold for transcranial magnetic stimulation. Clin. Neurophysiol. 2007, 118, 1617-1625. [CrossRef]

132. Cai, W.; George, J.S.; Chambers, C.D.; Stokes, M.G.; Verbruggen, F.; Aron, A.R. Stimulating deep cortical structures with the batwing coil: How to determine the intensity for transcranial magnetic stimulation using coil-cortex distance. J. Neurosci. Methods 2012, 204, 238-241. [CrossRef] [PubMed]

133. Herbsman, T.; Forster, L.; Molnar, C.; Dougherty, R.; Christie, D.; Koola, J.; Ramsey, D.; Morgan, P.S.; Bohning, D.E.; George, M.S.; et al. Motor threshold in transcranial magnetic stimulation: The impact of white matter fiber orientation and skull-to-cortex distance. Hum. Brain Mapp. 2009, 30, 2044-2055. [CrossRef] [PubMed]

134. Rosanova, M.; Casali, A.; Bellina, V.; Resta, F.; Mariotti, M.; Massimini, M. Natural frequencies of human corticothalamic circuits. J. Neurosci. 2009, 29, 7679-7685. [CrossRef] [PubMed]

135. Janssen, A.M.; Oostendorp, T.F.; Stegeman, D.F. The effect of local anatomy on the electric field induced by TMS: Evaluation at 14 different target sites. Med. Biol. Eng. Comput. 2014, 52, 873-883. [CrossRef]

136. Julkunen, P.; Saisanen, L.; Danner, N.; Awiszus, F.; Kononen, M. Within-subject effect of coil-to-cortex distance on cortical electric field threshold and motor evoked potentials in transcranial magnetic stimulation. J. Neurosci. Methods 2012, 206, 158-164. [CrossRef]

137. Danner, N.; Kononen, M.; Saisanen, L.; Laitinen, R.; Mervaala, E.; Julkunen, P. Effect of individual anatomy on resting motor threshold-computed electric field as a measure of cortical excitability. J. Neurosci. Methods 2012, 203, 298-304. [CrossRef] [PubMed]

138. Laakso, I.; Hirata, A.; Ugawa, Y. Effects of coil orientation on the electric field induced by TMS over the hand motor area. Phys. Med. Biol. 2014, 59, 203-218. [CrossRef]

139. Nazarova, M.; Kulikova, S.; Piradov, M.A.; Limonova, A.S.; Dobrynina, L.A.; Konovalov, R.N.; Novikov, P.A.; Sehm, B.; Villringer, A.; Saltykova, A.; et al. Multimodal assessment of the motor system in patients with chronic ischemic stroke. Stroke 2021, 52, 241-249. [CrossRef]

140. Schabrun, S.M.; Ridding, M.C. The influence of correlated afferent input on motor cortical representations in humans. Exp. Brain Res. 2007, 183, 41-49. [CrossRef]

141. Ziemann, U.; Ilic, T.V.; Alle, H.; Meintzschel, F. Cortico-motoneuronal excitation of three hand muscles determined by a novel penta-stimulation technique. Brain 2004, 127, 1887-1898. [CrossRef]

142. Knecht, S.; Sommer, J.; Deppe, M.; Steinstrater, O. Scalp position and efficacy of transcranial magnetic stimulation. Clin. Neurophysiol 2005, 116, 1988-1993. [CrossRef] [PubMed]

143. Davis, N.J. Variance in cortical depth across the brain surface: Implications for transcranial stimulation of the brain. Eur. J. Neurosci. 2021, 53, 996-1007. [CrossRef] [PubMed]

144. Trillenberg, P.; Bremer, S.; Oung, S.; Erdmann, C.; Schweikard, A.; Richter, L. Variation of stimulation intensity in transcranial magnetic stimulation with depth. J. Neurosci. Methods 2012, 211, 185-190. [CrossRef]

145. Foltys, H.; Krings, T.; Meister, I.G.; Sparing, R.; Boroojerdi, B.; Thron, A.; Topper, R. Motor representation in patients rapidly recovering after stroke: A functional magnetic resonance imaging and transcranial magnetic stimulation study. Clin. Neurophysiol. 2003, 114, 2404-2415. [CrossRef]

146. Schabrun, S.M.; Hodges, P.W.; Vicenzino, B.; Jones, E.; Chipchase, L.S. Novel adaptations in motor cortical maps: The relation to persistent elbow pain. Med. Sci. Sports Exerc. 2015, 47, 681-690. [CrossRef]

147. Nicolini, C.; Harasym, D.; Turco, C.V.; Nelson, A.J. Human motor cortical organization is influenced by handedness. Cortex 2019, 115, 172-183. [CrossRef]

148. Pitkanen, M.; Kallioniemi, E.; Julkunen, P. Extent and Location of the excitatory and inhibitory cortical hand representation maps: A navigated transcranial magnetic stimulation study. Brain Topogr. 2015, 28, 657-665. [CrossRef]

149. Uy, J.; Ridding, M.C.; Miles, T.S. Stability of maps of human motor cortex made with transcranial magnetic stimulation. Brain Topogr. 2002, 14, 293-297. [CrossRef] [PubMed]

150. Marconi, B.; Pecchioli, C.; Koch, G.; Caltagirone, C. Functional overlap between hand and forearm motor cortical representations during motor cognitive tasks. Clin. Neurophysiol. 2007, 118, 1767-1775. [CrossRef]

151. Kleim, J.A.; Kleim, E.D.; Cramer, S.C. Systematic assessment of training-induced changes in corticospinal output to hand using frameless stereotaxic transcranial magnetic stimulation. Nat. Protoc. 2007, 2, 1675-1684. [CrossRef]

152. Schabrun, S.M.; Stinear, C.M.; Byblow, W.D.; Ridding, M.C. Normalizing motor cortex representations in focal hand dystonia. Cereb. Cortex 2009, 19, 1968-1977. [CrossRef] [PubMed]

153. Borghetti, D.; Sartucci, F.; Petacchi, E.; Guzzetta, A.; Piras, M.F.; Murri, L.; Cioni, G. Transcranial magnetic stimulation mapping: A model based on spline interpolation. Brain Res. Bull. 2008, 77, 143-148. [CrossRef]

154. Cavaleri, R.; Schabrun, S.M.; Chipchase, L.S. Determining the optimal number of stimuli per cranial site during transcranial magnetic stimulation mapping. Neurosci. J. 2017, 2017, 6328569. [CrossRef] 
155. Chernyavskiy, A.Y.; Sinitsyn, D.O.; Poydasheva, A.G.; Bakulin, I.S.; Suponeva, N.A.; Piradov, M.A. Accuracy of Estimating the Area of Cortical Muscle Representations from TMS Mapping Data Using Voronoi Diagrams. Brain Topogr. 2019, 32, 859-872. [CrossRef]

156. Goldsworthy, M.R.; Hordacre, B.; Ridding, M.C. Minimum number of trials required for within- and between-session reliability of TMS measures of corticospinal excitability. Neuroscience 2016, 320, 205-209. [CrossRef]

157. Chang, W.H.; Fried, P.J.; Saxena, S.; Jannati, A.; Gomes-Osman, J.; Kim, Y.H.; Pascual-Leone, A. Optimal number of pulses as outcome measures of neuronavigated transcranial magnetic stimulation. Clin. Neurophysiol. 2016, 127, 2892-2897. [CrossRef]

158. Schmidt, S.; Bathe-Peters, R.; Fleischmann, R.; Ronnefarth, M.; Scholz, M.; Brandt, S.A. Nonphysiological factors in navigated TMS studies; confounding covariates and valid intracortical estimates. Hum. Brain Mapp. 2015, 36, 40-49. [CrossRef] [PubMed]

159. De Santo, G.; Tanner, P.; Witt, T.N.; Gebrecht, V.; Bötzel, K. Investigation of coil tilt by transcranial magnetic stimulation (TMS) of the motor cortex using a navigation system. Klin. Neurophysiol. 2006, 37, A38. [CrossRef]

160. Raffin, E.; Pellegrino, G.; Di Lazzaro, V.; Thielscher, A.; Siebner, H.R. Bringing transcranial mapping into shape: Sulcus-aligned mapping captures motor somatotopy in human primary motor hand area. Neuroimage 2015, 120, 164-175. [CrossRef] [PubMed]

161. Kallioniemi, E.; Kononen, M.; Julkunen, P. Repeatability of functional anisotropy in navigated transcranial magnetic stimulationcoil-orientation versus response. Neuroreport 2015, 26, 515-521. [CrossRef]

162. Kallioniemi, E.; Kononen, M.; Saisanen, L.; Grohn, H.; Julkunen, P. Functional neuronal anisotropy assessed with neuronavigated transcranial magnetic stimulation. J. Neurosci. Methods 2015, 256, 82-90. [CrossRef] [PubMed]

163. Balslev, D.; Braet, W.; McAllister, C.; Miall, R.C. Inter-individual variability in optimal current direction for transcranial magnetic stimulation of the motor cortex. J. Neurosci. Methods 2007, 162, 309-313. [CrossRef] [PubMed]

164. Gomez-Tames, J.; Hamasaka, A.; Laakso, I.; Hirata, A.; Ugawa, Y. Atlas of optimal coil orientation and position for TMS: A computational study. Brain Stimul. 2018, 11, 839-848. [CrossRef]

165. Opitz, A.; Windhoff, M.; Heidemann, R.M.; Turner, R.; Thielscher, A. How the brain tissue shapes the electric field induced by transcranial magnetic stimulation. Neuroimage 2011, 58, 849-859. [CrossRef]

166. Niskanen, E.; Julkunen, P.; Saisanen, L.; Vanninen, R.; Karjalainen, P.; Kononen, M. Group-level variations in motor representation areas of thenar and anterior tibial muscles: Navigated Transcranial Magnetic Stimulation Study. Hum. Brain Mapp. 2010, 31, 1272-1280. [CrossRef] [PubMed]

167. Ahdab, R.; Ayache, S.S.; Brugieres, P.; Farhat, W.H.; Lefaucheur, J.P. The hand motor hotspot is not always located in the hand knob: A neuronavigated transcranial magnetic stimulation study. Brain Topogr. 2016, 29, 590-597. [CrossRef] [PubMed]

168. Julkunen, P.; Saisanen, L.; Danner, N.; Niskanen, E.; Hukkanen, T.; Mervaala, E.; Kononen, M. Comparison of navigated and non-navigated transcranial magnetic stimulation for motor cortex mapping, motor threshold and motor evoked potentials. Neuroimage 2009, 44, 790-795. [CrossRef]

169. Rossini, P.M.; Burke, D.; Chen, R.; Cohen, L.G.; Daskalakis, Z.; Di Iorio, R.; Di Lazzaro, V.; Ferreri, F.; Fitzgerald, P.B.; George, M.S.; et al. Non-invasive electrical and magnetic stimulation of the brain, spinal cord, roots and peripheral nerves: Basic principles and procedures for routine clinical and research application. An updated report from an I.F.C.N. Committee. Clin. Neurophysiol. 2015, 126, 1071-1107. [CrossRef]

170. Sollmann, N.; Hauck, T.; Obermuller, T.; Hapfelmeier, A.; Meyer, B.; Ringel, F.; Krieg, S.M. Inter- and intraobserver variability in motor mapping of the hotspot for the abductor policis brevis muscle. BMC Neurosci. 2013, 14, 1-7. [CrossRef]

171. Wassermann, E.M.; McShane, L.M.; Hallett, M.; Cohen, L.G. Noninvasive mapping of muscle representations in human motor cortex. Electroencephalogr. Clin. Neurophysiol. 1992, 85, 1-8. [CrossRef]

172. Saisanen, L.; Maatta, S.; Julkunen, P.; Niskanen, E.; Kallioniemi, E.; Grohn, H.; Kemppainen, S.; Lakka, T.A.; Lintu, N.; Eloranta, A.M.; et al. Functional and structural asymmetry in primary motor cortex in Asperger syndrome: A navigated TMS and imaging study. Brain Topogr. 2019, 32, 504-518. [CrossRef]

173. Jonker, Z.D.; van der Vliet, R.; Hauwert, C.M.; Gaiser, C.; Tulen, J.H.M.; van der Geest, J.N.; Donchin, O.; Ribbers, G.M.; Frens, M.A.; Selles, R.W. TMS motor mapping: Comparing the absolute reliability of digital reconstruction methods to the golden standard. Brain Stimul. 2019, 12, 309-313. [CrossRef]

174. Sollmann, N.; Zhang, H.; Kelm, A.; Schroder, A.; Meyer, B.; Pitkanen, M.; Julkunen, P.; Krieg, S.M. Paired-pulse navigated TMS is more effective than single-pulse navigated TMS for mapping upper extremity muscles in brain tumor patients. Clinical Neuropsychol. 2020, 131, 2887-2898. [CrossRef]

175. Zhang, H.; Julkunen, P.; Schroder, A.; Kelm, A.; Ille, S.; Zimmer, C.; Pitkanen, M.; Meyer, B.; Krieg, S.M.; Sollmann, N. Shortinterval intracortical facilitation improves efficacy in nTMS motor mapping of lower extremity muscle representations in patients with supra-tentorial brain tumors. Cancers 2020, 12, 3233. [CrossRef] [PubMed]

176. Jussen, D.; Zdunczyk, A.; Schmidt, S.; Rosler, J.; Buchert, R.; Julkunen, P.; Karhu, J.; Brandt, S.; Picht, T.; Vajkoczy, P. Motor plasticity after extra-intracranial bypass surgery in occlusive cerebrovascular disease. Neurology 2016, 87, 27-35. [CrossRef] [PubMed]

177. Ille, S.; Kelm, A.; Schroeder, A.; Albers, L.E.; Negwer, C.; Butenschoen, V.M.; Sollmann, N.; Picht, T.; Vajkoczy, P.; Meyer, B.; et al. Navigated repetitive transcranial magnetic stimulation improves the outcome of postsurgical paresis in glioma patients-A randomized, double-blinded trial. Brain Stimul. 2021. [CrossRef] 
178. Sollmann, N.; Zhang, H.; Fratini, A.; Wildschuetz, N.; Ille, S.; Schroder, A.; Zimmer, C.; Meyer, B.; Krieg, S.M. Risk assessment by presurgical tractography using navigated TMS maps in patients with highly motor- or language-eloquent brain tumors. Cancers 2020, 12, 1264. [CrossRef]

179. Sollmann, N.; Giglhuber, K.; Tussis, L.; Meyer, B.; Ringel, F.; Krieg, S.M. nTMS-based DTI fiber tracking for language pathways correlates with language function and aphasia-A case report. Clin. Neurol. Neurosurg. 2015, 136, 25-28. [CrossRef] [PubMed]

180. Holodny, A.I.; Schulder, M.; Liu, W.C.; Maldjian, J.A.; Kalnin, A.J. Decreased BOLD functional MR activation of the motor and sensory cortices adjacent to a glioblastoma multiforme: Implications for image-guided neurosurgery. AJNR Am. J. Neuroradiol. 1999, 20, 609-612.

181. Holodny, A.I.; Schulder, M.; Liu, W.C.; Wolko, J.; Maldjian, J.A.; Kalnin, A.J. The effect of brain tumors on BOLD functional MR imaging activation in the adjacent motor cortex: Implications for image-guided neurosurgery. AJNR Am. J. Neuroradiol. 2000, 21, 1415-1422. [PubMed]

182. Gerhardt, J.; Sollmann, N.; Hiepe, P.; Kirschke, J.S.; Meyer, B.; Krieg, S.M.; Ringel, F. Retrospective distortion correction of diffusion tensor imaging data by semi-elastic image fusion-Evaluation by means of anatomical landmarks. Clin. Neurol. Neurosurg. 2019, 183, 105387. [CrossRef]

183. Ille, S.; Schwendner, M.; Zhang, W.; Schroeder, A.; Meyer, B.; Krieg, S.M. Tractography for Subcortical Resection of Gliomas Is Highly Accurate for Motor and Language Function: ioMRI-Based Elastic Fusion Disproves the Severity of Brain Shift. Cancers 2021, 13, 1787. [CrossRef] [PubMed]

184. Ille, S.; Schroeder, A.; Wagner, A.; Negwer, C.; Kreiser, K.; Meyer, B.; Krieg, S.M. Intraoperative MRI-based elastic fusion for anatomically accurate tractography of the corticospinal tract: Correlation with intraoperative neuromonitoring and clinical status. Neurosurg. Focus 2021, 50, E9. [CrossRef] [PubMed]

185. Mori, S.; Crain, B.J.; Chacko, V.P.; van Zijl, P.C. Three-dimensional tracking of axonal projections in the brain by magnetic resonance imaging. Ann. Neurol. 1999, 45, 265-269. [CrossRef]

186. Mori, S.; van Zijl, P.C. Fiber tracking: Principles and strategies-A technical review. NMR Biomed. 2002, 15, 468-480. [CrossRef]

187. Lazar, M.; Alexander, A.L. An error analysis of white matter tractography methods: Synthetic diffusion tensor field simulations. Neuroimage 2003, 20, 1140-1153. [CrossRef]

188. Anderson, A.W. Theoretical analysis of the effects of noise on diffusion tensor imaging. Magn. Reson. Med. Off. J. Soc. Magn. Reson. Med. 2001, 46, 1174-1188. [CrossRef] [PubMed]

189. Mukherjee, P.; Berman, J.I.; Chung, S.W.; Hess, C.P.; Henry, R.G. Diffusion tensor MR imaging and fiber tractography: Theoretic underpinnings. AJNR Am. J. Neuroradiol. 2008, 29, 632-641. [CrossRef]

190. Beaulieu, C. The basis of anisotropic water diffusion in the nervous system-A technical review. NMR Biomed. 2002, 15, 435-455. [CrossRef]

191. Michailovich, O.; Rathi, Y.; Dolui, S. Spatially regularized compressed sensing for high angular resolution diffusion imaging. IEEE Trans. Med. Imaging 2011, 30, 1100-1115. [CrossRef]

192. Rathi, Y.; Michailovich, O.; Setsompop, K.; Bouix, S.; Shenton, M.E.; Westin, C.F. Sparse multi-shell diffusion imaging. Med. Image Comput. Comput. Assist. Interv. 2011, 14, 58-65.

193. Zhang, H.; Schneider, T.; Wheeler-Kingshott, C.A.; Alexander, D.C. NODDI: Practical in vivo neurite orientation dispersion and density imaging of the human brain. Neuroimage 2012, 61, 1000-1016. [CrossRef] [PubMed]

194. Julkunen, P.; Jarnefelt, G.; Savolainen, P.; Laine, J.; Karhu, J. Facilitatory effect of paired-pulse stimulation by transcranial magnetic stimulation with biphasic wave-form. Med. Eng. Phys. 2016, 38, 813-817. [CrossRef] [PubMed]

195. Pitkanen, M.; Kallioniemi, E.; Jarnefelt, G.; Karhu, J.; Julkunen, P. Efficient mapping of the motor cortex with navigated biphasic paired-pulse transcranial magnetic stimulation. Brain Topogr. 2018, 31, 963-971. [CrossRef]

196. Mohammadi, A.; Ebrahimi, M.; Kaartinen, S.; Jarnefelt, G.; Karhu, J.; Julkunen, P. Individual characterization of fast intracortical facilitation with paired biphasic-wave transcranial magnetic stimulation. IEEE Trans. Neural Syst. Rehabil. Eng. 2018. [CrossRef] [PubMed]

197. Picht, T.; Krieg, S.M.; Sollmann, N.; Rosler, J.; Niraula, B.; Neuvonen, T.; Savolainen, P.; Lioumis, P.; Makela, J.P.; Deletis, V.; et al. A comparison of language mapping by preoperative navigated transcranial magnetic stimulation and direct cortical stimulation during awake surgery. Neurosurgery 2013, 72, 808-819. [CrossRef] [PubMed]

198. Tarapore, P.E.; Findlay, A.M.; Honma, S.M.; Mizuiri, D.; Houde, J.F.; Berger, M.S.; Nagarajan, S.S. Language mapping with navigated repetitive TMS: Proof of technique and validation. Neuroimage 2013, 82, 260-272. [CrossRef] [PubMed]

199. Sollmann, N.; Ille, S.; Hauck, T.; Maurer, S.; Negwer, C.; Zimmer, C.; Ringel, F.; Meyer, B.; Krieg, S.M. The impact of preoperative language mapping by repetitive navigated transcranial magnetic stimulation on the clinical course of brain tumor patients. $B M C$ Cancer 2015, 15, 1-8. [CrossRef]

200. Sollmann, N.; Kubitscheck, A.; Maurer, S.; Ille, S.; Hauck, T.; Kirschke, J.S.; Ringel, F.; Meyer, B.; Krieg, S.M. Preoperative language mapping by repetitive navigated transcranial magnetic stimulation and diffusion tensor imaging fiber tracking and their comparison to intraoperative stimulation. Neuroradiology 2016, 58, 807-818. [CrossRef]

201. Babajani-Feremi, A.; Narayana, S.; Rezaie, R.; Choudhri, A.F.; Fulton, S.P.; Boop, F.A.; Wheless, J.W.; Papanicolaou, A.C. Language mapping using high gamma electrocorticography, fMRI, and TMS versus electrocortical stimulation. Clin. Neurophysiol. 2016, 127, 1822-1836. [CrossRef] [PubMed] 
202. Laakso, I.; Murakami, T.; Hirata, A.; Ugawa, Y. Where and what TMS activates: Experiments and modeling. Brain Stimul. 2018, 11, 166-174. [CrossRef]

203. Weise, K.; Numssen, O.; Thielscher, A.; Hartwigsen, G.; Knosche, T.R. A novel approach to localize cortical TMS effects. Neuroimage 2020, 209, 116486. [CrossRef] [PubMed]

204. Pitkanen, M.; Kallioniemi, E.; Julkunen, P.; Nazarova, M.; Nieminen, J.O.; Ilmoniemi, R.J. Minimum-norm estimation of motor representations in navigated TMS mappings. Brain Topogr. 2017, 30, 711-722. [CrossRef] [PubMed]

205. Thielscher, A.; Antunes, A.; Saturnino, G.B. Field modeling for transcranial magnetic stimulation: A useful tool to understand the physiological effects of TMS? In Proceedings of the 2015 37th Annual International Conference of the IEEE Engineering in Medicine and Biology Society, Milan, Italy, 25-29 August 2015; pp. 222-225.

206. Saturnino, G.B.; Madsen, K.H.; Thielscher, A. Electric field simulations for transcranial brain stimulation using FEM: An efficient implementation and error analysis. J. Neural. Eng. 2019, 16, 066032. [CrossRef] 